\title{
Behaviour, uncertainty, and the role of information in resource management
}




\section{Propositions}

1) Humans need to acknowledge their own fallibility to manage natural resources sustainably.

(this thesis)

2) Highlighting that climate mitigation requires joint contributions by all, rather than joint avoidance, can increase cooperation in the climate commons. (this thesis)

3) The foundation of interdisciplinary research is in-depth knowledge of your own disciplinary field.

4) For joint research between ecology and economics to have impact, a combination of different methods is as important as agreeing on a joint research focus.

5) As soon as information is communicated it loses its objectivity.

6) The costs of online coffee breaks often outweigh the benefits.

Propositions belonging to the thesis, entitled

Behaviour, uncertainty, and the role of information in resource management

Esther Schuch,

Wageningen, 20 October 2020 


\section{Behaviour, uncertainty, and the role of information in resource management}




\section{Thesis committee}

\section{Promotor:}

Prof. Dr F Alpízar

Professor of Environmental Economics and Natural Resources Group

Wageningen University \& Research

\section{Co-promotors:}

Dr AP Richter

Associate Professor, Environmental Economics and Natural Resources Group

Wageningen University \& Research

Dr S Gabbert

Associate Professor, Environmental Economics and Natural Resources Group

Wageningen University \& Research

\section{Other members:}

Prof. Dr EH Bulte, Wageningen University \& Research

Prof. Dr SR Bush, Wageningen University \& Research

Dr I van Putten, CSIRO Oceans and Atmosphere, Hobart Tas. Australia

Dr J Schmidt, Kiel University, Germany

This research was conducted under the auspices of the Graduate School for Socio-Economic and Natural Sciences of the Environment (SENSE) 


\title{
Behaviour, uncertainty, and the role of information in resource management
}

\author{
Esther Schuch
}

Thesis

submitted in fulfilment of the requirements for the degree of doctor at

Wageningen University

by the authority of the Rector Magnificus

Prof. Dr A.P.J. Mol,

in the presence of the

Thesis Committee appointed by the Academic Board

to be defended in public

on 20 October 2020

at 11 a.m. in the Aula. 
Esther Schuch

Behaviour, uncertainty, and the role of information in resource management 178 pages.

PhD thesis, Wageningen University, Wageningen, NL (2020)

With references, with summary in English

DOI $10.18174 / 529422$

ISBN 978-94-6395-505-8 


\section{Acknowledgements}

What a long strange trip it has been. While starting a $\mathrm{PhD}$ is a very personal decision, actually finishing it requires a crew. This work would have not been possible without all these amazing people in my life you supported me in very different ways but all of them essential. I am for ever indebted to all of you.

First of all I have to thank my supervisor Andries who guided and supported me through the whole $\mathrm{PhD}$. He opened the door to academia for me and helped me to make the $\mathrm{PhD}$ thesis really my own. By giving me loads of stimuli and encouragement, my curiosity for different methods and topics was allowed to grow and expand, making this thesis what it is now. Andries, whilst being rigorous in academia, you were also up for having a laugh and a drink. Thank you for making my PhD journey this enjoyable.

I also am incredibly lucky to have also a second supervisor who took a lot of interest in my work but also in me as a person. Thank you Silke for making me feel at ease and encouraging me to take the time off that I needed when I was sick. The effort you made to accommodate my quirks such as wanting to write in Latex I value highly. Last but not least I want to thank my promotor Francisco who, even so he came a bit late to the party, gave me such valuable feedback and provided me with highly appreciated constructive criticism. Having such a motivated team is not at all common and I cannot thank you three enough for all the support you provided.

Finishing a $\mathrm{PhD}$ does not only require academic support but also a social environment that provides the necessary relief from the individual work as a PhD student. The ENR group provided not only academic support but also social engagement. Coffee breaks (in times when these happened in physical proximity), group outings, literature discussions, as well as the $\mathrm{PhD}$ seminars provided a combination of intellectual engagement as well as friendly chitchat that made coming to the office something to look forward to. A special thank you goes to Wil and Gre who helped with administrative issues from how to enrol as a graduate student to visa applications and on the requirements of running experiments in Cambodia.

A special shout-out goes to my office mates Anna, Sanmitra, and Tum. Having made friends like you makes the $\mathrm{PhD}$ so much more special. You are my three musketeers on whom I can always rely an and I will be eternally grateful for this bond. Tum, I will always cherish our time spend in Cambodia. When we were stuck in the rain and storm 
whilst on our way to prepare our experiments, the faces when you explained that I do not eat animal products, or us sitting in a pile of cash preparing the material. Anna, from the day you showed up in our office it simply was a match. You answered all my random questions on fish, we had so many great nights out in Wageningen and conferences, and whenever I felt stuck or down you provided moral support. Sanmitra, we spend so much time together the last 4.5 years, it is hard to imagine that this has come to an end. Being in the same project we got to travel to so many great places which we used to also explore the country a bit further. I love to remember our time watching the northern lights in Finland, playing werewolf in Sweden and even being stuck in Italy due to bad weather.

I was also incredibly lucky to be part of the amazing MARmaED crowd. This fellowship of the $\mathrm{PhD}$ made this at times daunting project so much more enjoyable. A special thank you goes to my fellow hobbits (Camilla, Tom, Leonie, Romain) who never failed to enjoy life, food, and drinks independent of what else was going on. A special thank you to Camilla who is silly enough to go running early in the morning with me so I was not the only one babbling on about the deer.

I also want to thank my family for nudging me to keep working by repeatedly asking when I will be finished and finally do some real work. I think I am close! I also thank Angela who did many hiking trips with me to clear my head and gather new energy to continue working. Then there are people who said the right thing at the right time to keep me going. Zahra by boosting my self-esteem when I was doubting, Alex by telling me to quit whining and start writing, Maria by confirming it is normal to struggle, and Kathi for always being up for a long session of gossiping.

The person to whom I will forever be grateful for making this $\mathrm{PhD}$ possible is my husband Jens. Thank you, for always believing in me, being at my side, loving me and being the patient person you are. Without you, this $\mathrm{PhD}$ thesis would not be what it is now. You are my sun and stars. You make me a better person just by being part of my life, I love you, and I look forward to our new adventures.

So while it has been a long and strange trip it was also the most exciting time of my life that was made special by all the people I met along the way and became part of my life.

\section{THANK YOU}




\section{Summary}


This thesis is part of the extensive research on natural resource management under uncertainty. Natural resources and their exploitation by humans form a social-ecological system which is influenced by resource dynamics, the ecological system, resource users, and the formal and informal institutional governance systems. Specifically, I focus in this thesis on the role of information, uncertainty and behaviour in fisheries management. I analyse how various actors handle different kinds of uncertainty. I differentiate between social uncertainty (what do the other people in my community do?), strategic uncertainty (what is the best thing to do?), and lastly the inherent uncertainty of fish stocks (how to provide policy advice if resource dynamics are uncertain?). Another focus point is the role of information in fisheries management. I start with studying cooperative behaviour in informal institutions and how it is impacted by the framing of the problem. I continue with analysing how scientific information is created and used in the management process. Two of the chapters are analysed with experimental data gathered in a lab-in-the field experiment conducted in 21 villages in rural Cambodia. Next to the experiments I also use survey data. The analysis in chapter 4 is based on a newly established data base of fish stock assessments and in chapter 5 a case study is used.

The thesis consists of six chapters. Chapter 1 provides the context in which this thesis is to be placed, motivates the research questions, and introduces the methods used. In chapter 2 and 3, the focus is on cooperation in informal institutions. Chapter 2 assesses the role of uncertainty and its impact on cooperation in natural resource management. I use a linear public good game and a threshold public good game to see what influences cooperative behaviour depending on the degree of uncertainty. In a linear public good game there is only social uncertainty (how much do other people cooperative to manage the resource), while in a threshold public good game there is also strategic uncertainty (the social optimal contribution strategy depends on the contributions of the other resource users). I find that individual preferences such as risk aversion and trust explain large parts of the cooperative behaviour while in the threshold public good game people use the threshold as a focal point, thus reducing the cooperative game to a coordination game.

Chapter 3 analyses the role of information and its interaction with uncertainty in cooperation. I frame the threshold public good game as either a public good or a public bad game and find that the success rate in reaching the threshold is higher in the public good framing than in the public bad framing. I also elicit beliefs of what people think the other resource users will contribute and find a framing effect here as well. People in the public bad treatment expect their peers to contribute a lot more than in the public good framing. Thus, in the public bad framing I observe that people overestimate the contributions of others which increases the risk of failing to reach the threshold. 
While in chapter 2 and 3 focus on informal institutions, chapter 4 and 5 analyse parts of the informal institutional setting. While in the experimental settings the resource dynamic was fully known, this often differs in reality. Therefore, in chapter 4 , the focus is on how uncertainty related to fish stocks is handled in management. Given the high uncertainty, fish stock assessment experts need to use intuitive judgement when estimating fish stock biomass. I test whether these judgement calls are influenced by behavioural factors such as anchoring. I find that the experts are influenced by the external pressure put on them as well as anchoring. Whenever there is uncertainty I find that experts anchor their estimates on the previous one, but without the room for judgement calls, the new estimates usually diverge from the old ones. This pattern is stronger if the fish stock is considered to be in a critical status. We find that experts handle the resource uncertainty by following a 'better safe than sorry' approach and provide overcautious estimates.

In chapter 5 the use of scientific information in the formal institutional setting is analysed. I use European Union fisheries management as an example for a formal institution. The European Common Fisheries Policy (CFP) is a science-based management approach. The EU employs a management system in which there is a clear separation between the creation of scientific information and its application to policy. I focus on how scientific information (e.g. fish stock assessments) is used in the management process and how well the EU is prepared to adjust to new information. I use the spatial distribution of fish stocks as an example to analyse the flexibility of the EU as an institution. Due to climate change the stocks are shifting towards the poles, however, the institutional system is too sticky to account for these shifts. A major hindrance in adjusting to distribution shifts is the distribution of national quotas. Thus, I argue that these obstacles could be overcome by establishing a predefined system that can redistribute national quotas. Having such a system would allow to make full use of the scientific information provided. The last chapter provides answers to the research questions, discusses their implications and suggests where future research should focus on. 



\section{Contents}

Page

Acknowledgements

$\mathbf{v}$

Summary

vii

List of Figures $\quad$ xiii

List of Tables $\quad$ XV

$\begin{array}{lll}\text { Chapter } 1 & \text { Introduction } & 1\end{array}$

Chapter 2 Cooperation under social and strategic uncertainty - The role of risk and trust among Cambodian farmers

Chapter 3 A threshold public good game with public good and public bad framing - Evidence from farmers and fishers in Cambodia

Chapter 4 Detecting intuitive judgement of experts in fish stock assessments data

Chapter 5 Sticky institutions may prevent adaptation of fisheries to climate change

Chapter 6 Synthesis

References

Appendices

xvii

Chapter A Experimental Instructions

xxi

Chapter B Survey

xli 



\section{List of Figures}

1.1 Core subsystems in social-ecological system according to Ostrom [2009]. . 3

1.2 Overview of this thesis and the parts of the social-ecological system analysed. . . . . . . . . . . . . . . . . . 7

2.1 The study site Kampong Chhnang province with three communes Tuol Phpous, Taing Krasaing, and Kouk Banteay where 21 villages where visited. 17

2.2 Degree of risk aversion and cooperative behaviour types based on the hierarchical cluster analysis. . . . . . . . . . . . . . . . . . . . 19

2.3 Optimal contribution strategy and symmetric Nash equilibria in the linear and the threshold public good game. . . . . . . . . . . . . . . 22

2.4 Contributions to the public fund in the linear public good and the threshold public good game. . . . . . . . . . . . . . . . . . 23

2.5 Individual payoffs depending on contribution level in the linear and the threshold public good game. . . . . . . . . . . . . . . . . . 24

2.A.1 Silhouette analysis. . . . . . . . . . . . . . . . . 36

2.A.2 Conditional contribution frequencies based on the hierarchical cluster analysis. . . . . . . . . . . . . . . . . . . . . 37

3.2.1 Optimal contribution strategy depending on the partners' contributions. . 45

3.3.1 Contributions to the public fund by treatment. . . . . . . . . . . . . . . 49

3.3.2 Belief about the partners' joint contributions to the public fund by treatment. . . . . . . . . . . . . . . . . 52

3.3.3 Quadratic marginal effects by treatment, estimated with interaction effect between treatment and beliefs . . . . . . . . . . . . . 54

3.3.4 Histogram of the difference between actual contributions and believed contributions by partners in the Public Good and the Public Bad treatment. 55

3.3.5 Believed contributions, sufficient contribution, and success by treatment. 56

4.2.1 Data base overview and calculation of relative change. . . . . . . . . . . . 64

4.2.2 Relative changes in fish stock assessments between report years depending on direction of change. . . . . . . . . . . . . . . . . . . . . . 67

5.2.1 EU Decision making system for quota setting in the European Union. . . 89 
5.2.2 Division of scientific areas (red lines) and ecoregions (coloured regions) taken from the ICES homepage $[$ ICES, 2017] . . . . . . . . . . . . . . 90

5.3 .1 Institutional mismatch. . . . . . . . . . . . . . . . . . . . . . . 93

5.4.1 The mismatch between management and scientific areas for the Western and the North Sea stock of horse mackerel in 1999. . . . . . . . . . . . . 97

A.1.1 Poster aid for the risk elicitation. . . . . . . . . . . . . xxv

A.2.1 Poster aid for the linear public good game . . . . . . . . . . . . .xxix

A.4.1 Poster for the public good treatment. . . . . . . . . . . . . xxxii

A.4.2 Belief elicitation in the public good treatment. . . . . . . . . . . xxxiii

A.4.3 Poster for the public bad treatment. . . . . . . . . . . . . . xxxvi

A.4.4 Belief elicitation in the public bad treatment. . . . . . . . . . . xxxvii 


\section{List of Tables}

2.1 Overview of sample population . . . . . . . . . . . . . 18

2.2 Determinants of contribution level in the linear public good game. . . . . 27

2.3 Determinants of contribution level in the threshold public good game. . . 28

2.4 Determinants of contribution levels in the threshold public good game.

Logit model for contributions below, at, and above the symmetric cooperative Nash equilibrium. . . . . . . . . . . . . . . . . . . . . . . . . . . 29

2.A.1 Summary statistics . . . . . . . . . . . . . . . . . . 33

2.A.2 Duda - Hart index, pseudo T-squared and Calinski/Harrabass pseudo-F to determine number of clusters. . . . . . . . . . . . . . . . . . 35

3.3.1 Average contribution, average believed contribution, and threshold reached per treatment. . . . . . . . . . . . . . . . . . . 50

3.3.2 Public good/bad framing treatment effect on contribution level. . . . . . 51

3.3.3 Treatment effect on believed contributions. . . . . . . . . . . . . . 53

3.A.1 Summary statistics. . . . . . . . . . . . . . . . . . . . . . . . 59

3.A.2 Balance test for the treatment populations . . . . . . . . . . . 60

3.A.3 Differences of contributions, believed contributions and difference between actual and believed contributions by treatment and success rate. . 60

4.3.1 Staggered difference in difference (DiD) Model. . . . . . . . . . . . . . . . 68

4.3.2 Linear fixed effects regression with absolute values of relative change as dependent variable. . . . . . . . . . . . . . . . . . . . . . . . . . . 69

4.A.1 Summary statistics . . . . . . . . . . . . . . . . 76

4.A.2 Robustness check. Different indicators for stock status. . . . . . . . . . 78

4.A.3 Interaction of stock status with type of assessment and data source. . . . 79

4.A.4 Robustness check. Sequential estimation of coefficients. . . . . . . . . . 80

4.A.5 Placebo test with randomized updates and benchmarks. . . . . . . . . . . 81

4.A.6 The basic model without updates and benchmarks. . . . . . . . . . . . . 82

5.4.1 Timeline of the main steps in Horse Mackerel case. . . . . . . . . . . . . . 98

5.4.2 Changes in the relative stability key for the North Sea and Western stock. 102

5.A.1 Commission proposal on how to calculate the new quotas for the agreed TAC of Horse Mackerel in the North Sea [European Commission, 2008] . . 107

5.A.2 Summary of the comments of the member states. . . . . . . . . . . 108 

Chapter 1

\section{Introduction}




\subsection{Background}

Seafood is an essential resource for global food security. The global production of fish for human consumption was 151 million tonnes in 2016. About 40.3 million people are, excluding aquaculture, engaged in fishing, the majority in Asia [FAO, 2018]. Yet, the long-term availability of the food source fish is endangered by a combination of different factors. Climate change, pollution, as well as over-fishing threaten the viability of fish stocks [Garrity, 2020, Kvamsdal et al., 2016]. While 90\% of the fish stocks were considered to be sustainably fished in 1974, only $66 \%$ were considered to be sustainable in 2015 . While $60 \%$ of global fish stocks are considered to be fished at maximum sustainable yield, only $7 \%$ are considered underexploited and about $30 \%$ are assumed to be over-fished [FAO, 2018, Garrity, 2020]. The decrease of global fish stocks can be traced back to different factors such as climate change and overfishing. Especially climate change poses a challenge to fisheries management since it changes the dynamics of the resource fish such as growth rate or migration patterns. This requires changes in human behaviour as well as adjustment of institutional settings to ensure a more sustainable management [Pinsky et al., 2018, Garrity, 2020]. Managing fish stocks poses a special challenge since fish is a scarce, common, transboundary, and non-static resource which requires often international cooperation or supranational institutions for management [Aanesen and Armstrong, 2016, Laxe, 2010]. The management is even further complicated by the uncertainties pertaining fisheries management such as the location and abundance of fish stocks [Fallon et al., 2015, Johnson et al., 2014], how stocks react to climate change [Lindkvist et al., 2017, Vaidyanathan, 2017], and the behaviour of the different actors. How do institutions handle uncertainties and which reforms are needed to make fisheries management viable [Symes and Hoefnagel, 2010, Symes, 2007, 2009, Dankel et al., 2012, Soomai, 2017], how do countries deal with these new situations caused by climate change dynamics [Østhagen et al., 2020, Spijkers and Boonstra, 2017, Mendenhall et al., 2020], and how are individuals handling uncertainties when they are harvesting fish [Mina et al., 2016, Cason and Gangadharan, 2015, Noussair et al., 2015]. Since fish are a common pool resource (non-excludable and rival) a lot of the management relies on cooperation, especially in informal management settings [Ostrom, 2010, Ratner and Allison, 2012].

Fisheries management is a complex and dynamic system that is characterised by the interaction between fishers, institutions involved in fisheries management, and the resource fish. These interactions are also called social-ecological system (SES). An SES consists of several, intertwined, subsystems [Ostrom, 2009]. Figure 1.1 provides an overview over the different components of social-ecological systems. While the resource (fish) is part of the system, it is not the center. Rather, the interactions between the resource (fish), the resource system (marine or fresh water fishing), the user (fishers), and the governance system (institutions and rules regarding fisheries) are at the nexus of the social-ecological 
system. The decision-making in these social-ecological systems is decentralised and happens on multiple levels and often simultaneously. These decisions are often only semiautonomous across the different institutional levels and stakeholder groups, thus forming a polycentric governance system. Given the semi-autonomy of the different subsystems, self-governance, relying to a large degree on cooperation between stakeholders, is often necessary [Ostrom, 2010, Ratner and Allison, 2012, Berardo and Lubell, 2016, Carlisle and Gruby, 2019].

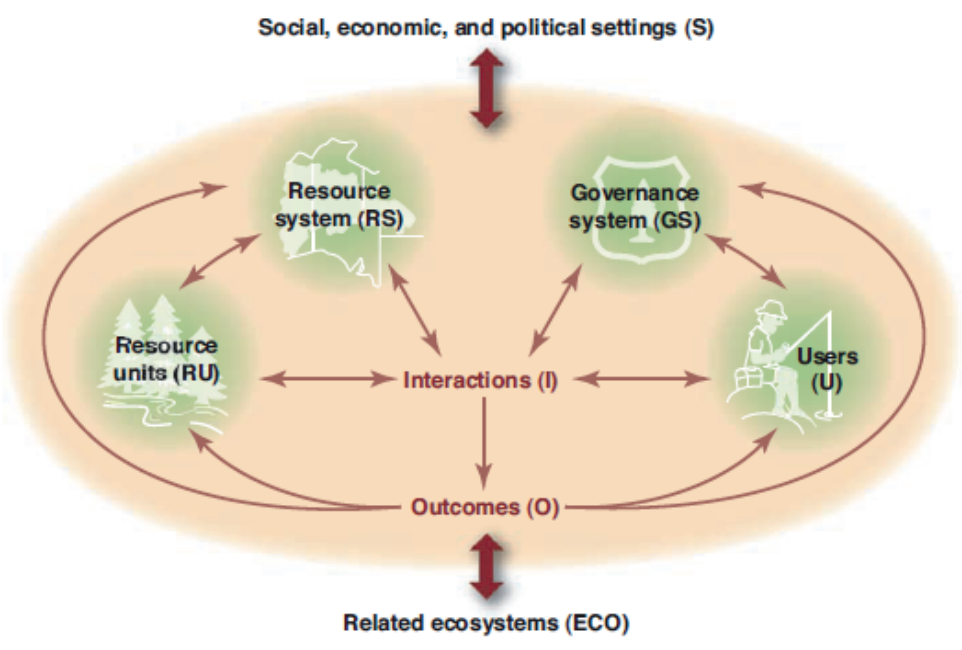

Figure 1.1: Core subsystems in social-ecological system according to Ostrom [2009].

Given the complexity of social-ecological systems and the different subsystems, I study the interactions between scientific uncertainty regarding the natural resource dynamics, the behavioural drivers of different stakeholders, and analyse the role of information in this process. Given the importance of cooperation in natural resource management one research focus is how resource users cooperate under uncertainty and the influence of information. In particular, I am analysing different kinds of uncertainty related to the cooperative behaviour of resource users. First, I analyse what determines cooperation when the only uncertainty is how cooperative the other people are (social uncertainty). The second kind of uncertainty related to cooperative behaviour that I analyse is what I term strategic uncertainty. In this setting, not only the cooperative behaviour of the other resource users is uncertain but also how to reach the social optimum is unclear since the strategy of reaching the social optimum depends on the contributions of the partners. To analyse the role of information in informal institutions I test in how far cooperative behaviour is shaped by the way the management problem is described (framing). I study uncertainty in cooperative behaviour under the assumption that there is no uncertainty related to the natural resource. Yet, since fish are a resource that de facto cannot be 
counted, the knowledge on the exact size and location of the fish stock is uncertain. The best estimate to be had on fish stocks, yet still uncertain, are fish stock assessments which are conducted by experts. The experts include all available scientific knowledge but are still forced to make judgement calls whenever there is a lack of data. Since these stock assessments are the basis for European fisheries management, I analyse how experts make these intuitive judgement calls in a realm of uncertainty. The information produced by the stock assessment experts feeds directly into the fisheries management process. The European Union has an intricate management system that is, in theory, well equipped to translate the best scientific advice available (the stock assessments) into policy (national fishing quotas). Yet, what happens if this system is required to react flexibly to new information such as ecosystem changes induced by climate change? One effect of climate change is that fish stocks shift out of their historical grounds and move towards the poles. This disrupts the fisheries management system since the national quotas are decided by a predefined distribution key (relative stability principle) for a given management area. If fish stocks migrate towards the poles, the scientific advice also applies to a different area. This spatial mismatch provides a fertile ground for analysing the flexibility of the European fisheries management system as well as to identify potential bottlenecks for adjustment. By zooming in on these entanglements between uncertainty, behaviour, and information I can identify potential problems in the polycentric governance system.

Achieving sustainable fisheries management in such a complex SES is challenging for several reasons. One of the most prominent problems is the uncertainty in regard to true size of fish stocks and how fish stocks react to external pressures such as fishing and climate change [Barange et al., 2014]. In the past years, several comprehensive models have been employed to estimate the size of fish stocks. Yet, these models also suffer from shortcomings such as high uncertainties, the high amount of data needed, the tendency to create misconceptions about dynamics, and the neglect of ecosystem dynamics [Kvamsdal et al., 2016]. For instance, while the models predicting the abundance of fish usually use linear models, it has become apparent that often nonlinear processes are happening [Gibbs, 2008, Scheffer et al., 2003, Young, 2017, Martin et al., 2020, Sguotti et al., 2019]. In particular, the crossing of thresholds, such as fishing a fish stock so low that its reproductive function is impaired, is problematic since a reversal is often impossible [Winter et al., 2020]. Due to these uncertainties, existing models are likely introducing estimation biases, for example with regard to uncertainty in the growth rate (recruitment) [Lee et al., 2012, Walters, 2004, Kehler et al., 2002, Myers and Barrowman, 1995, Marshall et al., 2006, Methot et al., 2011, Deroba and Miller, 2016, Francis, 2016], the estimation of natural fishing mortality and fishing pressure [Johnson et al., 2014, Dickey-Collas et al., 2007], the use and quality of data [Payne et al., 2009, Kraak et al., 2009, Ichinokawa et al., 2014], as well as biases related to spatial distribution [Soria et al., 1996, Fallon et al., 2015]. These uncertainties are increased by climate change since the 
resource itself experiences changes in abundance, the growth rate or the location of a fish stock which poses additional problems for management [Lindkvist et al., 2017, Kvamsdal et al., 2016, Sumaila et al., 2011].

Given these inherent uncertainties Palmer and Demarest [2018] conclude that "'truth" is an elusive construct in fisheries science'. This has implications on the institutions, the science-policy interface, as well as on the resource users [Kvamsdal et al., 2016, Dankel et al., 2012]. Resource users need to make decisions based on available information, even if this information is highly uncertain. This raises the question how people make decisions under uncertainty. Kahneman [2011] differentiates between system 1 and system 2 when making decisions. Whenever quick and intuitive decisions are made these happen in system 1. These intuitive judgements often use heuristics to make quick decisions [Garrity, 2020]. System 2 relies on conscious reasoning and mental effort to reach decisions [Kahneman, 2011]. Experts as well as laypeople employ both systems for decision-making. Since system 2 is the mentally challenging system it is not always feasible to use it due to time or information constraints. System 1 is used whenever a decision needs to be reached fast (e.g. a life-threatening situation), when emotions are involved, or if there is a lack of information. Experts as well as resource users in fisheries often experience a lack of information given the high uncertainties. Thus, they often have no choice but to employ heuristics (which are based on past experiences) to make decisions. While heuristics are useful they are also prone to errors [Garrity, 2020].

These heuristics are not the only behavioural components that influence natural resource management. While heuristics are a way of coping with uncertainty by individuals, human behaviour can also be a source of uncertainty on a group level. Since most natural resources can be classified as common goods, cooperation is necessary to ensure that the resource is not overexploited. Cooperation between individuals depends on several factors e.g. individual preferences [Fehr and Fischbacher, 2003, Fischbacher et al., 2012, Charness and Villeval, 2009], social norms [Bouma et al., 2008, Ockenfels and Weimann, 1999, Gneezy et al., 2015, Anderson et al., 2004], as well as trust [Anderson et al., 2004, Kocher et al., 2015]. These factors influencing cooperation have been studied in experimental economics by using a linear public good game. In a linear public good every member is required to decide how much of the endowment to contribute to a group fund and how much to keep for herself. For every coin in the public fund a fixed amount is added. The total public fund is divided evenly between all group members, independent of their contribution. Thus, the uncertainty in this setting is the behaviour of the other group members. Public good games represent a social dilemma since it is socially optimal if everyone contributes the full endowment to the public fund, but the individual maximises profits by contributing nothing to the public fund. While this linear setting is well researched it is arguable whether natural resource management is 
indeed best described as a linear game. While fish stocks can be exploited linearly up to a threshold, fishing beyond the threshold endangers the reproductive capacity of the fish stock and thus can lead to its collapse. Another example for nonlinear dynamics in natural resources management is water management. Maintenance of an irrigation structure requires that a certain level of cooperation is reached to ensure that the irrigation infrastructure is maintained. Yet, with nonlinear resources there are additional factors to be considered such as strategic uncertainty, since it is not clear how high the socially optimal contribution is without knowing what the other group members contribute. One way to study cooperative behaviour under strategic uncertainty are threshold public good games [Dannenberg et al., 2015, Tavoni et al., 2011, Barrett and Dannenberg, 2014, İiş et al., 2019, Au, 2004]. In these, the public good is only provided if a predefined amount is reached, otherwise the contributions to the public good are lost. Little is known how individual preferences, social norms, and trust influence cooperation in nonlinear public good games. Hence, it is not clear in how far the insights gained in linear public good games are transferable to threshold public good games. 


\subsection{Thesis objectives}

The focus of this thesis is on the role of information and decision-making in the uncertain environment of fisheries management. Within the SES I focus on two levels, the formal institutions (the governance system) and the informal institutions (the interaction of resource users with the resource) (see fig. 1.2). On both levels uncertainty and information play a crucial role and are shaped by, as well as influence, human behaviour.

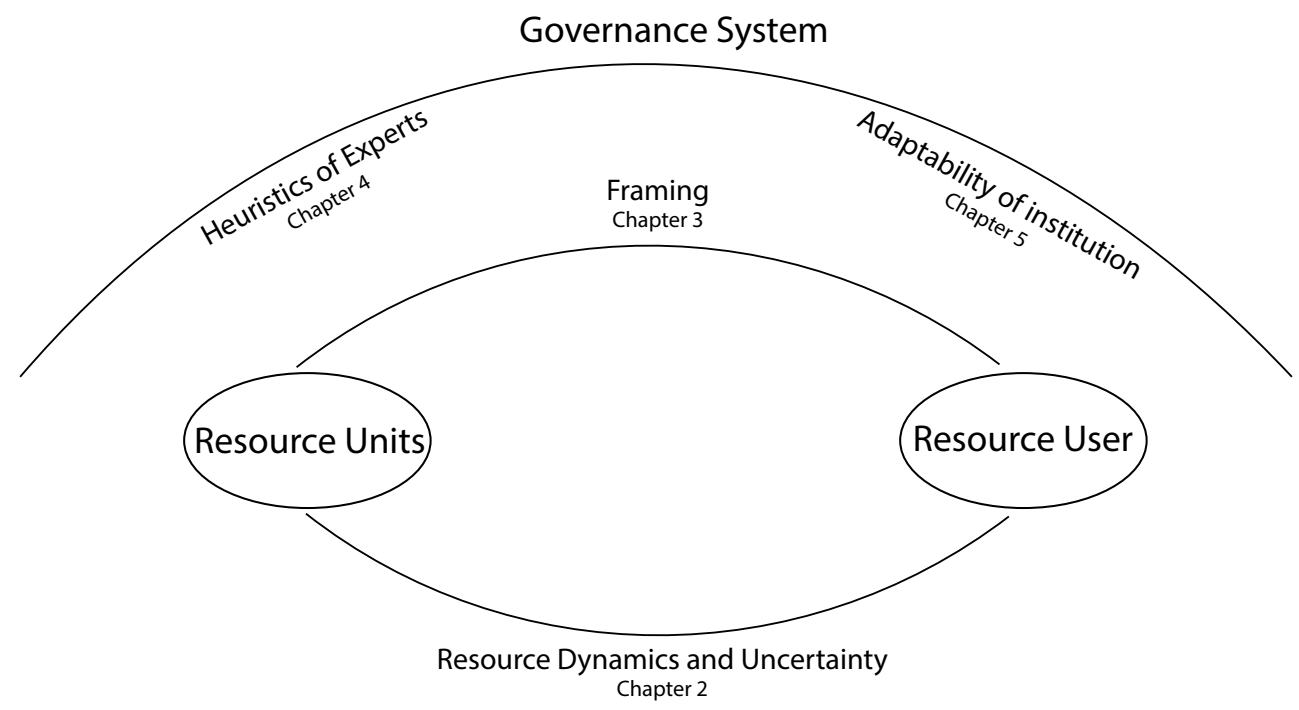

Figure 1.2: Overview of this thesis and the parts of the social-ecological system analysed. Chapter 2 and 3 focus on the informal institutional settings governing the interaction of the resource user with the resource. Chapter 2 analyses resource dynamics and uncertainties while chapter 3 analyses the impact of framing on resource management. Chapter 4 and 5 analyse parts of the formal institutions of the governance system. Chapter 4 scrutinizes the use of heuristics by fish stock assessment experts and chapter 5 zooms in on the flexibility of the EU to adjust to new dynamics of the resource fish.

In the first part of this thesis (chapter 2 and 3) I focus on the interaction between resource users jointly harvesting a common pool resource. Specifically, the focus of chapter 2 is on cooperation under uncertainty of Cambodian fishers and farmers and how cooperation is influenced by different kinds of uncertainty and individual attributes. Of particular interest is in how far cooperation differs between settings with either linear or nonlinear resources dynamics. Since cooperative behaviour has been mainly analysed in linear public good settings I use a linear as well as a threshold game to identify whether contribution strategies differ between these settings. Given the importance of information and its presentation I also analyse differences in cooperation depending on the framing of the problem (chapter 3). Does cooperation differ depending on the way the management 
problem is described? And what are the expectations towards the other resource users depending on the framing? Not only informal institutions are shaped by human behaviour but also formal institutions. Thus, I focus in the second part of the thesis on the European fisheries management system. In chapter 4 I analyse the decision-making of the people at the heart of the management process, namely the scientists conducting the stock assessments. I scrutinize which factors impact their decision-making under uncertainty e.g. which heuristics might be employed in their intuitive judgements. The stock assessment experts are crucial for the management since they produce the information upon which the complete management system rests, the total allowable catch. Moving away from individual decision-making I analyse in chapter 5 the functioning of institutional decision-making. Of particular interest is how flexible the EU integrates new scientific information into the fisheries management process. Given that climate change will alter the spatial as well as biological dynamics of fish stocks it is essential to assess how well the EU is equipped to incorporate new information into the management process.

The objective of this thesis is to disentangle the role of information, uncertainty, and behaviour in fisheries management. I focus on the following research questions:

1 How does uncertainty impact cooperation of people in natural resource management without formal institutions? (chapter 2)

2 What determines how cooperative people are when managing natural resources? (chapter 2)

3 In how far is cooperation influenced by the presentation of the resource management problem? (chapter 3)

4 How are the expectations of other resource users' cooperativeness influenced by the presentation of the management problem? (chapter 3)

5 How are fish stock assessments influenced by intuitive judgements of experts? (chapter 4)

6 Which challenges do institutions like the EU encounter when dealing with new ecosystem dynamics? (chapter 5)

7 How flexible can the EU adapt their fisheries management processes to new scientific information? (chapter 5)

\subsection{Thesis outline}

In this thesis I use different methods to answer questions on how to improve fisheries management. I focus specifically on the role of information and uncertainty within a social-ecological system. To analyse the decision-making under uncertainty on the 
resource user level I use experimental economics to discern causality. The focus is on individual decision-making. Since natural resources such as fish are often treated as linear whilst frequently showing nonlinear dynamics I use a linear as well as a threshold public good game to analyse behavioural differences (chapter 2). Of particular interest is whether individual preferences and trust have the same impact in linear and nonlinear settings. I zoom into the nonlinear dynamics and its relation to information provision by using framing to test whether people adjust their contributions as well as beliefs about the partners' contributions. The threshold game is either framed as a public good or a public bad game (chapter 3). To grasp the role of information under uncertainty in the governance system I use two different approaches. In chapter 4 I concentrate on the experts conducting the European fish stock assessments and how their use of heuristics when making intuitive judgement calls might impact the fish stock assessment model output. These assessments are the backbone of European fisheries management since they indicate the size and location of the fish stocks. I use panel data econometrics to find behavioural patterns such as anchoring. Chapter 5 focuses on the adaptability of institutions to new scientific information. Given that under climate change the resource fish is inherently changing, institutions need to be able to adjust to those changes to ensure sustainable fisheries management. I use Atlantic Horse mackerel as a case study to get a grasp on the degree of adaptability and the reasons for a potential lack of adaptability of the EU.

Chapter 2 explores individual decision-making of resource users under uncertainty. Resource users play a linear and a threshold public good game which allows analysing different contribution strategies to the public good depending on the game. Specific attention is given to the uncertainty in the games. While a linear public good game only has social uncertainty (how much do the partners contribute), threshold games also address the additional complexity of strategic uncertainty (the socially optimal contribution strategy depends on the contributions of the partners). Further, we elicit risk attitudes and cooperative behaviour types and use survey data on trust to analyse whether these attitudes have the same impact in both games. Hence, chapter 2 provides novel insights into individual decision-making depending on the level of uncertainty and allows an analysis of which individual characteristics are more influential in a linear or a nonlinear resource management problem.

In chapter 3 the role of information and its interaction with uncertainty is analysed in more depths. By playing the threshold game as a public good and a public bad game it is possible to see the effect of information provision. I test whether cooperation differs if the problem is framed as 'achieving a public good' or as 'avoiding a public bad'. Since contributions by the partners is essential in a threshold game to determine the socially optimal contribution, I also test whether framing has an impact on the believed contributions. This experiment, just as the experiments in chapter 2, were carried out in 
rural Cambodia where the population is used to managing natural resources (fish and water) on a communal basis. This paper is the first to test the framing effect in a threshold game with a population that deals with natural resource management on a daily basis.

While chapter 2 and 3 focus on the individual decision-making of resource users under informal institutions, chapter 4 analyses expert decision-making within a formal institution. Even though it is generally acknowledged that fish stock assessments are riddled with uncertainties, these uncertainties are usually attributed to technical questions such as, e.g. biases in statistical estimates. The role of expert decision-making in these stock assessments has been neglected. Expert error is usually seen as something random. Yet, experts often have to make judgement calls on how to use and interpret data points. Here, I show for the first time that experts deviations in fish stock assessments are systematic. I use panel data econometrics on a newly established database of fish stock assessments to estimate where behavioural factors of experts influence fish stock assessments. This paper is the first to analyse the behavioural patterns in non data-poor fish stock assessments. Given the importance of fish stock assessments in the management process, it is essential to find these patterns and raise awareness to avoid negative, maybe irreversible, effects.

Whereas chapters 2 - 4 focus on human behaviour, chapter 5 analyses the adaptability of formal institutions within which fisheries management takes place. The focus is on European fisheries management and its flexibility to adapt to new information. The European fisheries management is a science-based management system which sometimes fails to fully incorporate scientific information. Scrutinizing the institutional "stickiness" and identifying the reasons as well as the costs for the lack of flexibility is essential as it facilitates adjusting the process in a more targeted way in order to better deal with ecosystem dynamics that are to be expected under climate change. 


\section{Chapter 2}

\section{Cooperation under social and strategic uncertainty - The role of risk and trust among Cambodian farmers}

This chapter is based on a manuscript revised and resubmitted to the Journal of Behavior and Experimental Economics, Schuch, E., Dirks, S., Nhim, T. and Richter, A. (2020). Cooperation under social and strategic uncertainty - The role of risk and trust in rural Cambodia. 


\section{Abstract}

Cooperation in a social dilemma is noble but risky because one is not sheltered against individuals who are selfish. This "social uncertainty" is essentially captured in the linear public good game, where it is socially optimal to contribute everything to the public good, while it is privately optimal to keep everything for oneself. Many real-world social dilemmas have an additional source of "strategic uncertainty", as socially and privately optimal strategies depend on actions of others. Here, we compare the determinants of cooperation in a linear public good game and a threshold game, where individuals are challenged to guess the contributions of the partners to determine an appropriate investment that aligns with private and collective interest. We combine elicited risk preferences and cooperative attitudes with information from a survey on trust and demographics to analyse what explains cooperation. Our experiments are carried out with farmers in Cambodia who are exposed to various social dilemmas on a daily basis. We find that risk and trust explain cooperation in the linear public good game, but not in the threshold game. These findings call for a more careful examination of real world social dilemmas that typically feature both elements of coordination and cooperation.

Keywords: cooperation, social risk, public goods game, threshold game, natural resource management, uncertainty 


\subsection{Introduction}

Cooperation in social dilemma situations has been studied extensively. The linear public good game is the canonical model to analyse cooperative behaviour in a situation where each individual is torn between personal gains and collective welfare. While it is individually optimal to contribute nothing to the public fund regardless of what other players are doing, it is socially optimal to contribute everything [Fehr and Fischbacher, 2003, Willinger and Ziegelmeyer, 1999]. The social optimum is reached if all players contribute their full endowment to the public good. Yet, the most frequently observed behaviour is neither free riding nor full cooperation but rather contributions around $40-50 \%$ of the endowment [Ledyard, 1995, Fehr and Fischbacher, 2003, Burton-Chellew and West, 2013]. Fischbacher et al. [2001] established that individuals can be classified according to their contribution strategies, such as free riding, conditional cooperation or unconditional cooperation. The notion of conditional cooperation highlights the role of beliefs about the partners' contributions how much individuals contribute [Fehr and Fischbacher, 2003, Fischbacher et al., 2012]. Intuitively, individuals try to avoid being the "sucker" [Kerr, 1983] who contributes while others take a free ride.

Most real world social dilemmas are more complex than the linear public goods game suggests. While in the linear public good game the strategies on how to achieve the social optimum are known this is not necessarily the case in nonlinear public good games. In nonlinear games, the strategy on how to achieve the social optimum depends on the actions of the partners [Isaksen et al., 2019, van Soest et al., 2016]. Hence, in linear public good games the socially optimal strategy - contribute everything - is independent of the contributions of partners, but whether the social optimum materializes does. In contrast, in nonlinear public good games also the socially optimal strategy depends on the partners actions. ${ }^{1}$ One example of nonlinear public goods are irrigation systems to which farmers contribute to ensure maintenance. This infrastructure only retains functionality if a minimum amount of contributions is reached. Those nonlinearities can be formalized in threshold public good games, where players contribute jointly to a group account. If the joint contributions are below a threshold, all contributions are lost and the public good is not provided. In this setting, the strategy to achieve the social optimum (reaching the threshold exactly) depends on the partners contributions [Cadsby and Maynes, 1999].

The linear public good game and the threshold game both feature a form of "social risk", as coined by Iris Bohnet and Zeckhauser [2008] who introduce the term "to describe situations where decisions by other human beings are the prime source of uncertainty".

\footnotetext{
${ }^{1}$ Mathematically, the contribution levels of partners is an argument in the socially optimal contribution level of a non-linear public goods game, but not in a linear public goods game.
} 
What differs across the games is the main source of social risk. In the linear public good game there is only the (social) risk of deviating from contributions of co-players. Depending on the social context, it may be both undesirable to contribute more or less than others. In the threshold public good game, these consideration may also play a role, but there is an additional source of risk. As the best response depends on the unknown contributions of others, there is a risk of contributing inefficiently and either failing to reach the threshold or providing more than needed.

In this paper we unpack the source of social risk by distinguishing the fear of deviating from what the social norm is, which we call "social uncertainty" and the difficulty of gauging contributions of others to make a best response which we call "strategic uncertainty". Social uncertainty is present in the linear and the threshold public good game, while strategic uncertainty is only present in the threshold public good game. We conduct lab in the field experiments with Cambodian fishers and farmers. We ask the question how individual factors, such as risk tolerance, trust, or demographic variables affect cooperation under social and strategic uncertainty. A key feature of this subject pool is that the participants are commonly exposed to social dilemmas, such as contributing to irrigation infrastructure or harvesting a fish stock. We are primarily interested whether trust and social capital (e.g. the level of support for community tasks, being a member of a voluntary association), as well as risk aversion and prosocial preferences determine contributions levels.

Our paper contributes to the literature in two ways. First, by investigating the various factors that play a role when individuals engage in social dilemma situations, accounting for the role of social and strategic uncertainty. Second, we explore under which conditions farmers and fishers successfully overcome social dilemmas, building upon the social-ecological systems literature pioneered by Ostrom and others [Ostrom, 1990]. In particular, trust and risk can act as factors influencing contribution levels. Anderson et al. [2004] and Kocher et al. [2015] find that trust increases contribution levels and Charness and Villeval [2009] observe that risk seeking people invest more in the public good than risk averse people. Contrary, Kocher et al. [2015] do not find any significant effect of risk preferences on contribution levels. Cárdenas et al. [2017] run a public good game, where the return on the public good or the private account is risky (there is a $50 \%$ chance that it is paid out or doubled). They observe that risk in the public account leads to lower investments in that account than risk in the private account. Apart from individual preferences, social norms and community characteristics also influence cooperative actions [Bouma et al., 2008]. Ockenfels and Weimann [1999] show that being raised in a socialist society (East Germany) leads to different cooperation patterns than growing up in a market based society (West Germany). Gneezy et al. [2015] find that daily life experiences shape cooperative behaviour by analysing two distinct groups 
of Brazilian fishers (lake versus open sea fisheries). Lake fishing is a rather individual activity while fishing at the open sea is a collective action. They see higher cooperation amongst sea fishers than lake fishers. Also, being a member of a voluntary association has been observed to have strong positive correlations with higher contributions to the public good [Anderson et al., 2004].

The remainder of the paper is organised as follows: section 2.2 describes the setting of the experiments as well as the data generated, section 2.3 explains the experimental setup, section 2.4 entails the results, and section 2.5 concludes.

\subsection{Materials and Methods}

\subsubsection{Study site in Cambodia}

In Cambodia, the management of natural resources (water, fisheries, and forestry) relies to a large extend on community management. While the resource management is decentralised it is still part of a multilevel governance setting [Chou et al., 2011]. The implementation of the community approach has been an ongoing process since the 1990's.

In 1994, the Cambodian government initiated the transfer of the water management from the national level to the communities [Perera, 2006]. This process was further formalised in 1999 when the Participatory Irrigation Management and Development program was introduced that created a formal setting in which the irrigation governance is the task of formal user groups. These Farmer Water User Communities (FWUCs) consist of farmers and are responsible for the maintenance, repair, and improvement of the irrigation system, as well as the establishment of equitable and reliable access to water [Chou, 2010, Perera, 2006]. While the official guidelines and regulations provided by the state ensure a framework for running the FWUCs, the experiences within the communes differ widely, depending on social norms and environmental characteristics [Chou et al., 2011].

The rural population in Cambodia is often involved in the management of multiple types of natural resources. Depending on the region the main income is generated via fishing or rice farming but rarely does a household depend on only one income source. To ensure income from rice farming it is essential to have a functioning water infrastructure. The management of the water infrastructure is a communal task, requiring a high level of cooperation. Cooperation is also essential in managing fisheries to ensure that people do not over-exploit the fish stocks to avoid a stock collapse.

In the last 20 years, the fisheries sector experienced two major reforms. Up to 2001, 
the fishing grounds were controlled by elites. The fishing grounds are divided in so-called fishing lots. In 2001, part of these fishing lots were made open access. In the second reform in 2012, all of the fishing lots were made accessible to everyone, installing an open access system in Cambodian inland fisheries [Sreyphea Chap, 2016]. As a result, Cambodia has 412,205 ha of public fishing areas which are all managed at least partially by communities [Sithirith, 2015]. Similar to the reform in the water sector, the fisheries reform from 2012 introduced Common Fisheries (CFi) organisations [Sreyphea Chap, 2016]. These CFis are community lead organisations and are responsible for the management of the fisheries [Kurien, 2017]. In general, the open access fisheries are governed under formal as well as informal norms which are specific to the communities. Each community handles the access to resources, solving of conflicts, as well as questions relating to equity in their own way. Whilst these rules and norms are usually not written down they are widely known and respected [Sreyphea Chap, 2016].

Water as well as fisheries are managed by communities with the help of local formal institutions (Common Fisheries organisation and Farmer Water User Communities) which are run by the local farmers and fishers. While these organisations have to follow broad state regulations, they are also strongly influenced by social norms of the communities [Sreyphea Chap, 2016]. Hence, natural resource management in Cambodia is mainly done by communities relying on the cooperative characteristics of individuals as well as social norms.

\subsubsection{Study population and experiment conduction}

The experiments were conducted in May/June 2019 in the province Kampong Chhnang, Cambodia. The research took place in 21 villages in three communes; Tuel Phpos, Tank Krasang and Kouk Bonteay (see fig. 2.1). All experiments and research ideas were reviewed by the Social Sciences Ethic Committee of Wageningen University and registered as a pre-analysis plan; see Richter et al. [2020]. Participants were recruited through the village chief. Only one participant per household was allowed to take part, preferably but not necessarily, the household head. Further requirements were that participants should represent all parts of the village's society. Also, participants had to be 18 years old and healthy enough to sit on the floor for the duration of the experiments (see table 2.1 for an overview).

An experimental session began with an introduction of the research team. The participants were told that the study aims at understanding livelihood improvements such as those related to farming and fishing. Furthermore, they were instructed about the duration and the monetary reward for this research. Participants received a show up fee of 4000 Cambodian Riel (KHR) ${ }^{2}$ and 6000 KHR for their effort to stay until the end of

\footnotetext{
${ }^{2} 4000 \mathrm{KHR}$ are equivalent to one USD.
} 


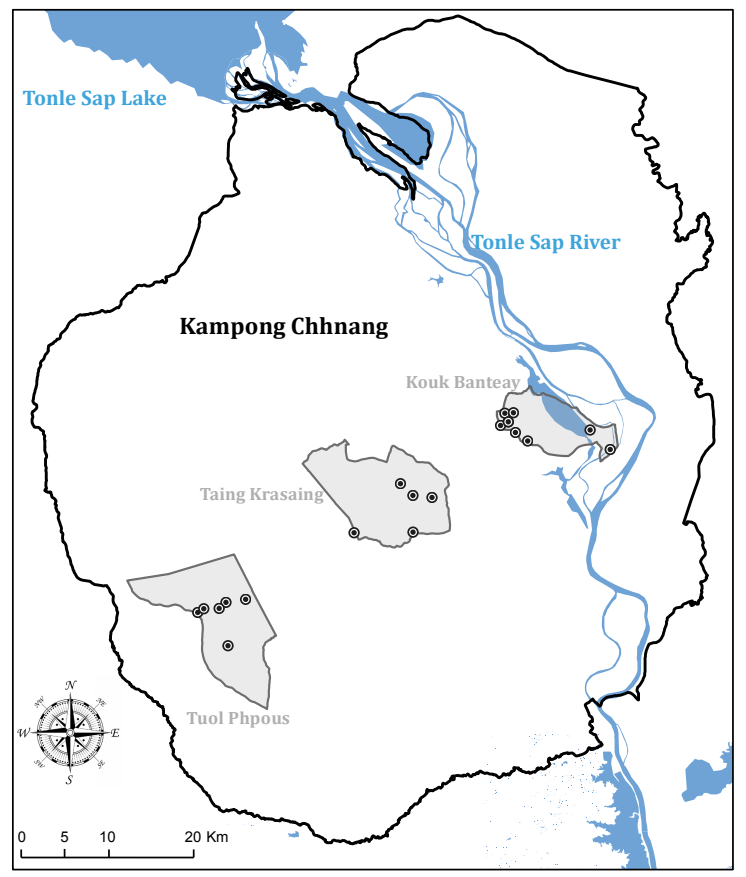

\section{Cambodia}
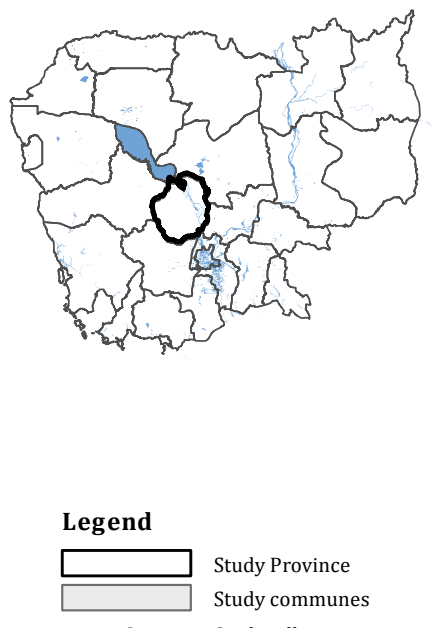

Study Province

Study communes

○

Study villages

Figure 2.1: The study site Kampong Chhnang province with three communes Tuol Phpous, Taing Krasaing, and Kouk Banteay where 21 villages where visited.

the meeting. The sessions lasted 3 hours including a break. At the end of the session one of the games was chosen randomly to be paid out to the individual.

All instructions were given verbally and aided with posters and examples to ensure understanding in a population with high illiteracy rates (all instructions, visual aids, as well as the survey are available in the appendix). The verbal consent also included information about the confidentiality and anonymity of the decisions and answers that the participants gave. Moreover, subjects were made aware that participation is voluntary and that they could leave at any time without negative consequences. Participants were stimulated to ask questions at all times. Once the participants had no further questions, the experimental tasks started. Participants played four economic games in the following order: risk elicitation, linear public good game, conditional linear public good game and the threshold public good game. No feedback was given between these games to avoid confounding behaviour.

The risk elicitation task follows Gneezy and Potters [1997] and the conditional public 
Table 2.1: Overview of sample population

\begin{tabular}{l|l}
\hline \hline & Household Characteristics \\
\hline Gender & male (104), female (177), preferred not to say (1) \\
Age & $18-80$ \\
Years of school attended & $0-16$ \\
Relation to Household head & HH head (128), Spouse (122), Child (2), Parent (25), Other (5) \\
Primary occupation & Rice farmer (239), Fisher (1), Housewife (12), Other (30) \\
Household members & $1-11$ \\
Children per Household & $0-6$ \\
Earners per Household & $0-6$ \\
Rice cultivation (2018) & yes (265), no (17) \\
Fishing (2018) & yes (63), no (219) \\
\hline & Area \\
\hline Communes & 3 \\
Villages & 21 \\
\hline \hline
\end{tabular}

good game Fischbacher et al. [2001] with the instructions adapted from Rustagi et al. [2010]. The risk elicitation and the conditional public good game are used to measure risk aversion and define cooperative types. For all the games we randomly and anonymously assign new partners. All participants also answered survey questions in regard to sociodemographics and social capital. In 23 cases we have incomplete data which leaves us with 282 full observation sets. Table 3.A.1 in the appendix provides an overview of the summary statistics from the survey as well as the experiments. Finally, subjects are paid their individual payoff privately and in cash.

\subsubsection{Eliciting risk and social preferences}

To analyse impacts on contribution strategies between games we conducted a risk elicitation task and played a conditional public good game. The risk elicitation task provides us with a measure for risk aversion which runs from zero (highly risk seeking) to six (highly risk averse). We see that the majority of our sample is more or less risk neutral (values from two to four) and only few show extreme risk aversion (value of six) or risk seeking (value of zero) behaviour (fig. 2.2). We play a conditional public good game based on Fischbacher et al. [2001] which measures contribution in public goods without any source of social risk. Fischbacher et al. [2001] find that some people free ride independent of how much the other person contributes, others match the contributions of their partners (conditional cooperators), while some match contributions to a certain point from which on they reduce contributions to the public good again (hump-shaped contributions). Rustagi et al. [2010] include further behaviour types such as altruists (unconditional cooperation) 

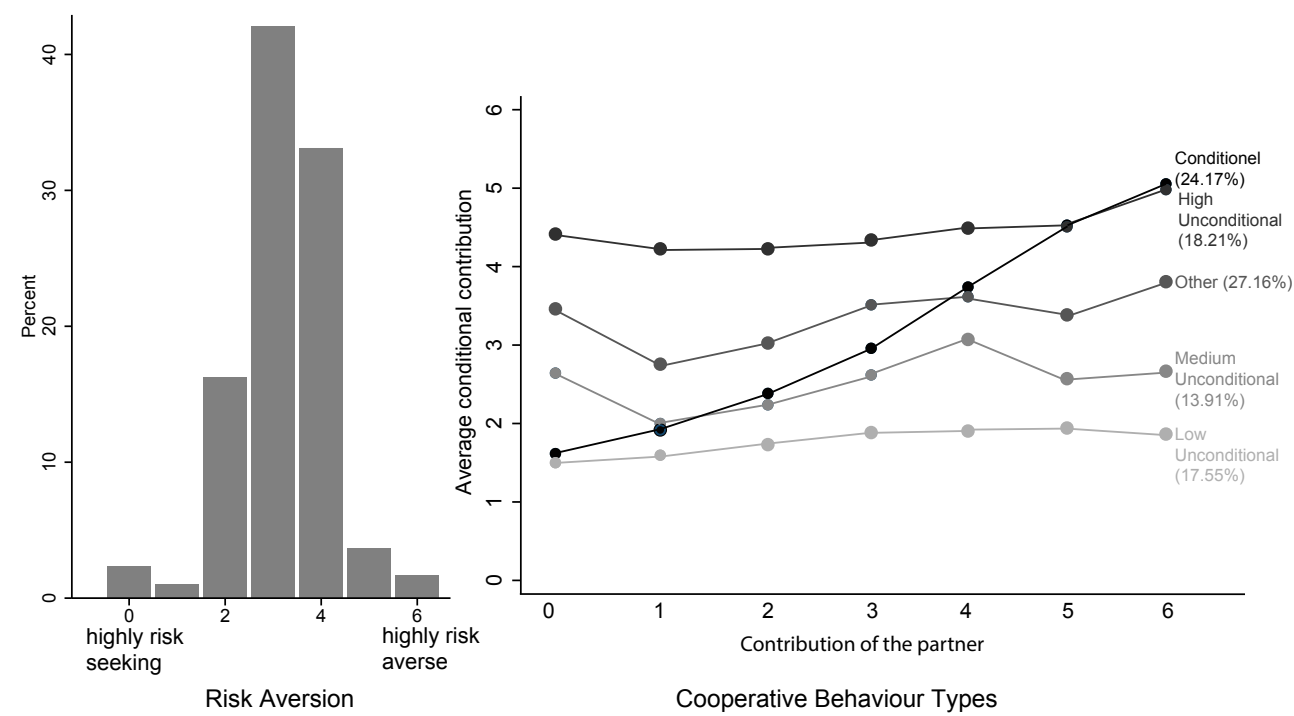

Figure 2.2: Degree of risk aversion and cooperative behaviour types based on the hierarchical cluster analysis.

and weak conditional cooperators (no exact matching of the contributions, but close). When applying the classification of cooperative behaviour types by Rustagi et al. [2010] they do not explain a lot of the cooperative behaviour in our Cambodian population ${ }^{3}$. This may not be surprising, given that behavioural types are hardly universal, but embedded in cultural contexts [Henrich et al., 2001]. For example, there is a strong aversion towards free riding in Cambodia, a behaviour that is entirely absent in our experiment. An alternative way to the standard approach by Fischbacher et al. [2001] is the hierarchical cluster analysis proposed by Fallucchi et al. [2018]. Cluster analysis matches variables into groups by analysing their similarities to each other (see appendix section 2.A.1 for details). Fallucchi et al. [2018] show that the hierarchical cluster analysis is able to reproduce the classifications of Fischbacher et al. [2001] if these are the prevalent behaviour types. Yet, the advantage of the hierarchical cluster analysis is that it is also able to detect different contribution patterns. By applying this method to our population we find five behaviour types. A frequent contribution strategy is to contribute more or less the same amount independent of how much the partner contributes, but there are three distinct groups which differ in the level of contributions. Further, we identify a group that seems to be described best as conditional cooperators and one group that does not seem to match any pattern. Hence, we classify our behavioural types as follows: $18.48 \%$

\footnotetext{
${ }^{3}$ Based on Rustagi et al. [2010] we classified $8 \%$ as unconditional cooperators, $7 \%$ as conditional cooperators, $20 \%$ as weak conditional cooperators, $0 \%$ as free riders, $0 \%$ as hump shaped, and $65 \%$ as unclassified behaviour.
} 
high unconditional cooperators, $24.09 \%$ conditional cooperators, $13.86 \%$ medium unconditional cooperators, $17.49 \%$ low unconditional cooperators, and $26.07 \%$ unclassified other behaviour (see fig. 2.2). The average contribution in the conditional public good game of a high unconditional cooperator is 4.44 (SD 0.9), 2.54 (SD 0.77) of a medium unconditional cooperator, and 1.78 (SD 0.89) of a low unconditional cooperator. The last group of contributors shows no clear pattern of contributions with an average contribution of 3.37 (SD 1.17) (see table 3.A.1 for summary statistics and fig. 2.A.2 for contribution pattern of the five types). Figure 2.2 shows that conditional cooperators do increase contributions as the contributions of partners increase, but they do not match them exactly, partially because of a reluctance to contribute zero.

\subsection{Experimental Design}

\subsubsection{Linear Public Good Game}

We play a standard linear public good game to analyse cooperativeness under social uncertainty, but without strategic uncertainty. While the payoff for individual $i$ depends on the contributions of the partners, the strategies to achieve the social optimum or maximise individual gains do not. In the linear public good game the group size is set to two and we have the following individual payoff structure

$$
\pi_{i}=E_{i}-c_{i}+0.75 \sum_{j=1}^{n} c_{j}
$$

where $\pi_{i}$ is the individual $i$ 's payoff, $E$ is the endowment, and $c_{i}$ the individuals contribution to the public fund. For every 1000 KHR contributed to the public fund, another $500 \mathrm{KHR}$ are added. Thus, the marginal per capita return is 0.75 and since $0.75<1<0.75 \times N$, players face a social dilemma. In this game the profit maximising individual will contribute zero $\left(c_{i}=0\right)$ (the Nash equilibrium) and it is socially optimal to contribute everything $\left(c_{i}=E_{i}\right)$ (see fig. 2.3). Thus, the Nash and socially optimal strategy are independent of the size of the group and the contributions of the partners, but the payoffs clearly depend on the contributions of the partners. We use $6000 \mathrm{KHR}$ as endowment $E$. Contributions to the public fund are possible in discrete steps of 1000 KHR. The maximum social welfare is $18000 \mathrm{KHR}$, which is $9000 \mathrm{KHR}$ per person.

\subsubsection{Threshold Public Good Game}

In addition to the linear public good game we use a threshold public good game to implement strategic uncertainty on top of social uncertainty. The individual payoff $\pi_{i}$ in 
the threshold game is determined by

$$
\pi_{i}= \begin{cases}\left(E_{i}-c_{i}\right)+B & \text { if } \sum_{j=1}^{n} c_{j} \geq T \\ \left(E_{i}-c_{i}\right) & \text { if } \sum_{j=1}^{n} c_{j}<T\end{cases}
$$

where $B$ is a lump sum benefit every player gets if the threshold is reached, $c_{i}$ the individual contribution to the public good, $T$ denotes the threshold, and $E_{i}$ the endowment. Note that $E<T<N E$, hence no individual can reach the threshold by herself and reaching the threshold does not require contributing all of the endowment by everyone.

The game has two symmetric Nash equilibria: the pure uncooperative strategy in which everyone contributes zero to the public fund $\left(c_{i}=0\right)$ which we refer to as symmetric uncooperative Nash equilibrium, and the fair equilibrium strategy in which the threshold is reached via equal contributions by everyone $\left(c_{i}=T / N\right)$ which we refer to as symmetric cooperative Nash equilibrium. The fair equilibrium only exists if and only if $B \geq T / N$. The symmetric cooperative Nash equilibrium maximises social welfare and distributes it equally among the group, hence, the fair social optimum is reached. The best response for individual $i$ is $T / N$ if she believes that the others contribute $(N-1)(T / N)$, thus making the individuals contributions just enough to reach the threshold. Contributing zero to the public fund is the best strategy if the individual believes the partners also contribute zero (see fig. 2.3). Apart from those two symmetric equilibria there are also asymmetric equilibria, though symmetric equilibria might act as focal points [Cadsby and Maynes, 1999]. The requirements for an asymmetric equilibrium are $\sum_{j=1}^{n} c_{j}=T$ and $c_{i} \leq B$ for all $i$. Thus, with every additional partner, the number of asymmetric equilibria increases.

As in the linear public good game the endowment is $6000 \mathrm{KHR}$, contributions to the public fund are done in steps of 1000 KHR. The group size is set to three. The maximum social welfare in the threshold public good game is $27000 \mathrm{KHR}$. Thus, the individual payoff in the fair social optimum (every individual contributes the same amount) in the threshold game is the same as in the social optimum in the linear public good game (9000 KHR). The symmetric cooperative Nash equilibrium is reached if everyone contributes $3000 \mathrm{KHR}$. The linear as well as the threshold public good game are played as one-shot games in which we randomly assign new partners for each game to avoid intergroup dynamics such as retaliation ${ }^{4}$.

\footnotetext{
${ }^{4}$ The threshold game is set up as a framing experiment, where the threshold may resemble a public good or a public bad which is analysed in chapter 3. When analysing data, we always control for the framing effect.
} 
Linear Public Good Game

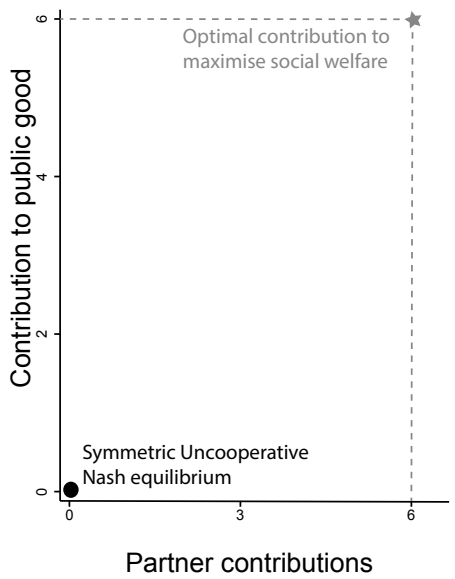

Threshold Public Good Game

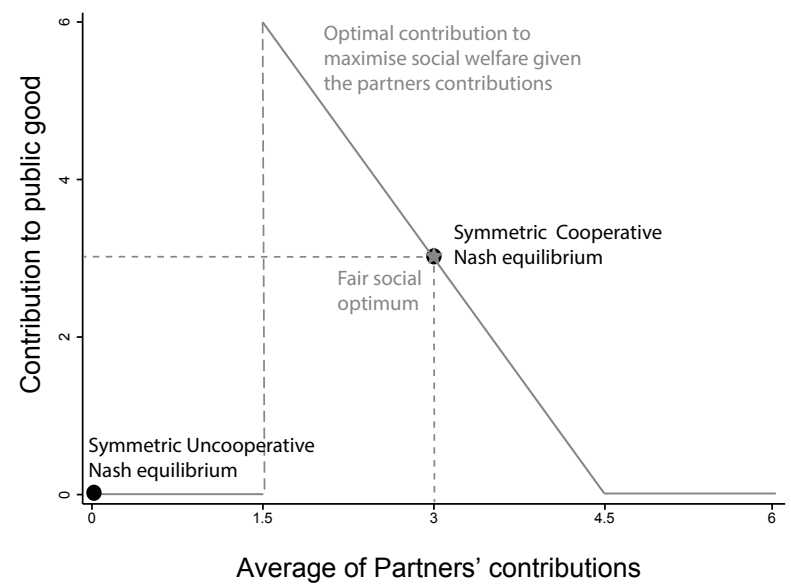

Figure 2.3: Optimal contribution strategy and symmetric Nash equilibria in the linear and the threshold public good game.

\subsection{Results}

First, we establish the contribution and welfare levels in the linear and the threshold public good games. Second, we analyse how individual preferences, socio-demographics, and social capital influence these contribution levels.

\subsubsection{Public good games}

\section{Contribution levels}

The average contribution to the public fund in the linear public good game is 3.11 (SD 1.11) and 3.15 (SD 1.18) in the threshold public good game. Figure 2.4 shows that in the linear public good game only $3.31 \%$ contribute the socially optimal amount of six bills and only $0.33 \%$ follow the individual profit maximisation strategy of zero contributions. The most frequently observed contribution is three bills $(37.42 \%)$. The most frequent observed contribution level in the threshold public good game is also three bills (48.50\%), but the contribution levels zero $(3.65 \%)$ and six $(4.65 \%)$ are also observed more often. While the 
Kolmogorov-Smirnov test confirms the difference of the distributions $(\mathrm{D}=5.9734, \mathrm{p}=$ $0.000)$, we cannot confirm differences in the mean.
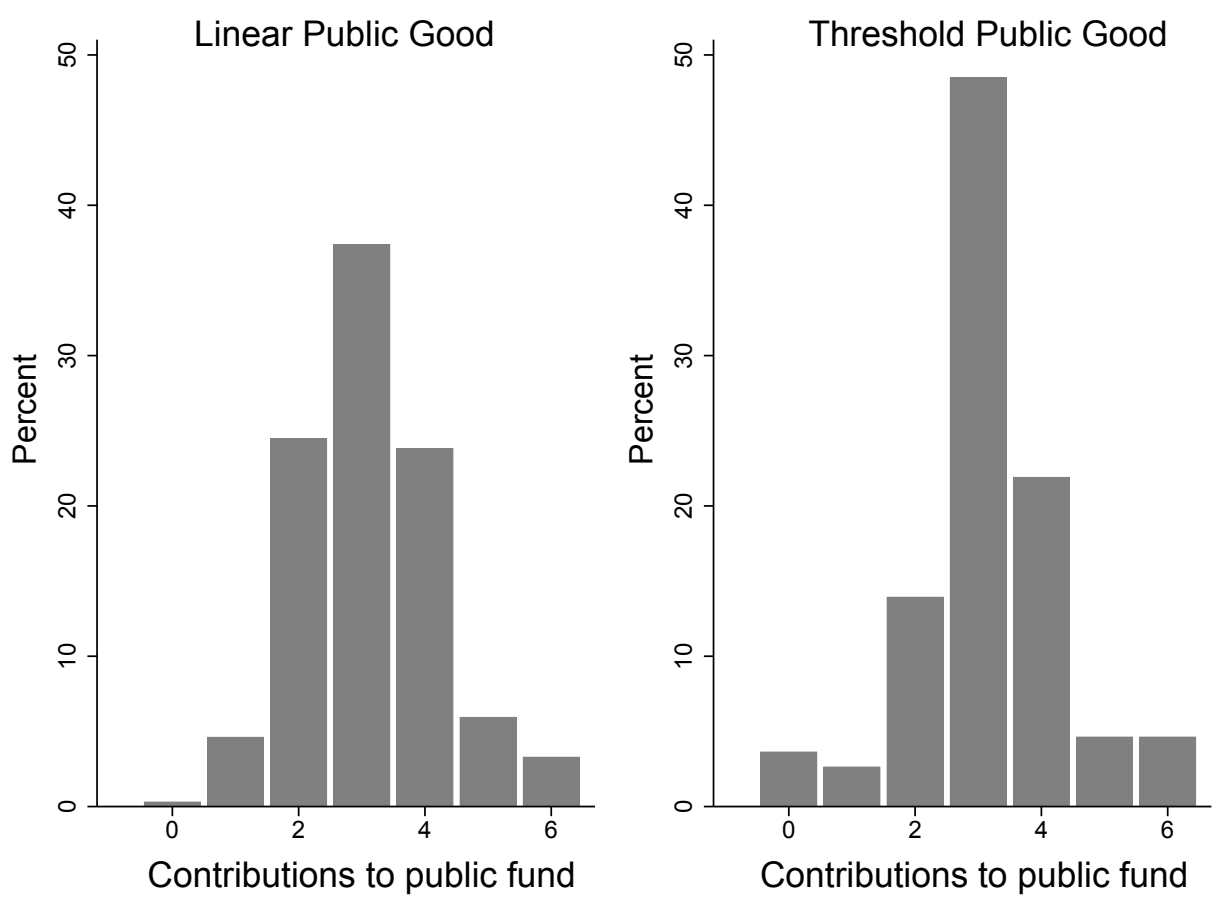

Figure 2.4: Contributions to the public fund in the linear public good and the threshold public good game.

Welfare levels

Comparing the individual payoffs per game, we find that the median payoff is considerably lower in the linear public good game (six) than in the threshold public good game (eight). Also, we find that the range of payoffs is lower in the linear (from four to eight) than in the threshold public good game (from two to twelve) (fig. 2.5). When we relate the payoffs to the contribution levels we see a negative relationship between contributions and realised payoffs in both games. This negative relationship is caused by the inherent feature of a social dilemma where contributing less is individually better, but collectively worse. We see that contributing to the public good often results in payoffs that are even lower than the symmetric uncooperative Nash equilibrium. In fig. 2.5 we can clearly see that in the linear public good game the payoffs are distributed around (often below) the Nash equilibrium, while in the threshold game two payoff branches (collective success / failure) are visible. 
This makes it also intuitively clear why the threshold game features an additional source of risk, as more contribution to the public fund comes at a cost, but reduces the risk of failing to meet the threshold. We see that the symmetric cooperative Nash equilibrium is a popular strategy with a very high chance of success, but also contributing slightly above Nash (four bills) is a strategy with fairly high success rates without having to sacrifice too much of the individual payoff.
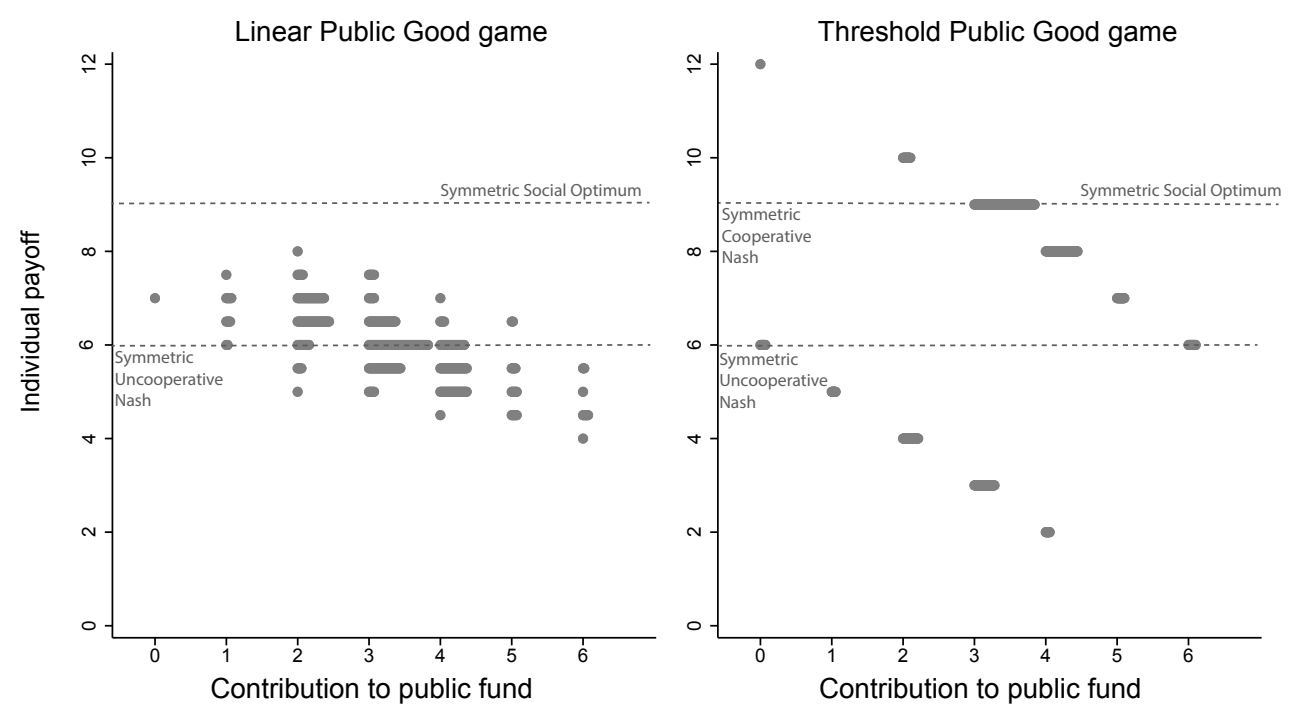

Figure 2.5: Individual payoffs depending on contribution level in the linear and the threshold public good game. The length of the bars indicate the frequency of the observed payoff levels.

\subsubsection{Determinants of contribution levels}

\section{Linear Public Good}

We run an OLS regression to explain contribution levels to the public good. We estimate the following model

$$
y_{i}=\alpha+\beta \boldsymbol{X}_{i}+\lambda+\mu_{i}
$$

with $y_{i}$ being the contributions to the public fund, $\alpha$ is the constant, $\boldsymbol{X}_{\boldsymbol{i}}$ includes the variables on individual preferences, socio-demographics, and social capital, $\lambda$ denotes the village fixed effects, and $\mu_{i}$ is the error term. Given the shared experiences within villages and the close social networks, we cluster the error term on the village level.

In the linear public good game we find that risk aversion is negatively correlated with contributions (table 2.2). This effect persists, independent of the covariates included in 
the model (model (1) to (4) in table 2.2). We also see that high unconditional cooperators contribute significantly more than low unconditional cooperators (which we use as a base). Also, conditional cooperators contribute more to the public good than low unconditional cooperators but to a lesser extent than high unconditional cooperators. None of the socio-demographics apart from remittances have any significant effect. We do see that a household that receives remittances, which probably belongs to the wealthier part of the population, contributes more to the public good than those households without remittances. Regarding trust and social capital, we do not find any effect of being a member of a voluntary organisation. We measured the support for community tasks ${ }^{5}$ and find that the higher the support for community tasks is the more people contribute to the public good, even though it is only significant at a $10 \%$ level.

\section{Threshold Public Good}

We run the same OLS for the contribution level in the threshold public good game. In this game risk aversion does not have a significant effect in any specification (see table 2.3). We do find an effect of cooperative types, but the effect is weaker than in the linear public good game. High unconditional cooperators do contribute more than the low unconditional cooperators, but the difference is less than in the linear public good. In the threshold public good game none of the socio-demographic variables has any significant effect, and the trust / social capital variables are insignificant as well.

A potential caveat is of course the very fact that the threshold game is nonlinear and therefore a linear regression may not be the best specification to explain contributions. Therefore, we run another model where we try to explain whether individuals contribute (i) less than the symmetric cooperative Nash equilibrium SCNE), (ii) more than the SCNE, and (iii) exactly the SCNE. We code those as dummy variables and run a logit model to test for the impact of risk aversion on those different contribution levels. Specifically, we run the following model for three different contribution levels (contribution levels below, at, or above the symmetric cooperative Nash equilibrium)

$$
P R\left(y_{i}=1\right)=\alpha+\beta \boldsymbol{X}_{\boldsymbol{i}}+\lambda+\mu_{i}
$$

where, as before, $\alpha$ is the constant, $\boldsymbol{X}_{\boldsymbol{i}}$ includes the variables on individual preferences, socio-demographics, and social capital, $\lambda$ denotes the village fixed effects, and $\mu_{i}$ is the error term clustered on the village level. The dependent variable $\operatorname{PR}\left(y_{i}=1\right)$ measures in model (1) in table 2.4 whether the contribution level is below three (below SCNE), in model (2) whether the contribution level is three (SCNE), and in model (3) whether the contribution level is above three (above SCNE) (see table 2.4).

\footnotetext{
${ }^{5}$ The exact question in the survey was: "Suppose that 10 of your neighbors are invited to help in community activities (e.g. repairing a canal or dam). How many would show up?" The possible answers ranged from 0 to 10 .
} 
We still do not see any effect of risk preferences but again, the cooperative behaviour types are significant. High unconditional cooperators have a high likelihood that they contribute above the SCNE, conditional cooperators do not show a pattern and medium unconditional cooperators prefer to play the SCNE. No socio-demographic variables nor community related variables have any significant effect. 
Table 2.2: Determinants of contribution level in the linear public good game.

\begin{tabular}{|c|c|c|c|c|}
\hline & $(1)$ & $(2)$ & $(3)$ & $(4)$ \\
\hline \multicolumn{5}{|l|}{ Individual Preferences } \\
\hline Risk Aversion & $\begin{array}{c}-0.201^{* * *} \\
(0.0524)\end{array}$ & $\begin{array}{c}-0.224^{* * *} \\
(0.0538)\end{array}$ & $\begin{array}{c}-0.229^{* * *} \\
(0.0484)\end{array}$ & $\begin{array}{r}-0.214^{* * *} \\
(0.0536)\end{array}$ \\
\hline High Unconditional Cooperators & $\begin{array}{c}1.587^{* * *} \\
(0.178)\end{array}$ & $\begin{array}{c}1.270^{* * *} \\
(0.191)\end{array}$ & $\begin{array}{c}1.257^{* * *} \\
(0.212)\end{array}$ & $\begin{array}{c}1.300^{* * *} \\
(0.192)\end{array}$ \\
\hline Conditional Cooperators & $\begin{array}{c}0.638^{* * *} \\
(0.165)\end{array}$ & $\begin{array}{c}0.426^{* *} \\
(0.199)\end{array}$ & $\begin{array}{l}0.423^{*} \\
(0.207)\end{array}$ & $\begin{array}{c}0.451^{* *} \\
(0.189)\end{array}$ \\
\hline Medium Unconditional Cooperators & $\begin{array}{c}0.511^{* *} \\
(0.194)\end{array}$ & $\begin{array}{c}0.238 \\
(0.231)\end{array}$ & $\begin{array}{c}0.313 \\
(0.261)\end{array}$ & $\begin{array}{c}0.371 \\
(0.250)\end{array}$ \\
\hline Other & $\begin{array}{c}0.740^{* * *} \\
(0.165)\end{array}$ & $\begin{array}{c}0.514^{* *} \\
(0.184)\end{array}$ & $\begin{array}{c}0.476^{* *} \\
(0.205)\end{array}$ & $\begin{array}{c}0.528^{* *} \\
(0.192)\end{array}$ \\
\hline \multicolumn{5}{|l|}{ Socio-demographics } \\
\hline Male & & & $\begin{array}{c}0.105 \\
(0.158)\end{array}$ & $\begin{array}{c}0.118 \\
(0.163)\end{array}$ \\
\hline Age & & & $\begin{array}{c}0.00365 \\
(0.00580)\end{array}$ & $\begin{array}{c}0.00180 \\
(0.00562)\end{array}$ \\
\hline Years of schooling completed & & & $\begin{array}{c}0.0192 \\
(0.0204)\end{array}$ & $\begin{array}{c}0.0129 \\
(0.0194)\end{array}$ \\
\hline Number of household members & & & $\begin{array}{c}0.0136 \\
(0.0283)\end{array}$ & $\begin{array}{l}0.00775 \\
(0.0291)\end{array}$ \\
\hline Household engaged in fishing (2018) & & & $\begin{array}{r}-0.0940 \\
(0.126)\end{array}$ & $\begin{array}{l}-0.133 \\
(0.125)\end{array}$ \\
\hline Household receives remittances & & & $\begin{array}{c}0.340^{* * *} \\
(0.109)\end{array}$ & $\begin{array}{c}0.331^{* * *} \\
(0.111)\end{array}$ \\
\hline \multicolumn{5}{|l|}{ Social Capital } \\
\hline Member in a water and/or fisher association & & & & $\begin{array}{c}0.163 \\
(0.173)\end{array}$ \\
\hline Expected help of neighbours in contributing to community tasks & & & & $\begin{array}{l}0.0531^{*} \\
(0.0278)\end{array}$ \\
\hline Constant & $\begin{array}{c}3.044^{* * *} \\
(0.288) \\
\end{array}$ & $\begin{array}{c}3.411^{* * *} \\
(0.262) \\
\end{array}$ & $\begin{array}{c}2.985^{* * *} \\
(0.296) \\
\end{array}$ & $\begin{array}{c}2.501^{* * * *} \\
(0.374) \\
\end{array}$ \\
\hline Village fixed effects & & $\sqrt{ }$ & $\sqrt{ }$ & $\sqrt{ }$ \\
\hline Observations & 302 & 302 & 281 & 281 \\
\hline$R^{2}$ & 0.257 & 0.420 & 0.446 & 0.460 \\
\hline Adjusted $R^{2}$ & 0.245 & 0.367 & 0.378 & 0.388 \\
\hline
\end{tabular}

Standard errors in parentheses, clustered on village level.

${ }^{*} p<0.10,{ }^{* *} p<0.05,{ }^{* * *} p<0.01$ 
Table 2.3: Determinants of contribution level in the threshold public good game.

\begin{tabular}{|c|c|c|c|c|}
\hline & $(1)$ & $(2)$ & $(3)$ & $(4)$ \\
\hline \multicolumn{5}{|l|}{ Individual Preferences } \\
\hline Risk Aversion & $\begin{array}{c}0.0247 \\
(0.0716)\end{array}$ & $\begin{array}{c}0.0474 \\
(0.0693)\end{array}$ & $\begin{array}{c}0.0520 \\
(0.0671)\end{array}$ & $\begin{array}{c}0.0463 \\
(0.0663)\end{array}$ \\
\hline High Unconditional Cooperators & $\begin{array}{c}0.785^{* * *} \\
(0.222)\end{array}$ & $\begin{array}{c}0.562^{* *} \\
(0.248)\end{array}$ & $\begin{array}{c}0.552^{* *} \\
(0.262)\end{array}$ & $\begin{array}{c}0.597^{* *} \\
(0.266)\end{array}$ \\
\hline Conditional Cooperators & $\begin{array}{c}0.417^{* *} \\
(0.148)\end{array}$ & $\begin{array}{c}0.121 \\
(0.213)\end{array}$ & $\begin{array}{l}0.0836 \\
(0.225)\end{array}$ & $\begin{array}{l}0.0935 \\
(0.223)\end{array}$ \\
\hline Medium Unconditional Cooperators & $\begin{array}{c}0.238 \\
(0.155)\end{array}$ & $\begin{array}{c}0.152 \\
(0.167)\end{array}$ & $\begin{array}{c}0.168 \\
(0.186)\end{array}$ & $\begin{array}{c}0.188 \\
(0.177)\end{array}$ \\
\hline Other & $\begin{array}{c}0.633^{* * *} \\
(0.196)\end{array}$ & $\begin{array}{l}0.421^{*} \\
(0.243)\end{array}$ & $\begin{array}{c}0.393 \\
(0.259)\end{array}$ & $\begin{array}{c}0.401 \\
(0.247)\end{array}$ \\
\hline \multicolumn{5}{|l|}{ Socio-demographics } \\
\hline Male & & & $\begin{array}{l}0.0630 \\
(0.206)\end{array}$ & $\begin{array}{l}0.0639 \\
(0.207)\end{array}$ \\
\hline Age & & & $\begin{array}{l}0.000918 \\
(0.00754)\end{array}$ & $\begin{array}{c}0.0000688 \\
(0.00703)\end{array}$ \\
\hline Years of schooling completed & & & $\begin{array}{l}0.0461^{*} \\
(0.0263)\end{array}$ & $\begin{array}{c}0.0439 \\
(0.0262)\end{array}$ \\
\hline Number of household members & & & $\begin{array}{c}0.0165 \\
(0.0632)\end{array}$ & $\begin{array}{c}0.0144 \\
(0.0622)\end{array}$ \\
\hline Household engaged in fishing (2018) & & & $\begin{array}{c}-0.0961 \\
(0.139)\end{array}$ & $\begin{array}{l}-0.101 \\
(0.136)\end{array}$ \\
\hline Household receives remittances & & & $\begin{array}{c}-0.0820 \\
(0.124)\end{array}$ & $\begin{array}{r}-0.0760 \\
(0.131)\end{array}$ \\
\hline \multicolumn{5}{|l|}{ Social Capital } \\
\hline Member in a water and/or fisher association & & & & $\begin{array}{c}0.186 \\
(0.157)\end{array}$ \\
\hline Expected help of neighbours in contributing to community tasks & & & & $\begin{array}{l}-0.0123 \\
(0.0325)\end{array}$ \\
\hline Constant & $\begin{array}{c}2.868^{* * *} \\
(0.322) \\
\end{array}$ & $\begin{array}{c}2.887^{* * *} \\
(0.289) \\
\end{array}$ & $\begin{array}{c}2.556^{* * *} \\
(0.488) \\
\end{array}$ & $\begin{array}{c}2.554^{* * *} \\
(0.611) \\
\end{array}$ \\
\hline Village fixed effects & & $\sqrt{ }$ & $\sqrt{ }$ & $\sqrt{ }$ \\
\hline Framing & $\sqrt{ }$ & $\sqrt{ }$ & $\sqrt{ }$ & $\sqrt{ }$ \\
\hline Observations & 301 & 301 & 280 & 280 \\
\hline$R^{2}$ & 0.087 & 0.206 & 0.229 & 0.233 \\
\hline Adjusted $R^{2}$ & 0.069 & 0.130 & 0.130 & 0.126 \\
\hline
\end{tabular}

Standard errors in parentheses, clustered on village level.

${ }^{*} p<0.10,{ }^{* *} p<0.05,{ }^{* * *} p<0.01$ 
Table 2.4: Determinants of contribution levels in the threshold public good game. Logit model for contributions below, at, and above the symmetric cooperative Nash equilibrium.

\begin{tabular}{|c|c|c|c|}
\hline & $\begin{array}{c}(1) \\
\text { below SCNE }\end{array}$ & $\begin{array}{c}(2) \\
\text { SCNE }\end{array}$ & $\begin{array}{c}(3) \\
\text { above SCNE }\end{array}$ \\
\hline \multicolumn{4}{|l|}{ Indiviual Preferences } \\
\hline Risk Aversion & $\begin{array}{l}-0.159 \\
(0.135)\end{array}$ & $\begin{array}{c}0.185 \\
(0.131)\end{array}$ & $\begin{array}{r}-0.0226 \\
(0.129)\end{array}$ \\
\hline High Unconditional Cooperators & $\begin{array}{l}-1.072^{*} \\
(0.561)\end{array}$ & $\begin{array}{l}-0.268 \\
(0.467)\end{array}$ & $\begin{array}{l}1.387^{* *} \\
(0.570)\end{array}$ \\
\hline Conditional Cooperators & $\begin{array}{l}-0.626 \\
(0.458)\end{array}$ & $\begin{array}{c}0.603 \\
(0.464)\end{array}$ & $\begin{array}{l}0.0952 \\
(0.580)\end{array}$ \\
\hline Medium Unconditional Cooperators & $\begin{array}{c}-1.400^{* *} \\
(0.603)\end{array}$ & $\begin{array}{l}1.322^{* *} \\
(0.515)\end{array}$ & $\begin{array}{l}-0.362 \\
(0.661)\end{array}$ \\
\hline Other & $\begin{array}{c}-1.284^{* *} \\
(0.558)\end{array}$ & $\begin{array}{l}0.0893 \\
(0.512)\end{array}$ & $\begin{array}{l}1.166^{* *} \\
(0.592)\end{array}$ \\
\hline \multicolumn{4}{|l|}{ Socio-demographics } \\
\hline Male & $\begin{array}{l}-0.633 \\
(0.454)\end{array}$ & $\begin{array}{r}-0.0240 \\
(0.331)\end{array}$ & $\begin{array}{c}0.551 \\
(0.357)\end{array}$ \\
\hline Age & $\begin{array}{l}0.0263^{*} \\
(0.0151)\end{array}$ & $\begin{array}{l}-0.0138 \\
(0.0143)\end{array}$ & $\begin{array}{l}-0.00768 \\
(0.0189)\end{array}$ \\
\hline Years of schooling completed & $\begin{array}{l}0.00288 \\
(0.0807)\end{array}$ & $\begin{array}{l}-0.0446 \\
(0.0598)\end{array}$ & $\begin{array}{c}0.0457 \\
(0.0657)\end{array}$ \\
\hline Number of household members & $\begin{array}{c}0.00502 \\
(0.159)\end{array}$ & $\begin{array}{l}0.0830 \\
(0.107)\end{array}$ & $\begin{array}{r}-0.0991 \\
(0.125)\end{array}$ \\
\hline Household engaged in fishing (in 2018) & $\begin{array}{c}0.112 \\
(0.558)\end{array}$ & $\begin{array}{l}-0.147 \\
(0.344)\end{array}$ & $\begin{array}{c}0.154 \\
(0.365)\end{array}$ \\
\hline Household receives remittances & $\begin{array}{l}-0.295 \\
(0.484)\end{array}$ & $\begin{array}{c}0.273 \\
(0.324)\end{array}$ & $\begin{array}{l}-0.149 \\
(0.255)\end{array}$ \\
\hline \multicolumn{4}{|l|}{ Social Capital } \\
\hline Member in a water and/or fisher association & $\begin{array}{l}-0.0828 \\
(0.523)\end{array}$ & $\begin{array}{l}-0.256 \\
(0.323)\end{array}$ & $\begin{array}{c}0.356 \\
(0.369)\end{array}$ \\
\hline Expected help of neighbours in contributing to community tasks & $\begin{array}{c}0.0255 \\
(0.0923)\end{array}$ & $\begin{array}{l}-0.0259 \\
(0.0511)\end{array}$ & $\begin{array}{c}0.0101 \\
(0.0693)\end{array}$ \\
\hline Constant & $\begin{array}{l}-1.231 \\
(1.356)\end{array}$ & $\begin{array}{c}-0.620 \\
(1.061)\end{array}$ & $\begin{array}{c}-0.702 \\
(1.345)\end{array}$ \\
\hline Village fixed effects & $\sqrt{ }$ & $\sqrt{ }$ & $\sqrt{ }$ \\
\hline Framing & $\sqrt{ }$ & $\sqrt{ }$ & $\sqrt{ }$ \\
\hline Observations & 236 & 280 & 280 \\
\hline Pseudo $R^{2}$ & 0.159 & 0.123 & 0.231 \\
\hline
\end{tabular}

Standard errors in parentheses, clustered on village level

${ }^{*} p<0.10,{ }^{* *} p<0.05,{ }^{* * *} p<0.01$

Note: We have four villages where nobody contributes less than the symmetric cooperative Nash equilibrium which leads to fewer observations in model (1). 


\subsection{Discussion and Conclusion}

A key question in the literature concerns the individual and contextual factors around cooperation in social dilemma situations. An inherent feature of social dilemmas is the fear of being exploited or betrayed by others, which has been coined "social uncertainty". In addition, some games feature an additional source of risk or "strategic uncertainty", as socially and privately optimal strategies depends on actions of others. The predominant way to analyse social dilemma situations is the use of the linear public good game, where the strategies to achieve the social optimum are independent of behaviour of others and, hence strategic uncertainty is absent. In this paper we analyse the underlying factors of cooperation in (i) a linear public good game without strategic uncertainty and (ii) a threshold public good game with strategic uncertainty. By running both games we are able analyse the determinants of contribution levels in light of social and strategic uncertainty.

We find that cooperative behaviour types play a role for contribution levels with and without strategic uncertainty. Yet, the differences between the cooperative behaviour types are less pronounced in the threshold public good game. The symmetric cooperative Nash equilibrium serves as a clear focal point which may put individuals in a mode of coordination, rather than cooperation. Also, our trust variable explains cooperation in the linear public good game, but not in the threshold public good game, lending further support to the idea that the the threshold public good game is not necessarily perceived as a game of cooperation.

While risk aversion plays a role in the linear public good game, we cannot find any impact of risk aversion in the threshold public good game. This finding is somewhat surprising given that the threshold game has a very clear risk component of failing to reach the threshold (the strategic uncertainty), in addition to the social uncertainty of deviating from the social norm of what others are doing. Hence, we expected that risk plays a larger role in the threshold public good game, but we cannot find evidence for this. Perhaps the focal point in the threshold game acts as such strong coordination device making it obvious what is the right thing to do, which would eliminate social risk. As a result, the overall game would appear less risky and risk preferences would play less of a role, but we cannot validate this argument with the data that we have. An obvious follow up experiment would be to explore the role of social risk further, and let the threshold game also be played in a setting where co-players would be computers, rather than humans [Iris Bohnet and Zeckhauser, 2008].

In both games the most frequently observed contribution level is $50 \%$ of the endowment. 
The tendency of contribution around $50 \%$ of the endowment has been observed many times before [Ledyard, 1995, Fehr and Fischbacher, 2003, Burton-Chellew and West, 2013]. In a setting where the symmetric cooperative Nash equilibrium corresponds to $50 \%$ of the endowment this choice is observed even more frequently. Thus, the observed welfare levels are considerably higher in the threshold public good game than in the linear public good game. While it is generally difficult to compare welfare levels across games, setting the symmetric cooperative Nash equilibrium to $50 \%$ probably made coordination easier because it is the point that maximizes social welfare and is also in line with a fairness norm to contribute around $50 \%$ of the endowment. Future research could test cooperation in strategic interaction settings where the symmetric cooperative Nash equilibrium differs from the preferred contribution level of 40 - 50\% [Hichri, 2004, Willinger and Ziegelmeyer, 1999].

Finally, many real world social dilemmas, such as harvesting a renewable resource or contributing to joint infrastructure, resemble a threshold game. However, the linear public good game remains the key device to measure cooperation in most experimental research. Our results suggest that the determining factors in a linear public good game do not necessarily carry over to a threshold game. While our experiments are conducted in a specific Cambodian context and thus may not be generalisable, they do raise the question to what extent results from linear public good games can be used to explain cooperation in the field. 



\section{Appendix}

\section{A Appendix}

Table 2.A.1: Summary statistics

\begin{tabular}{|c|c|c|c|c|c|}
\hline & Observations & Mean & Standard Deviation & Min & Max \\
\hline \multicolumn{6}{|l|}{ Risk Elicitation } \\
\hline Contribution to the risky account & 302 & 2.80 & 1 & 0 & 6 \\
\hline \multicolumn{6}{|l|}{ Linear Public Good game } \\
\hline Contribution to public fund & 303 & 3.11 & 1.11 & 0 & 6 \\
\hline \multicolumn{6}{|l|}{ Conditional Public Good game } \\
\hline Contribution to public fund if partner contributes 0 & 299 & 2.72 & 1.5 & 0 & 6 \\
\hline Contribution to public fund if partner contributes 1000 & 299 & 2.51 & 1.29 & 0 & 6 \\
\hline Contribution to public fund if partner contributes 2000 & 299 & 2.75 & 1.19 & 0 & 6 \\
\hline Contribution to public fund if partner contributes 3000 & 299 & 3.11 & 1.1 & 0 & 6 \\
\hline Contribution to public fund if partner contributes 4000 & 299 & 3.43 & 1.24 & 0 & 6 \\
\hline Contribution to public fund if partner contributes 5000 & 299 & 3.50 & 1.42 & 0 & 6 \\
\hline Contribution to public fund if partner contributes 6000 & 299 & 3.82 & 1.62 & 0 & 6 \\
\hline \multicolumn{6}{|l|}{ Threshold Public Good game } \\
\hline Contribution to public fund & 301 & 3.15 & 1.18 & 0 & 6 \\
\hline \multicolumn{6}{|l|}{ Socio-demographics } \\
\hline Gender $($ Male $=1)$ & 281 & 0.37 & 0.48 & 0 & 1 \\
\hline Age & 282 & 46.2 & 13.22 & 18 & 80 \\
\hline Number of Household members & 282 & 4.76 & 1.7 & 1 & 11 \\
\hline Years of Schooling & 282 & 4.05 & 3.48 & 0 & 16 \\
\hline Fishing $($ yes $=1)$ & 282 & 0.22 & 0.42 & 0 & 1 \\
\hline Remittances (yes $=1$ ) & 282 & 0.32 & 0.47 & 0 & 1 \\
\hline \multicolumn{6}{|l|}{ Social Capital } \\
\hline Membership (yes = 1) & 282 & 0.35 & 0.48 & 0 & 1 \\
\hline Support of neighbours for community task & 282 & 7.33 & 2.35 & 0 & 10 \\
\hline \multicolumn{6}{|l|}{ Cooperative behaviour types -contributions } \\
\hline Conditional Cooperators & 73 & 3.17 & 1.55 & 0 & 6 \\
\hline High Unconditional Cooperators & 56 & 4.44 & 0.9 & 0 & 6 \\
\hline Medium Unconditional Cooperators & 42 & 2.54 & 0.77 & 0 & 5 \\
\hline Low Unconditional Cooperators & 53 & 1.77 & 0.89 & 0 & 6 \\
\hline Unclassified other behaviour & 79 & 3.37 & 1.17 & 0 & 6 \\
\hline
\end{tabular}




\section{A.1 Hierarchical Cluster Analysis}

In an experimental setting outside the lab with a study population other than university students, the heterogeneity in behavioural responses in a conditional public goods game is expected to increase [Fallucchi et al., 2018]. In such a case, the standard approach by Fischbacher et al. [2001] may not reflect the reality in the field and a more general approach, such as the hierarchical cluster analysis proposed by Fallucchi et al. [2018] is preferred.

We follow Fallucchi et al. [2018] by using Ward's minimum variance method with the Manhattan distance as a dissimilarity measure. Cluster analysis matches variables into groups by analysing their similarities to each other. Two contribution strategies are more similar if the distance separating them is smaller. While Fischbacher et al. [2001] have four behavioural types, Rustagi et al. [2010] already extended the behavioural types to five. Yet, there is no reason to assume that those are the only relevant strategies. Hence, we analyse which number of behavioural types seems appropriate. The coherence within clusters and the number of clusters that can be handled in a meaningful way is always a trade-off.

We use, as do Fallucchi et al. [2018], the Duda - Hart index $(J e(2) / J e(1)=$ $\left.W\left(t_{1}\right)+W\left(t_{2}\right) / W\left(t_{1} \cup t_{2}\right)\right)$ complemented by a silhouette analysis. Duda and Hart propose to pick the number of clusters which corresponds to a large $J e(2) / J e(1)$ and a low pseudo T-squared value with a much larger T-squared value next to it. At the same time the Calinski/Harabasz pseudo-F should be high. We see that in table 2.A.2 $J e(2) / J e(1)$ is the second highest for five clusters (0.8550) which corresponds to a significant drop in the pseudo T-squared (12.04) compared to four clusters (23.86) whilst at the same time corresponding to the pseudo-F of 75.91. Hence, we use five groups to categorize pro-social behaviour.

The silhouette analysis confirms those clusters (see fig. 2.A.1). The silhouette value measures how well an object fits into the cluster it is assigned to and how different it is to other clusters. High values indicate that an object is similar to the other objects within the cluster and that it is distinctly different from the objects in other clusters. Negative values mean that the object is not well matched to the objects within a cluster and that it is not clearly separated from other clusters. In our clustering we only have few borderline cases apart from cluster one, which is the unclassified "other" category. We also run a Kruskal-Wallis test which confirms that the clusters are different $(p=0.0001)$.

To label behaviour strategies within clusters we plotted them (see fig. 2.A.2). We see 
Table 2.A.2: Duda - Hart index, pseudo T-squared and Calinski/Harrabass pseudo-F to determine number of clusters.

\begin{tabular}{cccc}
\hline & \multicolumn{2}{c}{ Duda - Hart } & \\
Number of clusters & $J e(2) / J e(1)$ & pseudo T-squared & Calinski/Harabass pseudo-F \\
\hline 1 & 0.7208 & 116.59 & 116.59 \\
2 & 0.7836 & 56.88 & 102.17 \\
3 & 0.7868 & 36.05 & 90.67 \\
4 & 0.7958 & 23.86 & 75.91 \\
5 & 0.8550 & 12.04 & 64.97 \\
6 & 0.8496 & 13.63 & 60.36 \\
7 & 0.7817 & 16.48 & 57.18 \\
8 & 0.8007 & 12.69 & 52.94 \\
9 & 0.8122 & 12.49 & 49.83 \\
10 & 0.7612 & 12.55 & 47.99 \\
11 & 0.7127 & 11.69 & 45.86 \\
12 & 0.6866 & 11.87 & 43.96 \\
13 & 0.7477 & 9.45 & 42.64 \\
14 & 0.7722 & 11.80 & 40.98 \\
15 & 0.9173 & 3.79 & \\
\hline \hline
\end{tabular}

that three clusters can be defined as unconditional cooperators (high, medium, and low contribution levels), one can be classified as conditional cooperators and one is unclassified behaviour (group one in the silhouette analysis). 


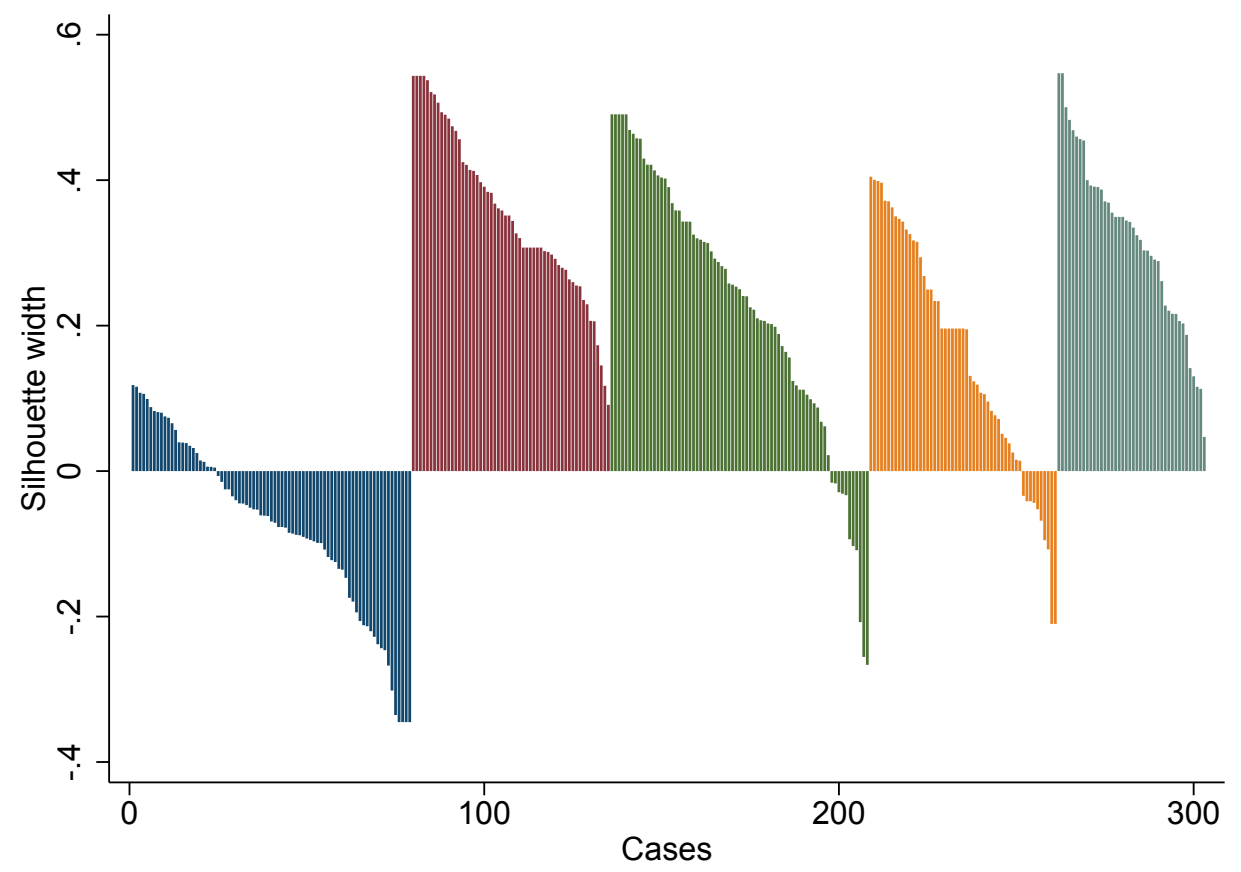

Figure 2.A.1: Silhouette analysis. Colours indicate clusters, positive values mean that the object is similar to other objects in the cluster, negative values mean that an object is different to other objects in the cluster. 
High Unconditional Contributors
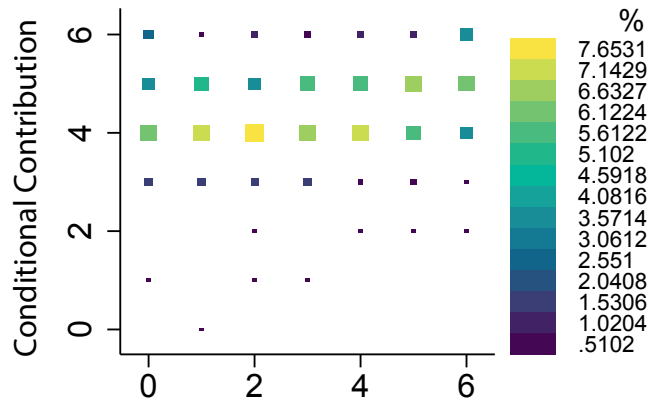

Low Unconditional Contributors
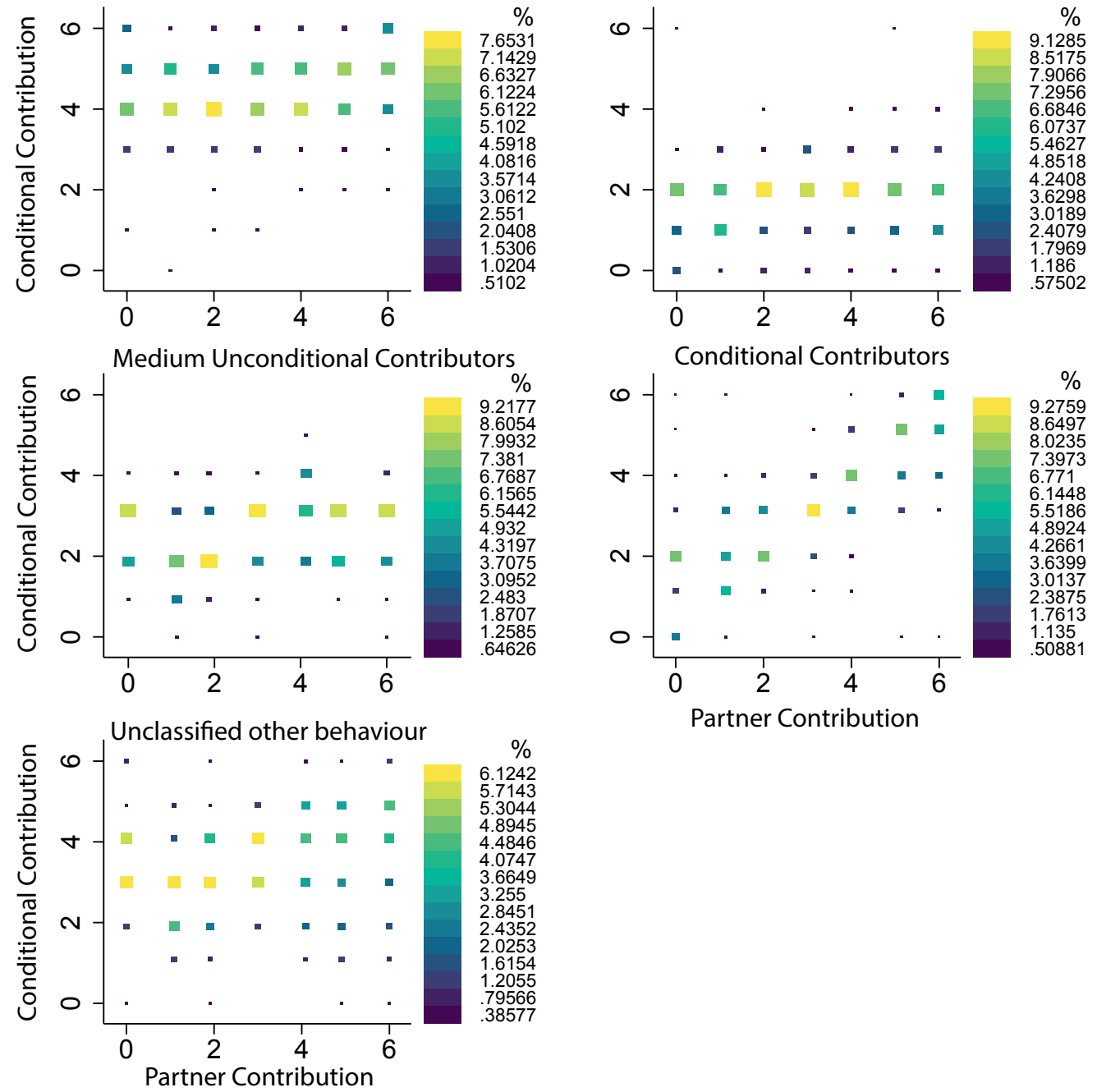

Figure 2.A.2: Conditional contribution frequencies based on the hierarchical cluster analysis. 



\section{Chapter 3}

\section{A threshold public good game with public good and public bad framing - Evidence from farmers and fishers in Cambodia}

This chapter is based on the manuscript Schuch, E., Richter, A. and Nhim, T. (2020). A threshold game with public good and public bad framing - Evidence from farmers and fishers in Cambodia. 


\section{Abstract}

In Cambodia, fishery governance relies largely on informal agreements of community groups, organized per village. Farmers and fishers rely on the management of the resources through social norms to avoid a collapse of the resource (e.g. the fish stock collapse) or to ensure access to a resource (maintaining irrigation infrastructure). Natural resource management has mainly been studied in linear public good games whilst many resources show nonlinear dynamics. Hence, we perform a threshold public good game to analyse cooperative behaviour when a threshold has to be reached before cooperation pays off. We conduct a de-contextualized lab-in-the-field experiment in 21 villages in Cambodia. In particular, we are interested whether we can see framing effects when presenting the game as a public good or a public bad game. We are the first to test the framing effect on a population that is used to managing natural resources on a daily basis. We find that the level of cooperation is higher in a public good than a public bad framing confirming that the framing effect exists outside of the lab. We also find a framing effect in the believed contributions of the partners which is contrary to the existing literature. We find that the believed contributions in the public good are lower than in the public bad treatment. The people in the public good treatment severely underestimate their partners contributions while they overestimate contribution in the public bad treatment. As a result, groups in the public good treatment are better in achieving the threshold. 


\subsection{Introduction}

Natural resources are collective goods and their management is a social dilemma. Many of these natural resources have a nonlinear behaviour, yet, social dilemmas are mostly studied in linear settings such as a standard voluntary contribution mechanism [Rustagi et al., 2010, Voors et al., 2011, Cárdenas et al., 2011, 2017, Werthmann et al., 2010, Prediger, 2011]. A more appropriate setting are threshold games in which cooperation needs to reach a certain level for the collective good to be managed in a meaningful way [Dannenberg et al., 2015, Tavoni et al., 2011, Barrett and Dannenberg, 2014, İriş et al., 2019, Au, 2004]. If the threshold is not met all contribution towards the threshold are lost. Depending on the natural resource the threshold can act as a target that needs to be reached or one that needs to be avoided. While some resources are commonly associated with either a public good or a public bad framing, these settings can, theoretically, also be reversed since not achieving a public good is equivalent to sticking to a public bad. The positive connotation of reaching a target resembles e.g. the creation and maintenance of an irrigation structure since a critical mass of contributions is necessary to manage the irrigation system. Insufficient contributions can lead to badly, or not at all, functioning irrigation systems. Avoiding a threshold is a goal in fishing since when fishing at an unsustainable level (above the threshold) the fish stock is prone to collapse. While the irrigation problem is usually associated with a public good setting, the fisheries problem is often described as a public bad. We focus on whether the presentation of the problem, the framing, impacts cooperation. Though framing effects have repeatedly been shown in the literature, relevant studies have explored them predominantly in the context of a linear public good setting [Andreoni, 1995, Isaksen et al., 2019, Khadjavi and Lange, 2015, Fujimoto and Park, 2010, Gächter et al., 2017, Cox and Stoddard, 2015, Kingsley, 2015] and only to a lesser extent in a threshold public good game [Sonnemans et al., 1998, Kotani et al., 2008, 2014, Iturbe-Ormaetxe et al., 2011, Cartwright et al., 2019].

The first one to show the framing effect is Andreoni [1995]. He uses a linear public good game with positive or negative externalities. The game is played with groups of five and for ten rounds. After each round the participant is randomly assigned to a new group. After each round the participants are provided with an overview over investments of the group members and the individual earnings. Andreoni finds that cooperation decays over the course of the ten rounds in both treatments. In the positive framing the starting contribution is $47 \%$ of the endowment and reduces to $21 \%$ of the endowment while in the negative framing the starting contribution is $27 \%$ of the endowment and decays to $1 \%$ in round ten [Andreoni, 1995]. While the framing effect has been replicated frequently [Isaksen et al., 2019, Khadjavi and Lange, 2015, Fujimoto and Park, 2010, Gächter et al., 2017, Cox and Stoddard, 2015, Kingsley, 2015, Fujimoto and Park, 2010, Cox, 2015], the mechanism causing the effect is less than clear. Different individual preferences such 
as value orientation [Park, 2000], or political attitude in combination with cooperative behaviour types [Fosgaard et al., 2019] have been shown to have an impact on framing, while loss aversion does not [Cox, 2015].

Contrary to linear public good games, the public good in a threshold public good game (also referred to as step-level public good or provision point mechanism) is only provided if a certain amount of cooperation is achieved. There are two basic mechanisms how to measure cooperation in a threshold game. Either, the participants only have the choice to cooperate or not to cooperate. The threshold in these settings refers to the number of people needed. This is known as a binary choice design. The second option are stepwise contribution designs in which the participants contribute different amounts towards the public good. Van de Kragt et al. [1983] are, to our knowledge, the first ones to play a threshold public good game. They used a binary setup with a certain threshold and allowed for communication between the group members. As a result they had a $100 \%$ success rate in the provision of the public good. Several studies examine uncertain thresholds and find that uncertainty of the threshold decreases the likelihood of reaching the threshold [Au, 2004, Barrett and Dannenberg, 2014, McBride, 2010] while communication increases the likelihood and is able to counterbalance uncertainty to some extend [Barrett and Dannenberg, 2014].

Framed threshold games have been much less common. The first threshold game with framing by Sonnemanns et al. (1998) uses a binary setup and is played for 20 rounds in groups of five people. They do confirm the framing effect found by Andreoni but only after five rounds. They also confirm findings of McBride [2010] that people are more likely to cooperate if the likelihood of them being pivotal for reaching the threshold is higher, independent of the treatment. This experiment is extended by Kotani et al. [2008] where the group is reshuffled after each round. They also test for value orientation according to Park [2000] and find that the framing effect differs according to value orientation but cannot find a framing effect in general. Further binary threshold games were conducted by Kotani et al. [2014], Iturbe-Ormaetxe et al. [2011] and Cartwright et al. [2019] mainly analysing the effect of uncertainty and size of the threshold and its impact on cooperation. Kotani et al. (2014) find that threshold uncertainty decreases cooperative behaviour independent of the framing. They do not find any significant differences between treatments. When testing for the size of the threshold (number of people needed to show cooperative behaviour), Iturbe-Ormaetxe et al. [2011] find that only if the threshold is exceptionally low (one out of three people need to be cooperative) cooperation is actually higher in the public good than the public bad setting. When varying the size of the public good or public bad, Cartwright et al. (2019) find that the framing effect is confirmed, but the framing effect is larger when the public good and public bad are large. All framed threshold games are binary games and have been 
conducted in the lab.

Contribution levels are often influenced by the beliefs about the partners' contributions [Fischbacher et al., 2001]. The role of beliefs in framed linear public good games is analysed by Dufwenberg et al. [2011] and Cubitt et al. [2011]. While Cubitt et al. [2011] do not find any framing effect on beliefs, Dufwenberg et al. [2011] find that the believed contributions are higher in the public good framing. These believed contributions are even more important in the threshold games than the linear public good games, since the optimal contribution strategy depends on the contributions of the partners. Sonnemans et al. [1998] and Fosgaard et al. [2014] elicit believed contributions in the framed threshold games. Sonnemans et al. [1998] find that believed contributions are higher in the public good than the public bad framing but, independent of the treatment, the partners contributions are overestimated. Fosgaard et al. [2014] also find that people expect higher contributions from their partners in the public good treatment.

We are playing a de-contextualised field experiment with Cambodian farmers using a threshold public good/bad framing design. We use a threshold game to capture the nonlinearity of natural resource management. We use two treatments, one in which reaching the threshold leads to "gaining a public good" and one in which reaching the threshold leads to "avoiding a public bad". All of the previous experiments with framing treatments are lab studies. We are interested whether we see a framing effect in a population that is used to managing nonlinear natural resources on a daily basis. Our population is experienced in jointly managing irrigation infrastructures as well as fishing grounds. Since optimal contributions in a threshold game depend on the believed contributions by the other group members, we also elicit those.

All these lab experiments, apart from Fosgaard et al. [2019] who use Danish citizens, were done with students. While there are some cultural effects, see Goerg and Walkowitz [2010] and Cartwright et al. [2019], the public good/bad framing effects have been mainly studied in a fairly homogeneous group of students. Our paper is, to the best of our knowledge, the first exploring framing effects in the field. We test whether the framing effect is also prevalent if the population is used to managing nonlinear resources on a daily basis compared to the standard Western Educated Industrialized Rich Democratic (WEIRD) population. Further, we extend the framed binary threshold games to allow for a discrete contribution mechanism, to gain a deeper understanding on the different levels of contributions due to framing. Lastly, we focus on the effect of believed contributions on contribution levels and success rates of reaching the threshold.

The remainder of the paper is organised as follows: section 3.2 explains the experimental 
setup, section 3.3 entails the results, and section 3.4 concludes.

\subsection{Experimental Setup}

\subsubsection{Study Region}

The rural population in Cambodia is often involved in the management of more than one natural resource. Depending on the region the main income is generated via fishing or rice farming but a household rarely depends on only one income source. Rice farmers have to rely on a fair and functioning water infrastructure in order to secure their income. Fishers have to ensure that people do not over-exploit the fish stocks in order to avoid a stock collapse.

The maintenance of the irrigation system has the characteristics of a public good. The irrigation infrastructure is a collective good which needs to be maintained to ensure functioning. Yet, excluding people from using the water is difficult, if not impossible, independent of whether the person contributed to the public good or not. The maintenance of the irrigation system also has a threshold characteristic. If the contributions to the public good are not sufficient, the irrigation system breaks down and all the previous investments are lost.

While farmers are used to a public good setting (managing the irrigation system), fishers are often exposed to a public bad setting (managing fish stocks). Fishers have to ensure that the cooperative level is high enough to avoid overexploitation of the fish stock (e.g. people refrain from overfishing). Again, the resource depicts a clear threshold behaviour, since the overexploitation of a fish stock results in a sudden collapse of the stock. Hence, the rural population in Cambodia is used to managing non-linear natural resources on a day-to-day basis. Depending on the region (the commune people live in), people are used to a public good setting, a public bad setting, or both. Thus, Cambodia provides the perfect setting to study cooperation of nonlinear resources framed as a public good or public bad.

\subsubsection{Threshold Public Good Game}

Previous research on public good/bad framing in a threshold public good game has been done in a binary setting; either players contribute or they do not contribute to the public good. We extend this setting to allow for a range of contribution levels. The individual payoff $\pi_{i}$ is determined by

$$
\pi_{i}= \begin{cases}\left(E_{i}-g_{i}\right)+B & \text { if } G \geq T \\ \left(E_{i}-g_{i}\right) & \text { if } G<T\end{cases}
$$


where $E_{i}$ is the individual endowment, $g_{i}$ the individual contribution to the public good, where, $G=\sum_{j=1}^{n} g_{j}$. $B$ is a lump sum benefit every player gets if the threshold $T$ is reached.

Unlike previously framed threshold games that were conducted in the lab, we run a lab-in-the-field experiment with Cambodian farmers and fishers. Our subjects are largely illiterate, so we use a setup with bills of money and envelops. While the group size in Sonnemans et al. [1998], Kotani et al. [2008, 2014] and Cartwright et al. [2019] are five players, we reduce the group size to three in order to reduce cognitive load, while preserving the features of a cooperation game. We use a between subject design to test the public good/bad framing effect. To ensure that participants understand the task we follow Rustagi et al. [2010], who have a similar subject pool, in the way of providing instructions. We use control questions as well as a lot of interactive examples to make sure that everyone understands the design. Further, we encourage questions in front of the whole group to make sure that everyone, including those who are reluctant to ask questions, receives the same information. Given the shown relevance of individual characteristics on framing effects (see Park [2000], Kotani et al. [2008] and Kotani et al. [2014]) we elicited risk and pro-social preferences.

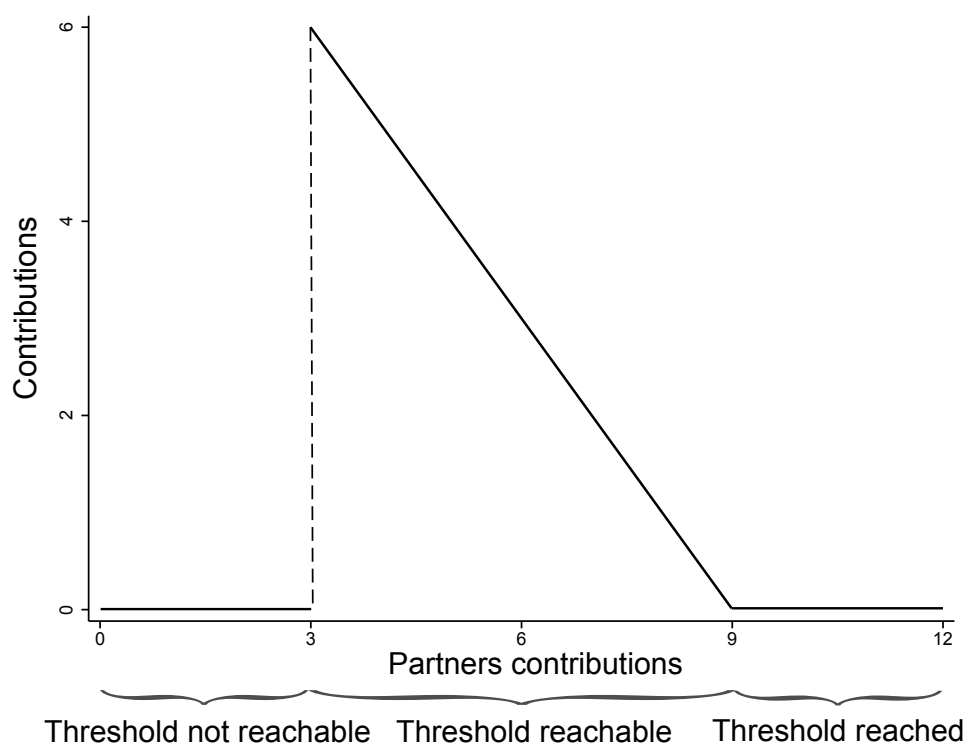

Figure 3.2.1: Optimal contribution strategy depending on the partners' contributions.

Each subject receives 6000 Cambodian Riel (KHR) as an endowment (1000 KHR are 25 cents USD). The task is to distribute these $6000 \mathrm{KHR}$, in discrete steps of 1000 
KHR, between a private fund and a public fund. In order to get a payment of the public fund a certain amount of contributions (9000 KHR) is needed. If the threshold is reached, each group member receives $6000 \mathrm{KHR}$ but if the threshold is not met nobody gets anything of the public fund and all the contributions towards the public fund are lost. The marginal per capita return to the public good in the fair social optimum is two (every group member contributing $3000 \mathrm{KHR}$ to the public good). The fair social optimum is only one of many social optima. Whenever the contributions to the public fund are exactly meeting the threshold, a social optimum is reached. The individual payoff maximisation is reached when the subject invests zero to the public good while the two partners invest sufficient amounts to reach the threshold. If the two partners match the threshold exactly, the payoff maximisation of one player can also be a social optimum. Hence, the optimal contribution strategy depends on the contributions of the partners (see fig. 3.2.1). If the partners contribute less than three bills (threshold not reachable) the optimal contribution strategy is to not contribute anything. If the partners are believed to contribute nine bills or more (threshold reached) the optimal strategy is also to not contribute anything. It is only optimal to contribute a positive amount if one beliefs that the partners invest between three and eight bills in the group account.

We use one-shot games to avoid confounding the framing effect with intergroup dynamics such as retaliation. Since the social optimum depends on the contribution of the other two players we also conduct a belief elicitation about the level of the joint contributions of the two other group members. If the amount is correct we pay another $1000 \mathrm{KHR}$.

\subsubsection{Public Good/Bad Treatments}

We provide each participant with six bills of $1000 \mathrm{KHR}$ and two envelopes, one white and one green. We ask each participant to divide these six bills into these two envelopes, white being the private fund and green the public fund. We have two framing treatments. The first setting is 'achieving a public good' and the second is 'avoiding a public bad'. The frames are economically equivalent, but the wording is different. In the public good setting the instructions state that the group fund yields either $6000 \mathrm{KHR}$ or zero KHR, depending on how much the three group members combined put into the green envelope. If the joint amount in the green envelopes is 9000 KHR or more, each group member gets $6000 \mathrm{KHR}$. If less than $9000 \mathrm{KHR}$ are in the green envelopes, each group member gets zero KHR from the group fund. ${ }^{1}$ In the public bad setting the instructions are changed

\footnotetext{
${ }^{1}$ The actual wording for the public good framing is "The money you want to contribute to the group fund, you put in the green envelope. The amount of money you get from the group fund can change, depending on how much you and the other two group members put into the green envelopes. Each group member either gets zero Riel or 6000 Riels from the group fund. If 9000 Riels or more are in the green envelopes, each group member will get 6000 Riel from the group fund. If less than 9000 Riels are in the
} 
to state that the group fund yields either 6000 or zero KHR, depending on how much the three group members put into the white envelopes. If the joint amount in the white envelopes is more than $9000 \mathrm{KHR}$, each group member gets zero from the group fund. If less than 9000 KHR are in the white envelopes, each group member gets $6000 \mathrm{KHR}$ from the group fund. ${ }^{2}$

We avoid any wordings such as 'contribution' and 'extraction' and stick to neutral language such as 'put' to avoid biasing the participants. Further, by making the participants distribute all of the six bills between the two envelopes we ensure that, independent of the framing, the task is always the same between the treatments. Thus, contributions to the public fund as well as keeping the money for oneself is always an active choice. The belief elicitation is framed just as the threshold game. While the subjects in the public good treatment are asked to indicate how much they think the other two group members will contribute jointly to the public fund ${ }^{3}$ the subjects in the public bad framing are asked to indicate how many bills they think the partners in the group will keep in the private fund. ${ }^{4}$ The beliefs are elicited just before the contributions were made.

Apart from the threshold game we also conduct a risk elicitation following Gneezy and Potters [1997]. We further play a standard one shot public good game which is followed by a conditional public goods game with strategy elicitation to classify cooperative types according to Fallucchi et al. [2018]. ${ }^{5}$ Each session starts with eliciting risk preferences, followed by determining cooperative behaviour types before we play the threshold game. We elicit individual attributes to be able to control for them when analysing the robustness of the public good/bad treatment effect. We announce at the start of the session that only one of the games will be paid out to the participants. This will be decided randomly at the end of the session. We play all the games without giving feedback about

green envelopes, each group member will get zero Riel from the group fund."

${ }^{2}$ The actual wording for the public bad framing is "The money you want to contribute to the group fund, you put in the green envelope. The amount of money you get from the group fund can change, depending on how much you and the other two group members put into the white envelope. Each group member either gets zero Riels or 6000 Riels from the group fund. If 9000 Riels or less are in the white envelopes, you get 6000 Riel each from the group fund. If more than 9000 Riels are in the white envelopes, each of you gets zero from the group fund."

${ }^{3}$ The exact wording for the belief elicitation in the public good framing is "We would like to know what you think how much your partners will put in the green envelope. Therefore, we included a paper slip in the green envelope [show the paper slip]. This paper shows you the thirteen options of how much your other two group members could jointly put into the green envelopes."

${ }^{4}$ The exact wording for the belief elicitation in the public bad framing is "We would like to know what you think how much your partners will put in the white envelope. Therefore, we included a paper slip in the white envelope [show the paper slip]. This paper shows you the thirteen options of how much your other two group members could jointly put into the white envelopes."

${ }^{5}$ We also used traditional behaviour types according to Fischbacher et al. [2001] but these do not capture the behaviour of our non WEIRD population. See chapter 2. 
performance and behaviour of partners in any of the games. The participants only learn at the end of the session how much they earned from the game which is chosen to be paid out.

The experiment is followed by a survey (see appendix for instructions and survey). Each session lasts 3 hours including breaks. To account for the time investment we pay each participant a show-up fee of $4000 \mathrm{KHR}$ and another $6000 \mathrm{KHR}$ if they stay till the end of the session. The average payout is around $17000 \mathrm{KHR}$ which is equivalent to $\$ 4.25$.

\subsubsection{Implementation of design}

We conducted the experiments in three communes in the Kampong Chhnang province in Cambodia. In Tuol Phpous and Kouk Banteay we visited all villages within the commune. In Taing Krasaing, the biggest of the three communes, we randomly selected half of the villages. In total we visited 21 villages, seven in Tual Phpous, six in Taing Krasaing, and eight in Kouk Banteya. Given the cultural setting in Cambodia, the participants were recruited via the commune and village chiefs. We asked them to pick participants from all social spheres within the village. We also required that the participants are at least 18 years old and that they should be able to sit on the floor for around three hours. We restricted the participants to one per household. Our preferred participants were household heads $(\mathrm{HH})$ or the spouses of the household heads. Our sample population is not representative of the Cambodian population. Rather, the selection of the population ensured that the participants show no systematic deviations in their cooperative behaviour based on family ties or other social affiliations. In total we had 303 participants in the experiments of which two did not provide us with valid belief elicitations. For 282 out of the 301 we also have survey information. Table 3.A.1 in the appendix provides an overview of the summary statistics from the survey as well as the experiments. We asked participants what their main occupation is which indicated that most people consider themselves to be farmers. We also asked whether their household undertook any fishing activity in the previous year. If people answered affirmative, we consider them to have fishing experience which we will refer to as fishers. We run two-sample t tests to test that no systematic differences exist between the randomly assigned treatment groups (see table 3.A.2). The tests confirm that the treatment populations do not show systematic differences.

\subsection{Results}

We analyse first the contribution to the public fund. We are interested whether we see differences in the contribution levels depending on the public good/bad framing treatment. Further, we test whether the framing effect is driven by socio-demographics or social preferences. This section will be followed by an analysis of the believed contribution by the partners to the public fund (the belief elicitation). The last part of the analysis will 
focus on the relationship between believed contributions of the partners and the actual contribution level.

\subsubsection{Contribution to the public fund}

\section{Treatment Effect}

We convert all variables into 'contribution to the public fund' in order to facilitate analysis. This variable runs in discrete steps from zero to six. The average contribution to the public fund is 3.15 (SD 1.17).

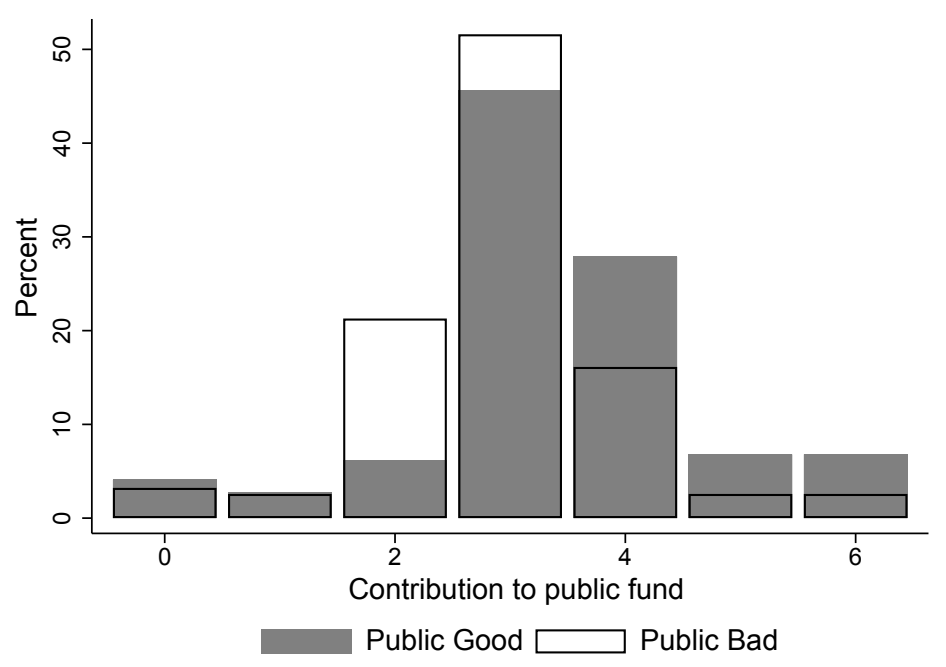

Figure 3.3.1: Contributions to the public fund by treatment.

The most common contribution level is three (the fair social optimum) with $48.5 \%$, followed by four with $21.93 \%$, two with $13.95 \%$, five and six with $4.65 \%$ each, zero with $3.65 \%$ and the least observed is a contribution of one with $2.66 \%$. The average contribution in the public good treatment is 3.38 (SD 1.25) and 2.93 (SD 1.05) in the public bad treatment (see table 3.3.1). A Fishers test shows that this difference in means is significant (Pearson $\chi^{2}=14.3694, \mathrm{p}=0.000$ ). We also run Mann-Whitney-Wilcoxon rank-sum tests which confirm the differences between treatments for contribution levels $(\mathrm{z}=4.411, \mathrm{p}=0.0000)$ and indicates that the contributions are higher in the public good framing (probability $=62.8 \%$ ). The Kolmogorov-Smirnov test confirms that the distribution of contribution levels differs across treatments (contribution $\mathrm{D}=0.2021, \mathrm{p}=$ 0.004) (see fig. 3.3.1). 
Apart from differences in contribution levels by treatment, we also find differences in success rates. While $77.55 \%$ of the participants in the public good treatment are in a group that manages to reach the threshold, only $52.26 \%$ of the participants in the public bad treatment reach the threshold (table 3.3.1).

Table 3.3.1: Average contribution, average believed contribution, and threshold reached per treatment. Standard deviations are reported in brackets.

\begin{tabular}{cccc}
\hline \hline Treatment & Contribution & Believed Contribution & Threshold reached \\
\hline Public Good & 3.380952 & 5.383562 & $77.55 \%$ \\
& $(1.251483)$ & $(3.051874)$ & \\
Public Bad & 2.929032 & 6.993548 & $52.26 \%$ \\
& $(1.051342)$ & $(2.942074)$ & \\
\hline \hline
\end{tabular}

We find a clear public good/bad framing treatment effect on contribution levels. Thus, this effect also exists outside the lab. We see distinctly higher contributions to the public good than the public bad. Yet, it is not clear what drives this framing effect. Based on the literature we hypothesize that believed contributions by the partners play a significant role. We also anticipate that the daily life experiences with managing different collective action problems such as maintaining a water infrastructure or avoiding the collapse of a fish stock could influence the reaction to the framing. So as a next step we will analyse what impacts contribution levels other than framing which will than be followed by an analysis of expected contribution levels.

\section{Robustness of treatment effect on contribution levels}

We test whether the public good/bad framing treatment effect is influenced by factors such as risk aversion or cooperative behaviour types. We further control for socio-demographics to ensure that the effect is not based on a subpopulation such as people with fishing experience. We run an OLS where we use the treatment as covariate (see table 3.3.2). Further, we control for commune or village fixed effects, cooperative behaviour type, risk aversion, and socio-demographics (age, education, gender, fishing experience, and number of household members). None of the control variables has a significant effect on contribution levels. We see that the treatment effect is robust and not influenced by social preferences or socio-demographics.

\subsubsection{Believed contribution by partners to the public fund}

In regard to believed contribution we are focussing on two aspects: (i) whether or not we observe a framing effect as discovered for the contribution levels, and (ii) what determines 
Table 3.3.2: Public good/bad framing treatment effect on contribution level.

\begin{tabular}{lccccc}
\hline \hline Dep. Var.: Contribution to public fund & & & & \\
& $(1)$ & $(2)$ & $(3)$ & $(4)$ & $(5)$ \\
\hline Public Bad & $-0.459^{* * *}$ & $-0.383^{* * *}$ & $-0.396^{* * *}$ & $-0.373^{* *}$ & $-0.475^{* * *}$ \\
& $(0.134)$ & $(0.133)$ & $(0.140)$ & $(0.144)$ & $(0.143)$ \\
& & & & \\
Constant & $3.453^{* * *}$ & $3.375^{* * *}$ & $3.084^{* * *}$ & $2.954^{* * *}$ & $2.931^{* * *}$ \\
& $(0.327)$ & $(0.503)$ & $(0.666)$ & $(0.686)$ & $(0.527)$ \\
\hline Fixed Commune Effects & $\sqrt{ }$ & & & & $\sqrt{ }$ \\
Fixed Village Effects & & $\sqrt{ }$ & $\sqrt{ }$ & $\sqrt{ }$ & \\
Risk aversion & $\sqrt{ }$ & $\sqrt{ }$ & $\sqrt{ }$ & $\sqrt{ }$ & $\sqrt{ }$ \\
Cooperative behaviour type & & & & $\sqrt{ }$ & $\sqrt{ }$ \\
Socio-demographics & & & $\sqrt{ }$ & $\sqrt{ }$ & $\sqrt{ }$ \\
Observations & 301 & 301 & 280 & 280 & 280 \\
$R^{2}$ & 0.038 & 0.180 & 0.205 & 0.229 & 0.111 \\
Adjusted $R^{2}$ & 0.025 & 0.115 & 0.120 & 0.132 & 0.068 \\
\hline \hline
\end{tabular}

Standard errors in parentheses, robust

${ }^{*} p<0.10,{ }^{* *} p<0.05,{ }^{* * *} p<0.01$

the believed contribution levels.

\section{Treatment Effect}

The believed total contributions by the partners range from zero to twelve in discrete steps. As in the case of contributions we convert the variable into believed contribution to the public fund by partners to facilitate analysis. The believed average contribution to the public fund in the public good treatment is 5.38 (SD 3.05) while the believed average contribution to the public fund in the public bad treatment is 6.99 (SD 2.94) (see table 3.3.1). The difference between the mean beliefs is significantly different (Pearson $\left.\chi^{2}=33.8343, \mathrm{p}=0.000\right)$. On average we see that in the public good treatment people believe that the partners contribute less than the fair social optimum to the public good while in the public bad treatment the subjects believe that the partners contribute more than the fair social optimum. The distribution of the elicited beliefs differs between treatments (Kolmogorov-Smirnov test: $\mathrm{D}=0.3612, \mathrm{p}=0.000$ ).

In fig. 3.3.2 we see that the fair social optimum is a prominent choice in both treatments (in the public bad treatment slightly above $20 \%$ and in public good treatment around $18 \%$ ). Yet, while in the public good treatment the most often chosen option is a joint contribution of three, the option we observe most in the public bad treatment is nine. Overall, we see that the majority of believed contributions in the public bad treatment is six or higher while in the public good treatment the majority of the believed contributions is six or lower. This treatment effect is confirmed by the Kruskal-Wallis test $\left(\chi^{2}=25.108\right.$, $\mathrm{p}=0.0001)$ and Mann-Whitney-Wilcoxon rank-sum test $(\mathrm{z}=-5.052, \mathrm{p}=0.0000)$. While 


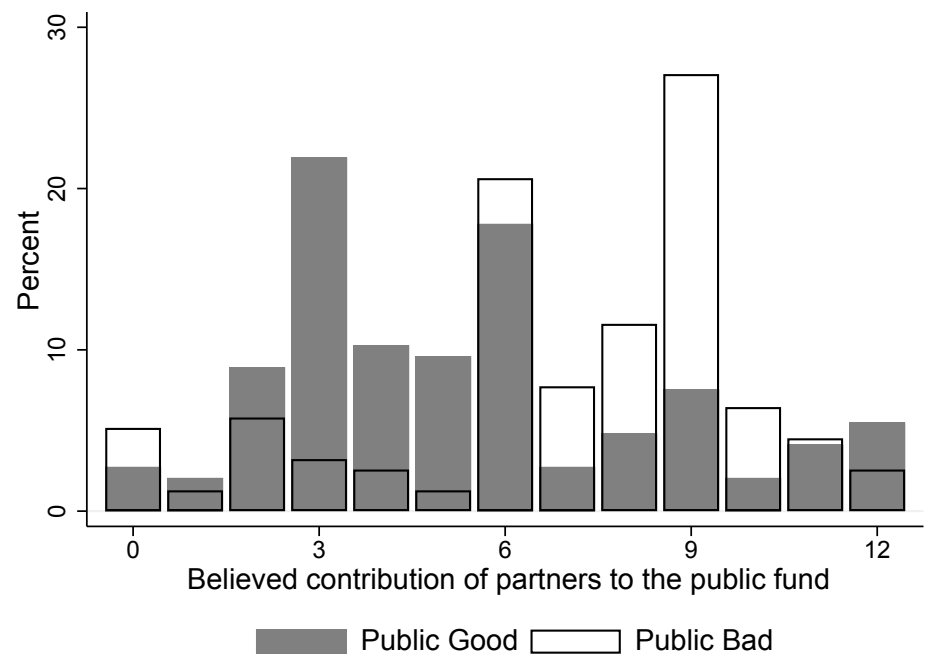

Figure 3.3.2: Belief about the partners' joint contributions to the public fund by treatment.

we do find a framing effect in the beliefs, the effect is not necessarily as expected. While Dufwenberg et al. [2011] and Fosgaard et al. [2019] find that beliefs in the public good are higher than in the public bad treatment, we do find the reverse.

\section{Robustness of treatment effect on believed contributions}

As in the case of the contribution level we are interested whether the framing effect persists when we control for social preferences and socio-demographics. We use the same OLS model as before to explain what determines the believed contributions (see table 3.3.3). We do see a clear framing effect of higher believed contributions in the public bad treatment than in the public good treatment whilst controlling for several covariates such as risk aversion, commune or village fixed effects, socio-demographics, and cooperative behaviour type.

\subsubsection{Relationship between believed contribution and contribution lev- els}

So far, we analysed contributions and expected contributions separately. For both we see clear framing effects: while individuals believe others to contribute more in the public bad treatment, they tend to contribute less themselves in the public bad treatment. We take a closer look at the relationship between contributions and believed contributions by testing whether we should expect a linear, quadratic, or any other polynomial relationship. We can clearly reject a linear relationship between contributions and believed contributions 
Table 3.3.3: Treatment effect on believed contributions.

\begin{tabular}{|c|c|c|c|c|c|}
\hline Dep. Var.: Believed Contrib & $\begin{array}{c}\text { tions by } p \\
\text { (1) }\end{array}$ & $\begin{array}{c}\text { rrtners to } \\
(2)\end{array}$ & $\begin{array}{l}\text { ublic func } \\
\text { (3) }\end{array}$ & (4) & (5) \\
\hline Public Bad & $\begin{array}{l}1.521^{* * *} \\
(0.349)\end{array}$ & $\begin{array}{c}1.467^{* * *} \\
(0.342)\end{array}$ & $\begin{array}{c}1.464^{* * *} \\
(0.346)\end{array}$ & $\begin{array}{l}1.423^{* * *} \\
(0.353)\end{array}$ & $\begin{array}{l}1.504^{* * *} \\
(0.361)\end{array}$ \\
\hline Constant & $\begin{array}{c}6.119^{* * *} \\
(0.697)\end{array}$ & $\begin{array}{c}7.110^{* * *} \\
(1.125)\end{array}$ & $\begin{array}{c}6.023^{* * *} \\
(1.375)\end{array}$ & $\begin{array}{c}6.298^{* * *} \\
(1.391)\end{array}$ & $\begin{array}{c}6.598^{* * *} \\
(1.058)\end{array}$ \\
\hline $\begin{array}{l}\text { Fixed Commune Effects } \\
\text { Fixed Village Effects }\end{array}$ & $\sqrt{ }$ & $\sqrt{ }$ & $\sqrt{ }$ & $\sqrt{ }$ & $\sqrt{ }$ \\
\hline $\begin{array}{l}\text { Risk aversion } \\
\text { Cooperative behaviour type }\end{array}$ & $\sqrt{ }$ & $\sqrt{ }$ & $\sqrt{ }$ & $\begin{array}{l}\sqrt{ } \\
\sqrt{ }\end{array}$ & $\begin{array}{l}\sqrt{ } \\
\sqrt{ }\end{array}$ \\
\hline Observations & 300 & 300 & 279 & 279 & 279 \\
\hline$R^{2}$ & 0.090 & 0.187 & 0.213 & 0.221 & 0.107 \\
\hline Adjusted $R^{2}$ & 0.077 & 0.122 & 0.129 & 0.123 & 0.064 \\
\hline
\end{tabular}

$(\mathrm{p}$-value $=0.658)$ but we cannot reject that there is a quadratic relationship ( $\mathrm{p}$-value $=$ 0.031). Looking at the quadratic marginal effect we see that the contributions increase with increasing beliefs up to a belief of six when contributions start to reduce again (see fig. 3.3.3).

Looking at the impact of belief on contributions in the two treatments we find that there are small differences in the curves (fig. 3.3.3). While the general pattern persists we can see two things. The level of contributions is in general higher in the public good than in the public bad treatment. Also, the shape of the curve differs slightly between treatments. In the public good, the highest point estimate is reached if the believed contributions are six, while the highest point estimate in the public bad corresponds to believed contributions of seven. Further, the contributions in the public good treatment start at a higher contribution level than the fair social optimum, even if the believed contributions are zero. In the public bad treatment, the biggest confidence intervals are in the area of zero believed contributions. The contributions start at 2.4 and rise to around three, before they fall again.

\section{Determinants of success rate in reaching the threshold}

In fig. 3.3.3 we see that while the contributions based on believed contributions follow a similar pattern, the overall contributions are higher in the public good. Basing the contributions exactly on the believed contributions can lead to social optima if the believed contributions are equal to the actual contributions. Yet, people are not able to consistently guess the partners contributions correctly. The error of guessing the others contributions incorrectly can be costly since it may lead to either failure to reach the 

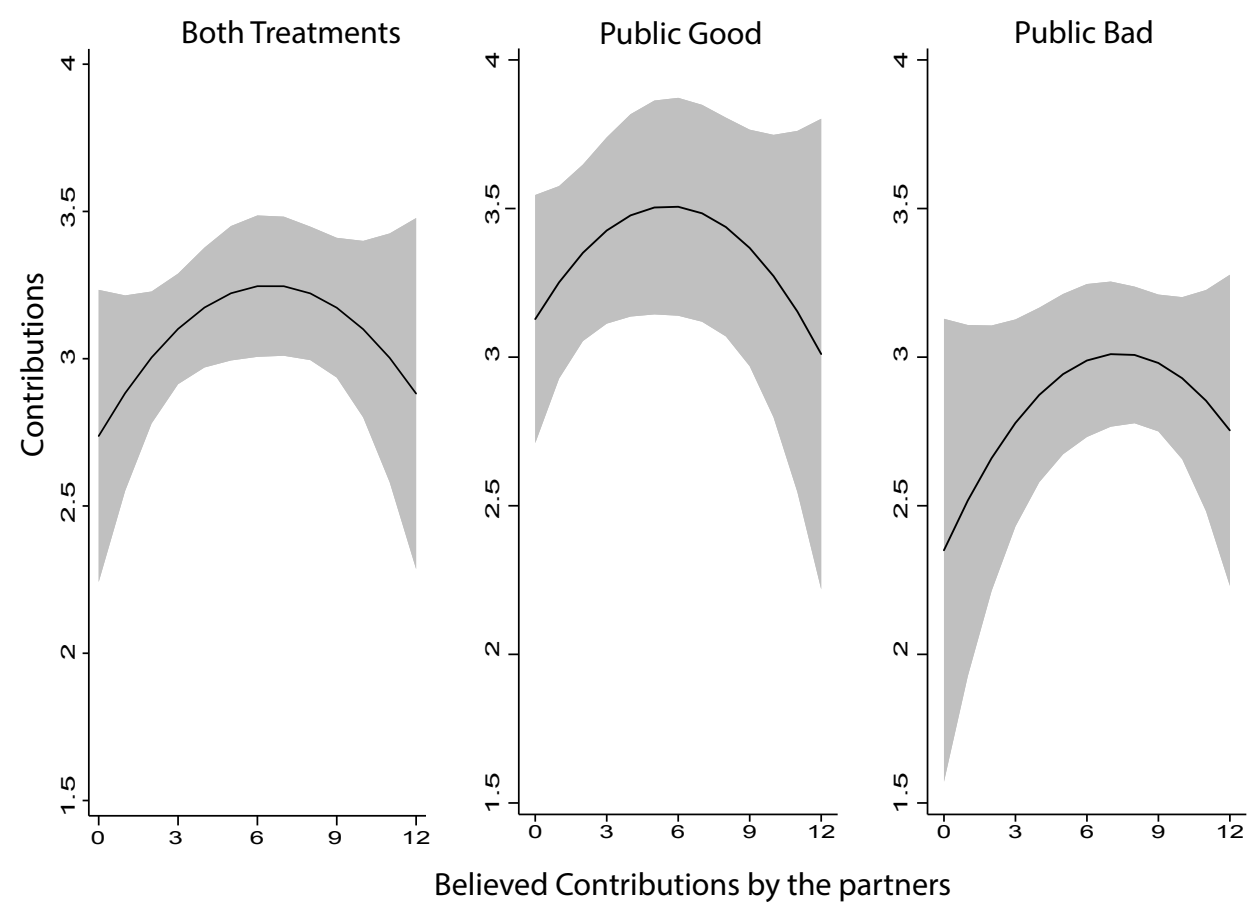

Figure 3.3.3: Quadratic marginal effects by treatment, estimated with interaction effect between treatment and beliefs

threshold or overprovision, which is inefficient.

Looking at the treatments we find that the accuracy (absolute difference between actual and believed contributions) of guessing the partners contributions correctly is the same in the two treatments (Kolmogorov-Smirnov test, $\mathrm{D}=0.1249, \mathrm{p}=0.196$ ) but the direction of the error differs. Figure 3.3.4 shows that contributions in the public bad are often overestimated while they are underestimated in the public good (Kolmogorov-Smirnov test, $\mathrm{D}=0.3838, \mathrm{p}=0.000)$.

We find that $58.46 \%$ of all thresholds were reached in the public good and $41.54 \%$ in the public bad treatment whereas $69.16 \%$ of the threshold not reached were in the public bad treatment and only $30.84 \%$ in the public good treatment. We observe distinct differences between the treatments when analysing the groups reaching the threshold. In the public good treatment reaching the threshold often corresponds to an underestimation of partners contributions. In the public bad we find that if the overestimation of the partners contributions is not too severe (one or two bills), the threshold is often reached. 


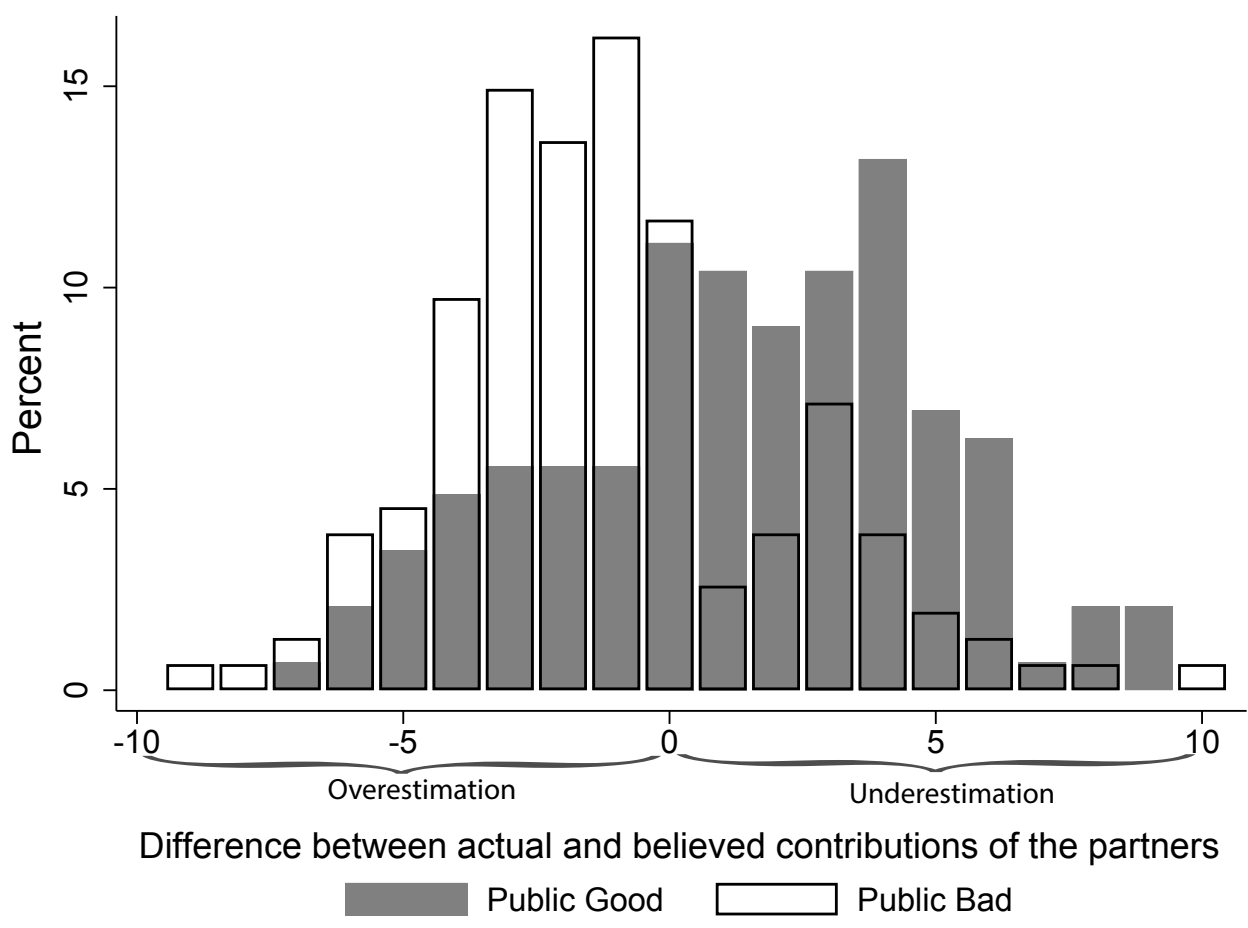

Figure 3.3.4: Histogram of the difference between actual contributions and believed contributions by partners in the Public Good and the Public Bad treatment.

If the threshold is not reached we do not discern a clear pattern between believed and actual contributions of the partners. In both treatments under- as well as overestimation of the partners contributions can lead to missing the threshold.

Looking at the groups which reached the threshold we find that the average contribution is higher in the public good treatment and the believed contributions are higher in the public bad treatment. Yet, in the public good treatment we have an underestimation of how much the partners are going to contribute, while in the public bad treatment the contributions by the partners are slightly overestimated. While an average error size of -0.46 is small enough to reach the threshold in the public bad treatment, a similar average difference between actual and believed contributions in the public good treatment corresponds to missing the threshold. The average error size in the groups that failed to reach the threshold in the public bad treatment is considerably larger with -1.86 (see table 3.A.3).

The consequences of the over- and underestimation of partners' contributions differ be- 

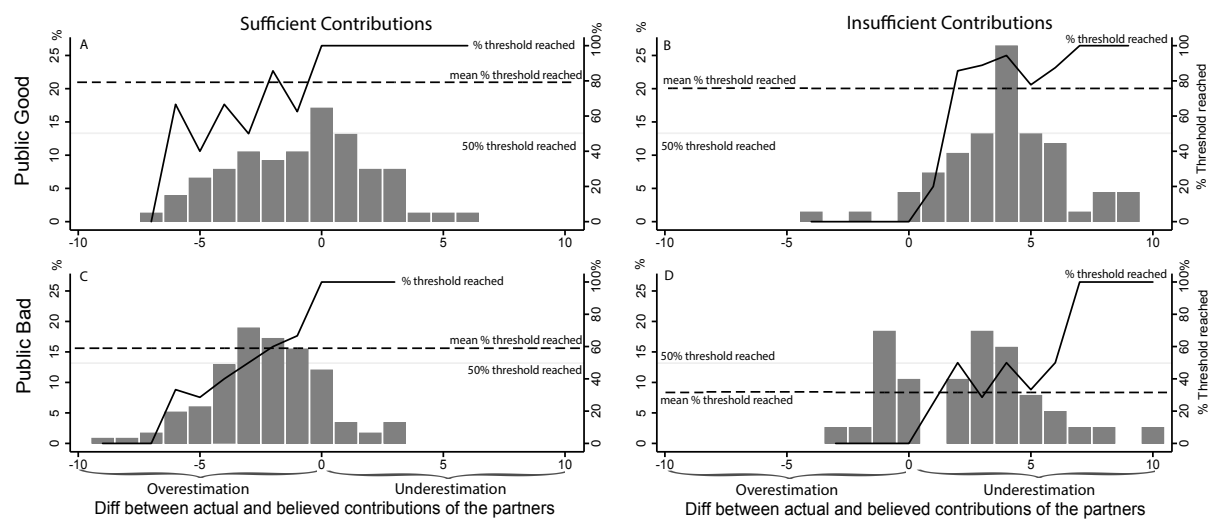

Figure 3.3.5: Believed contributions, sufficient contribution, and success by treatment. Sufficient contributions are contributions which would lead to reaching the threshold if the partners' contributions were guessed correctly. Insufficient contributions are contributions that are too low to reach the threshold if the partners' contributions were guessed correctly.

tween treatments. An interesting question is, therefore, what this means for people who based their contributions on the believed contributions? We compare people who contribute sufficient amounts (at least enough to make it to the threshold based on what they believe the partners will contribute) to the public fund, to people who contribute insufficient amounts (less than is needed to reach the threshold based on what they believe the partners will contribute). Contributing sufficiently increases the likelihood of reaching the threshold but the chances of success differ by treatment. In fig. 3.3.5 we see the interaction between sufficient contributions and the errors made in guessing the contributions of the partners correctly by treatment. In both treatments contributing sufficiently corresponds to a higher overall success rate compared to insufficient contributions. It is also clear that underestimating the partners' contributions corresponds to higher success rates than overestimating, independent of treatment and contribution strategy. Comparing sufficient contributions by treatment we see that the mean success rate is considerably higher in the public good treatment than in the public bad. The highest mean success rate is achieved if people contribute sufficient amounts in the public good (fig. 3.3.5 A) while the lowest mean success rate is observed if people contribute insufficient amounts in the public bad (fig. 3.3.5 D). Overestimating in the public bad treatment corresponds to lower success rates than overestimating in the public good while underestimation has similar success rates in both treatments. Comparing insufficient contributions by treatments we find strong differences. The mean success rate is significantly higher in the public good compared to the public bad treatment (fig. 3.3.5 B \& D). In the public good treatment the high success rate stems from an underestimation of the partners contributions which are high enough to compensate the insufficient contributions which is not the case in the public bad. 


\subsection{Discussion}

We find that the framing effect is not confined to lab experiments but is also prevalent in a lab-in-the field setting. As Andreoni [1995] we find higher cooperation in the public good framing than in the public bad. Yet, we also find an unexpected framing effect regarding believed contributions by partners. While Dufwenberg et al. [2011] and Fosgaard et al. [2019] find that believed contributions of the partner are higher in the public good framing we find that believed contributions are higher in the public bad treatment. We establish that believed contributions of partners impact contribution levels. In general, people contribute to the public fund if they believe that the partners do the same and their own contribution has an impact on whether the threshold is reached or not. The contributions are highest if the believed contributions are close to the fair social optimum.

While the relationship between believed contributions of partners and own contribution is similar in both treatments, we see different success rates in reaching the threshold. Since in both treatments the individual contributions are based on the believed contributions, the success of a group depends on the accuracy of the believed contributions. If the contributions of the partners are overestimated the success rate is lower while underestimating the partners contributions corresponds to higher success rates. In the public bad we see that people overestimate the partners contributions and in the public bad we see an underestimation. Basing one owns contribution level on one's beliefs thus leads to lower success rates in the public bad than the public good treatment.

Overall, extending the threshold public good game from a binary to a discrete contribution mechanism allows us to analyse cooperative behaviour in more detail. We find that people contribute different amounts depending on the assumptions they make regarding the cooperative level their partners exhibit. By taking the framing experiment to the field we are able to test whether the framing effect is a WEIRD population effect only, or whether the framing effect also occurs in a more natural population. We found that the framing effect occurs as well in populations which are used to handling public good and/or public bad situations as part of their daily life.

Since, to our knowledge, we are the first ones to test for a public good/bad treatment effect in the field further research is needed to establish that the effect is indeed prevalent in the field. The role of believed contributions has not been studied as extensively as the framing effect on contribution levels. Yet, we see that a systematic over- or underestimation of the contributions made by the partners has severe implications for successful natural resource management. Thus, the public good/bad treatment effect on believed contributions of the partners should be investigated further, to test whether it exists outside the Cambodian 
context. 


\section{Appendix}

\section{A Appendix}

Table 3.A.1: Summary statistics. Including the results of the risk elicitation and the prosocial behaviour types.

\begin{tabular}{|c|c|c|c|c|c|}
\hline & Observation & Mean & Standard Deviation & Min & Max \\
\hline $\begin{array}{l}\text { Risk Elicitation } \\
\text { Contribution to the risky envelope }\end{array}$ & 302 & 2.80 & 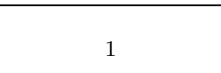 & 0 & 6 \\
\hline $\begin{array}{l}\text { Linear Public Good game } \\
\text { Contribution to public fund }\end{array}$ & 303 & 3.11 & 1.11 & 0 & 6 \\
\hline $\begin{array}{l}\text { Conditional Public Good game } \\
\text { Contribution to public fund if partner contributes } 0 \\
\text { Contribution to public fund if partner contributes } 1000 \\
\text { Contribution to public fund if partner contributes } 2000 \\
\text { Contribution to public fund if partner contributes } 3000 \\
\text { Contribution to public fund if partner contributes } 4000 \\
\text { Contribution to public fund if partner contributes } 5000 \\
\text { Contribution to public fund if partner contributes } 6000\end{array}$ & $\begin{array}{l}299 \\
299 \\
299 \\
299 \\
299 \\
299 \\
299\end{array}$ & $\begin{array}{l}2.72 \\
2.51 \\
2.75 \\
3.11 \\
3.43 \\
3.50 \\
3.82\end{array}$ & $\begin{array}{c}1.5 \\
1.29 \\
1.19 \\
1.1 \\
1.24 \\
1.42 \\
1.62\end{array}$ & $\begin{array}{l}0 \\
0 \\
0 \\
0 \\
0 \\
0 \\
0\end{array}$ & $\begin{array}{l}6 \\
6 \\
6 \\
6 \\
6 \\
6 \\
6\end{array}$ \\
\hline $\begin{array}{l}\text { Threshold Public Good game } \\
\text { Contribution to public fund (Public Good Treatment) } \\
\text { Contribution to public fund (Public Bad Treatment) } \\
\text { Expected Contribution to public fund (Public Good Treatment) } \\
\text { Expected Contribution to public fund (Public Bad Treatment) } \\
\text { Threshold reached }\end{array}$ & $\begin{array}{l}147 \\
156 \\
146 \\
155 \\
303\end{array}$ & $\begin{array}{l}3.38 \\
2.93 \\
5.38 \\
5.01 \\
0.64\end{array}$ & $\begin{array}{c}1.25 \\
1.05 \\
3 \\
3 \\
0.48\end{array}$ & $\begin{array}{l}0 \\
0 \\
0 \\
0 \\
0\end{array}$ & $\begin{array}{c}6 \\
6 \\
12 \\
12 \\
1\end{array}$ \\
\hline $\begin{array}{l}\text { Survey } \\
\text { Gender }(\text { Male =1) } \\
\text { Age } \\
\text { Number of Household members } \\
\text { Years of Schooling } \\
\text { Fishing (yes =1) } \\
\text { Rice Farming (yes =1) }\end{array}$ & $\begin{array}{l}281 \\
282 \\
282 \\
282 \\
282 \\
282\end{array}$ & $\begin{array}{l}0.37 \\
46.2 \\
4.76 \\
4.05 \\
0.22 \\
0.94\end{array}$ & $\begin{array}{c}0.48 \\
13.22 \\
1.7 \\
3.48 \\
0.42 \\
0\end{array}$ & $\begin{array}{c}0 \\
18 \\
1 \\
0 \\
0 \\
0\end{array}$ & \begin{tabular}{c|c}
1 & \\
80 & \\
11 \\
16 \\
1 \\
1
\end{tabular} \\
\hline
\end{tabular}


Table 3.A.2: Balance test for the treatment populations

\begin{tabular}{lcccccc}
\hline \hline & \multicolumn{2}{c}{ Public Good } & \multicolumn{2}{c}{ Public Bad } & \multicolumn{2}{c}{ T Test } \\
& & & & & & \\
& Mean & SD & Mean & SD & Difference & P-Value \\
\hline Socio-demographics & & & & & & \\
Male & 0.36 & 0.48 & 0.38 & 0.49 & -0.01 & $(0.84)$ \\
Age & 46.51 & 13.50 & 45.89 & 12.98 & 0.63 & $(0.69)$ \\
Years of schooling completed & 4.06 & 3.74 & 4.04 & 3.23 & 0.02 & $(0.96)$ \\
Number of household members & 4.79 & 1.74 & 4.72 & 1.67 & 0.07 & $(0.71)$ \\
Fishing experience & 0.21 & 0.41 & 0.23 & 0.42 & -0.02 & $(0.72)$ \\
Cooperative Behaviour Types & & & & & & \\
Unclassified behaviour & 0.25 & 0.44 & 0.27 & 0.45 & -0.02 & $(0.70)$ \\
High unconditional Cooperators & 0.18 & 0.38 & 0.19 & 0.39 & -0.01 & $(0.82)$ \\
Conditional Cooperators & 0.22 & 0.42 & 0.26 & 0.44 & -0.03 & $(0.50)$ \\
Low unconditional Cooperators & 0.17 & 0.38 & 0.11 & 0.31 & 0.06 & $(0.13)$ \\
Medium unconditional Cooperators & 0.17 & 0.38 & 0.11 & 0.31 & 0.06 & $(0.13)$ \\
Further variables of interest & & & & & & \\
Risk Aversion & 3.28 & 0.99 & 3.13 & 1.00 & 0.15 & $(0.19)$ \\
\hline Observations & 147 & & 155 & & 302 & \\
\hline \hline
\end{tabular}

Table 3.A.3: Differences of contributions, believed contributions and difference between actual and believed contributions by treatment and success rate.

\begin{tabular}{|c|c|c|c|c|c|c|}
\hline & \multicolumn{2}{|c|}{ Threshold reached } & \multicolumn{4}{|c|}{ Threshold not reached } \\
\hline & PG & PB & Fishers test & PG & $\mathrm{PB}$ & Fishers test \\
\hline Mean contribution & $3.68(\mathrm{SD} 1.05)$ & $3.4(\mathrm{SD} 0.88)$ & 0.019 & $2.33(\mathrm{SD} \mathrm{1.34)}$ & 2.4 (SD 0.98) & 0.959 \\
\hline Mean believed contributions & $5.37(\mathrm{SD} 3.05)$ & $7.27(\mathrm{SD} 2.76)$ & 0.000 & $5.43(\mathrm{SD} 3.12)$ & $6.66(\mathrm{SD} 3.13)$ & 0.023 \\
\hline Mean difference of contributions & $2(\mathrm{SD} 3.31)$ & $-0.46(\mathrm{SD} 3.07)$ & 0.000 & $-1(\mathrm{SD} 3.44)$ & $-1.86(\mathrm{SD} 3.22)$ & 0.359 \\
\hline $\mathrm{N}$ & 114 & 81 & & 33 & 74 & \\
\hline Percentage & $37.75 \%$ & $26.82 \%$ & & $10.93 \%$ & $24.5 \%$ & \\
\hline
\end{tabular}

We report the continuity corrected fishers' exact tests. 


\section{Chapter 4}

\section{Detecting intuitive judgement of experts in fish stock assessments data}

This chapter is based on the manuscript Schuch, E. and Richter, A. (2020). Detecting intuitive judgement of experts in fish stock assessments data. 


\section{Abstract}

Scientific advice is increasingly used to inform policy. Often, experts are asked to give advice when stakes are high, time pressure is severe, and uncertainty looms. In such environments, decisions tend to be guided by instincts and priors, rather than reason. However, when and to what extent experts are guided by intuitive judgements is unknown. Here, we use a data base of fish stock assessments to detect and quantify the role of the anchoring heuristic in scientific advice. We find evidence that if scientists have more freedom to vary model assumptions, biomass estimates tend to confirm previous estimates, which may serve as anchors. This is also the case if the assessed fish stock is in crisis. Interestingly, this applies mostly for upward shifts, which may imply that experts are reluctant to indicate that stocks in crisis are recovering. By providing advice that is biased towards previous results, the stock assessments may give of a false sense of security as more drastic changes may go undetected. 


\subsection{Intuitive judgement of experts}

Many governments strive for evidence-based policy, which typically relies heavily on the involvement of experts. Especially when stakes and uncertainty are high, and data is scarce, the objectivity of expert knowledge is sought after. Yet, while experts have a vast amount of knowledge and experience, their advice is often based on intuitive judgement [Sutherland and Burgman, 2015, Burgman, 2015]. After all, experts tend to, consciously or unconsciously, interpret data. How data is perceived or presented depends on what is at stake, but also stress levels, or concerns about reputation [Sutherland and Burgman, 2015, Burgman, 2015, Englich and Soder, 2009, Martin et al., 2012]. In particular, anchoring, the systematic tendency to put too much weight on previous information has been widely observed across experts and non-experts [Furnham and Boo, 2011, Englich and Soder, 2009, Tversky and Kahneman, 1981, Oskamp, 1965, McBride et al., 2012, Martin et al., 2012, Sinkey, 2015, Montibeller and Winterfeldt, 2015, Chrysafi et al., 2019]. Experts may be particularly prone to anchoring if new advice would align poorly with previous advice. As revising advice would appear inconsistent, new conflicting data may not be taken with the same weight as previous data. Experts have to rely upon their reputation as a knowledgeable and trustworthy person. Adjusting previous results can be seen as admitting to a mistake which can damage the reputation of the expert [Sinkey, 2015, Ottaviani and Sørensen, 2006] and thus they try to avoid these 'revision costs' [Hagafors, 1983, Nordhaus, 1987, Kirchgässner and Müller, 2006]. As a result, they often face the trade-off between adjusting previous assessments (running the risk of being perceived as 'correcting a mistake' or 'not knowing anything') and scientific accuracy. The reluctance to adjust estimates seems to be even stronger if these results, as well as their deviations from the previous ones, attract high publicity [Kirchgässner and Müller, 2006] or the experts are in a stressful situation [Starcke and Brand, 2012, Kassam et al., 2009]. For example, during Covid-19, the latest global pandemic, experts advising national governments have entered celebrity status and kitchen table conversations [Kupferschmidt, 2020]. While anchoring may play a large role in affecting decisions provided by experts, it has to our knowledge never been documented with observational field data. Here, we use European fish stock assessments to test whether anchoring plays a role in expert judgement.

\subsection{European fish stock assessments}

Natural resource management is riddled with uncertainties which gives experts a special role since their in-depth knowledge is the only way to gain insights [Martin et al., 2012]. In natural resource management, and especially in fisheries management, there are huge uncertainties in regard to quantity, distribution, as well as growth rate, which can only be handled via expert knowledge. 
The International Council for the Exploration of the Sea (ICES) gives scientific advice to governmental authorities on marine policy and management. ICES is a global organization responsible for providing scientific advice to governments, multinational organizations, and NGOs to manage marine living resources [ICES, 2016]. An important advisory product are recurrent stock assessments that advice on status of the stock, biomass levels, and evaluate exploitation relative to management objectives. While ecosystem based management is increasingly considered, in practice, advice on the single stock level remains the main input for the policy makers for setting a total allowable catch for a fish stock in a given year. This advice is based on output from computational models which are analysed by fisheries scientists, who are often employed by national institutes and universities. The assessment is carried out by working groups during annual meetings. One piece of output produced during the assessments is an estimation of historical time series of spawning stock biomass (SSB). This implies that the biomass estimates for a given year may be revised in future assessments (fig. 4.2.1).

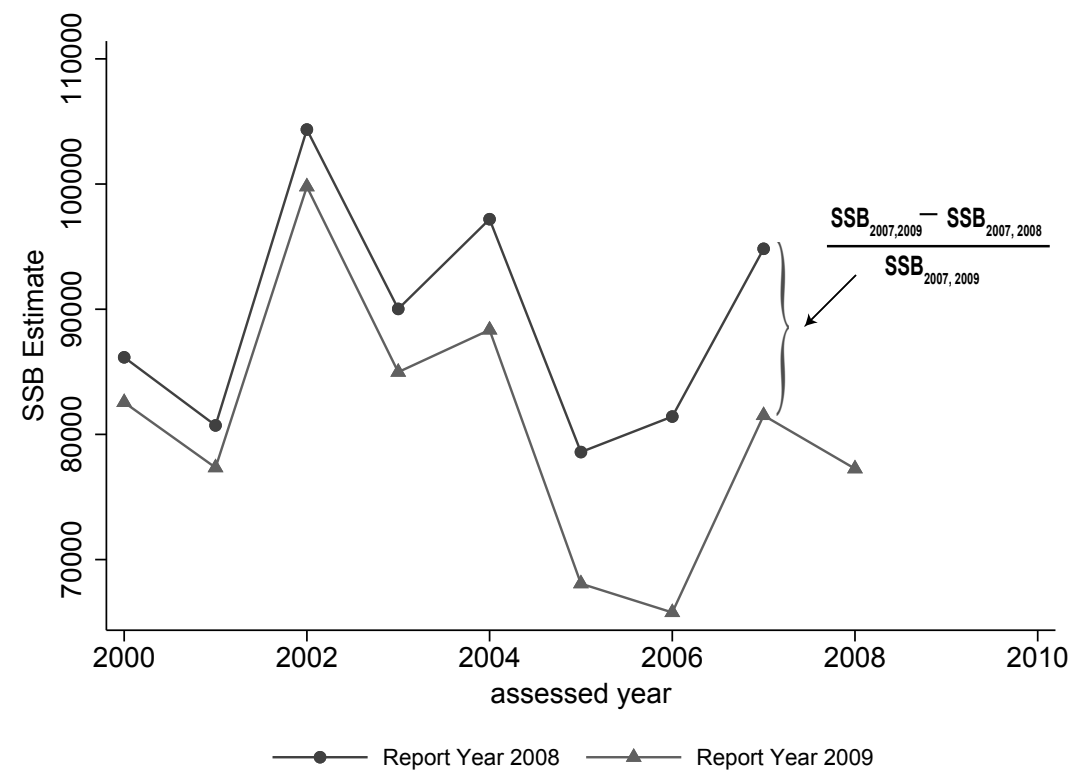

Figure 4.2.1: Data base overview and calculation of relative change. The estimates for SSB of herring (clupea harengus) in the Gulf of Riga in the report years 2008 and 2009. Report years are the years when the assessment was done. Assessed years are all the years for which a SSB estimate is provided. The assessed year 2007 provides an example for the calculation of the relative change between the report years 2008 and 2009.

Under high time pressure - the meetings have fixed lengths between five and ten days an advice report is produced. In this context a stock assessment scientist has said 'It's 
not really science anymore. We're number engineers. We fiddle with numbers to, you know, try to add some scientific credibility to an opinion' [Wilson, 2010]. Time pressure is high, and so are the stakes. The experts are fully aware that their advice is used for policy making and that the results generated have real consequences on fishing quota [Wilson, 2010]. The current setting in which scientists have to produce a specific number of fish that can be fished safely, leads to discomfort amongst the scientists. While they are required to produce a total allowable catch (TAC) for policy makers, they are acutely aware of the underlying uncertainties [Kraak et al., 2010].

The determination of TACs is a sensitive issue since they are the basis for the fishing policy in the European Union. Hence, these assessments have been scrutinised to avoid mistakes. There is an extensive literature on biases in fish stock assessments. The main biases analysed are related to uncertainty in recruitment [Lee et al., 2012, Walters, 2004, Kehler et al., 2002, Myers and Barrowman, 1995, Marshall et al., 2006, Methot et al., 2011, Deroba and Miller, 2016, Francis, 2016], the estimation of natural fishing mortality and fishing pressure [Johnson et al., 2014, Dickey-Collas et al., 2007], the use and quality of data [Payne et al., 2009, Kraak et al., 2009, Ichinokawa et al., 2014], as well as biases related to spatial distribution [Soria et al., 1996, Fallon et al., 2015]. The main research on what shapes stock assessments has been focused on technical measures and data issues. Yet, while the human factor of stock assessments is increasingly put on the agenda [Chrysafi et al., 2019, Fulton et al., 2011, Dankel et al., 2015], the role of experts in standard stock assessments is usually not addressed.

To streamline the assessments and to reduce biases ICES introduced benchmarking. The first benchmark was done in 2004 and was applied to more stocks over the years. Benchmarks are done in regular intervals (3-5 years) in which the assessment methodology (including the model and its specifications) are agreed upon. The benchmark is conducted by stock assessment experts as well as external experts to 'improve assessment quality and enhance in research credibility' [ICES, 2013]. Very much like pre-analysis plans [Coffman and Niederle, 2015], benchmarks also have the function to specify the methods ex ante to limit the freedom of researchers to "fiddle" with model input to produce certain results. In the years between those benchmarks the assessments are called updates. The protocol is less strict since the model has been agreed upon, and the data only has to be fed into the model to produce the advice. However, in practice there are sometimes diversions from the protocol. It may be necessary that experts make judgement calls e.g. on how to integrate new data into the model. Another example for experts' discretion is 'adequate weighting': if two data sources (e.g scientific surveys and catches) do not point in the same direction the experts weigh the data sources according to what they deem to be more plausible. 
Since "'truth" is an elusive construct in fisheries science' due to the inherent uncertainty [Palmer and Demarest, 2018], the experts always run the risk of getting it wrong after all. Mistakenly adjusting the biomass levels downwards implies that the stock is in better shape than suggested by the advice. Thus, there is a risk of catching less than what would be sustainable, leading to economic losses. However, mistakenly making an upward adjustment is most likely even costlier since it can endanger the sustainability of the stock, putting pressure on the experts. We hypothesise that such effect is particularly strong if the fishery is in crisis and a potential stock collapse comes to the minds of the experts.

We measure the difference for each assessed year between consecutive assessment years (fig. 4.2.1). Next to the absolute difference we differentiate between new assessment estimates that are higher or lower than the previous one (fig. 4.2.2). First, we expect that we observe stronger anchoring if there is more freedom to decide on model input. Thus, we hypothesize that updates (rather than benchmarks), and more data sources, allowing for 'adequate weighting', tend to be closer to previous results and lead to lower variation between assessments. Second, we hypothesize that when assessing an endangered stock, stakes are particularly high, and anchoring plays a larger role. 

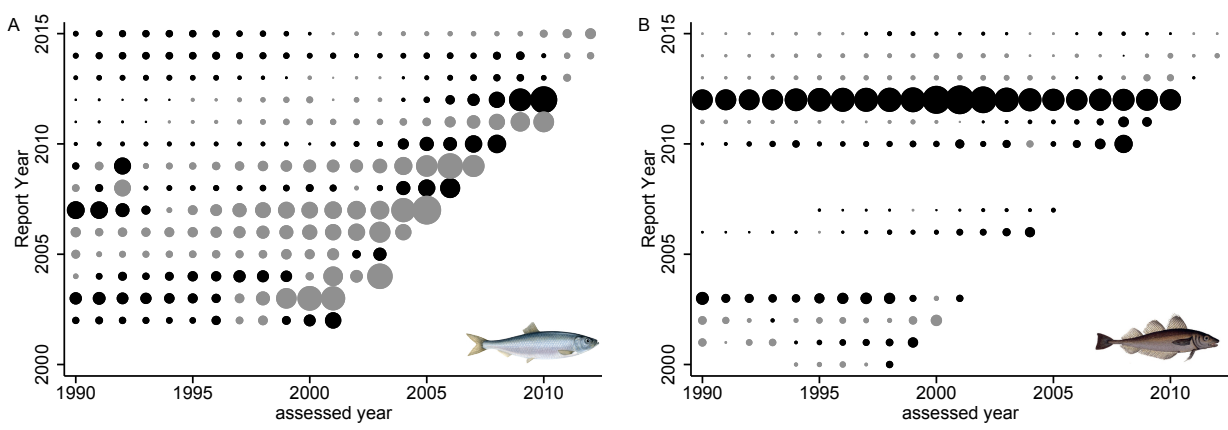

Figure 4.2.2: Relative changes in fish stock assessments between report years depending on direction of change. (A) Assessments of herring (clupea harengus) in the Gulf of Riga. The first estimate of spawning stock biomass (SSB) for herring was for the year 1977 (the time line is truncated at 1990 for graphical purposes). The first assessment conducted was in the report year 2001. (B) Assessments for whiting (merlangius merlangus) in the North Sea. The first estimate of SSB was done for the year 1980 and the first assessment conducted was in the report year 1996. In each report year, a time series of estimates for the previous years is generated. Each column indicates an assessed year. The size of the circle demonstrates the size of the relative change of SSB estimates between report years. If the estimate of the current report year yields the same SSB for a year as the previous report year the relative change is zero. Black circles indicate that the new estimate is higher than the previous one (upward change) and grey marks the cases when the new estimate is lower than the previous one (downward change).

\subsection{Results}

The benchmarking procedure has been introduced at different points of time across fish stock assessments. We conduct a staggered difference in difference (DiD) analysis to analyse whether variation is lower after benchmarking has been introduced. We run the analysis, looking at the absolute change between report years, as well as separating between downward (the new estimate is lower than the previous one) and upward (the new estimate is higher than the previous one) change. We can clearly see that the introduction of benchmarking leads to significantly different estimates in the assessment independent of whether it is higher or lower than the previous estimate. The effect of benchmarking is strongest in the case of an upward change with an absolute deviation of 0.0411 compared to an absolute deviation of 0.0328 in the downward changes (table 4.3.1). On average the introduction of benchmarking leads to an increase of 4.11 percentage points of relative change compared to the previous estimation.

Next, we investigate whether we can observe anchoring in a given year. Comparing 
Table 4.3.1: Staggered difference in difference (DiD) Model.

\begin{tabular}{|c|c|c|c|}
\hline & $\begin{array}{l}(1) \\
\text { Relative Change, full }\end{array}$ & $\begin{array}{c}(2) \\
\text { Relative Change, downward }\end{array}$ & $\begin{array}{c}(3) \\
\text { Relative Change, upward }\end{array}$ \\
\hline Stock benchmarked & $\begin{array}{l}0.0378^{* * *} \\
(0.00298)\end{array}$ & $\begin{array}{l}0.0328^{* * *} \\
(0.00263)\end{array}$ & $\begin{array}{l}0.0411^{* * *} \\
(0.00507)\end{array}$ \\
\hline Constant & $\begin{array}{c}0.0871^{* *} \\
(0.0289)\end{array}$ & $\begin{array}{l}0.0697 * * * \\
(0.000718)\end{array}$ & $\begin{array}{c}0.0914^{* *} \\
(0.0349)\end{array}$ \\
\hline $\begin{array}{l}\text { Fixed report year effect } \\
\text { Fixed assessed year per stock } \\
\text { Observations } \\
\text { Adjusted } R^{2}\end{array}$ & $\begin{array}{c}\sqrt{ } \\
\sqrt{ } \\
20994 \\
0.035\end{array}$ & $\begin{array}{c}\sqrt{ } \\
\sqrt{ } \\
9644 \\
0.109\end{array}$ & $\begin{array}{c}\sqrt{ } \\
\sqrt{ } \\
11350 \\
0.039\end{array}$ \\
\hline
\end{tabular}

updates and benchmarks, we see clearly that an update reduces the variability while a benchmark increases it (table 4.3.2). The flexible nature of an update leads to results that are close to the previous one (the relative change is 1.4 percentage points smaller than for the previous estimate), while the rigid structure of a benchmark leads to an increase in variability (the relative change is 8.8 percentage points bigger than for the previous estimation). This confirms our hypothesis that updates leave room to "fiddle", giving rise to anchoring.

To estimate whether adequate weighting of various data sources has an affect on variation, we compare variation of having only one source of data (survey data or catches) with having both data sources available. We see a clear difference between the input of only one data source in comparison to the use of both data sources. If only one data source is available, a larger diversion from previous results can be observed (table 4.3.2). If two data sources are available and adequate weighting can be applied, the results are closer to previous assessments, thereby confirming our hypothesis that adequate weighting provides room for stronger anchoring of results.

As hypothesized, a critical stock status leads to lower variation and estimates to be anchored closer to the previous ones (table 4.3.2). Note that this finding only applies for upward adjustments, i.e. announcing that a critical stock is recovering. The same effect can be observed when using high fishing pressure as a measure for overfishing, and also wider stock status indicators (table 4.A.2). Generally, anchoring seems larger if the new estimate indicates a higher fish abundance, calling for an upward adjustment (table 4.3.2).

Potentially, the previous findings regarding to whether or not an assessment is an update or benchmark and the source of information giving rise to adequate weighting 
Table 4.3.2: Linear fixed effects regression with absolute values of relative change as dependent variable. Full sample as well as upward and downward estimate. (1) Full sample, (2) Estimates done on the subsample when the new estimate was lower than the previous one, (3) estimates done on the subsample when the new estimate was higher than the previous one.

\begin{tabular}{|c|c|c|c|}
\hline & $\begin{array}{c}(1) \\
\text { Relative Change }\end{array}$ & $\begin{array}{c}(2) \\
\text { Relative Change, downward }\end{array}$ & $\begin{array}{c}\text { (3) } \\
\text { Relative Change, upward }\end{array}$ \\
\hline \multicolumn{4}{|l|}{ Type of Assessment } \\
\hline Update & $\begin{array}{c}-0.0140^{* * *} \\
(0.00212)\end{array}$ & $\begin{array}{c}0.00442 \\
(0.00231)\end{array}$ & $\begin{array}{c}-0.0232^{* * *} \\
(0.00355)\end{array}$ \\
\hline Benchmark & $\begin{array}{l}0.0880^{* * *} \\
(0.00362)\end{array}$ & $\begin{array}{l}0.0455^{* * *} \\
(0.00311)\end{array}$ & $\begin{array}{l}0.117^{* * *} \\
(0.00585)\end{array}$ \\
\hline $\begin{array}{l}\text { Health of Fishery } \\
\text { Critical Stock Status }\end{array}$ & $\begin{array}{c}-0.0481^{* * *} \\
(0.0129)\end{array}$ & $\begin{array}{c}0.0162 \\
(0.0119)\end{array}$ & $\begin{array}{c}-0.0732^{* * *} \\
(0.0203)\end{array}$ \\
\hline Relative Fishing Pressure & $\begin{array}{c}-0.0266 \\
(0.00592)\end{array}$ & $\begin{array}{c}0.00931 \\
(0.00549)\end{array}$ & $\begin{array}{c}-0.0574^{* * *} \\
(0.0100)\end{array}$ \\
\hline \multicolumn{4}{|l|}{ Data Source } \\
\hline Catches & $\begin{array}{l}0.0323^{* * *} \\
(0.00448)\end{array}$ & $\begin{array}{r}0.0196^{* * *} \\
(0.00492)\end{array}$ & $\begin{array}{c}0.0263^{* * *} \\
(0.00568)\end{array}$ \\
\hline Survey & $\begin{array}{l}0.0312^{* * *} \\
(0.00518)\end{array}$ & $\begin{array}{l}0.0489^{* * *} \\
(0.00702)\end{array}$ & $\begin{array}{l}0.0400^{* * *} \\
(0.00755)\end{array}$ \\
\hline Catches $\times$ Survey & $\begin{array}{c}-0.0355^{* * *} \\
(0.00742)\end{array}$ & $\begin{array}{c}-0.0591^{* * *} \\
(0.00904)\end{array}$ & $\begin{array}{l}-0.0240^{*} \\
(0.0109)\end{array}$ \\
\hline \multicolumn{4}{|l|}{ Control Variables } \\
\hline Duration of Stock Assessment & $\begin{array}{l}-0.00142 \\
(0.00135)\end{array}$ & $\begin{array}{c}-0.00220^{* * *} \\
(0.000218)\end{array}$ & $\begin{array}{l}-0.00132 \\
(0.00156)\end{array}$ \\
\hline Exploitation Range (SSB) & $\begin{array}{c}4.73 \mathrm{e}-09 \\
(5.70 \mathrm{e}-09)\end{array}$ & $\begin{array}{c}7.82 \mathrm{e}-09 \\
(4.99 \mathrm{e}-09)\end{array}$ & $\begin{array}{c}-2.09 \mathrm{e}-08^{* *} \\
(7.31 \mathrm{e}-09)\end{array}$ \\
\hline Recruitment range & $\begin{array}{l}0.00000547^{* * *} \\
(0.0000000658)\end{array}$ & $\begin{array}{c}-0.00000113^{* *} \\
(0.000000388)\end{array}$ & $\begin{array}{c}-0.00000536^{* * *} \\
(0.000000922)\end{array}$ \\
\hline Species Interaction & $\begin{array}{c}4.60 \mathrm{e}-10^{* * *} \\
(1.33 \mathrm{e}-10)\end{array}$ & $\begin{array}{c}2.61 \mathrm{e}-10 \\
(1.48 \mathrm{e}-10)\end{array}$ & $\begin{array}{c}-9.07 \mathrm{e}-10^{* * *} \\
(1.67 \mathrm{e}-10)\end{array}$ \\
\hline $\begin{array}{l}\text { Fixed report year effect } \\
\text { Fixed assessed year per stock } \\
\text { Observations } \\
\text { Adjusted } R^{2}\end{array}$ & $\begin{array}{c}\sqrt{ } \\
\sqrt{ } \\
16735 \\
0.189\end{array}$ & $\begin{array}{c}\sqrt{ } \\
\sqrt{ } \\
7706 \\
0.135\end{array}$ & $\begin{array}{c}\sqrt{ } \\
\sqrt{ } \\
9029 \\
0.267\end{array}$ \\
\hline
\end{tabular}

could interact with the critical stock status. We test this by analysing the model with interaction effects (table 4.A.3). We find that anchoring due to the nature of the assessment plays an even bigger role if stocks have a critical status. In regard to adequate weighting we do not see any interaction effect.

We conduct placebo tests in which we randomise the type of assessment while keeping everything else constant. In the first test (table 4.A.5 columns 1 - 3) we randomly assign 
updates and benchmarks across report years and within fish stock. In the second test (table 4.A.5 columns 4 - 6) we randomise across stocks and within report years. As expected, our placebo tests does not show any evidence of anchoring (table 4.A.6).

\subsection{Discussion}

We have shown that results from stock assessments are affected by intuitive judgement of experts. In general, we observe anchoring, which implies that new estimates tend to be very close to previous estimates if stock scientists can choose model input. Obviously, any recurrent assessment will not be made from scratch and will take previous knowledge into account. This is what learning is all about. But in such case, updates of estimates should be random, and not follow any systematic pattern unrelated to learning. To control for learning, we included various control variables, e.g. observed historical range of biomass levels, but these are not significant.

In particular, we find that anchoring is larger whenever there is "room to fiddle" or the stock is in a critical state. Generally, these factors tend to be stronger for upward adjustments. A potential explanation of this finding lies in the political nature of fish stock assessments. Since the experts know that higher biomass estimates translate into a higher total allowable catch, they are under high pressure to be certain that the spawning stock biomass really is higher. It seems that in this case experts follow (consciously or subconsciously) a precautionary road.

One of the key challenge about fisheries management is that one never learns about the true state of the world, calling for careful experimentation and trial and error [Jensen et al., 2012]. While the lack of immediate feedback makes learning much harder, it makes it also much more difficult to assess the quality of the assessments. While we documented how intuitive judgement affects experts advice, we do not know whether this brings us closer to the truth or not. There is ample evidence suggesting that relying on intuition, gut feeling, and heuristics is not only efficient, but often also produces better decisions than relying on careful reasoning and objective procedures [Gigerenzer and Todd, 1999, Gigerenzer and Gaissmaier, 2011, Gilovich et al., 2002, Kahneman, 2011]. So removing all possibilities for experts to make judgement calls will most likely not lead to better stock assessments. There is a reason - and value - for having human beings conducting out experts, rather than bots who are guided by machine learning and algorithms. After all, experts do have the ability to make judgement calls if something does not seem to add up, and making those judgement calls requires experience. Yet, we would like to point to two important dangers. First, treating diverging data as an outlier and relying on what we have seen before may be appropriate in many cases, but it may also lead to the rejection of very unlikely and implausible data which would require immediate 
attention [Taleb, 2007]. The collapse of Northern cod in Canada is a particular painful example where experts had trouble making sense of data that suggesting the stock was in realms they had never even deemed possible before [Steele et al., 1992, Finlayson and McCay, 1998]. In that light, it is actually comforting that anchoring plays a larger role when it comes to making upward shifts, which is more precautionary. Second, while work of experts - fishery scientists included - is often seen as a task carried out with surgical precision, there is a decisive human factor involved. Yet, we need to understand much better how this human factor works.

Since natural resource management relies on experts it is important to focus more on behavioural factors influencing their work. We used fish stock assessments as an example for how intuitive judgement patterns can impact natural resource management. Yet, experts in general are often unaware of these, just as policy makers. In light of the potential impacts it seems that gaining a deeper understanding of which internal and external factors are the main drivers should be the next step. Identifying the factors with the biggest impact on expert judgement and understanding how they influence natural resource assessments will aid the sustainable management of these resources. 



\section{Appendix}

\section{A Supplementary materials}

\section{A.1 Material and Methods}

\section{Data}

The analysis was conducted with a data base containing information on the stock assessments done by ICES. This data was compiled by Pastoors [2020] and will be publicly available upon publication of the manuscript. The data base consists of 71 fish stocks with 777 stock assessments and 25589 observations. Each stock assessment provides a historical time series of estimates for spawning stock biomass (SSB). We refer to the year the assessment is conducted as "report year" and "assessed year" refers to the years for which the estimates were provided. The first assessment was done in 1988 and the latest in 2015.

Some assessments are classified as either update or benchmark. An update is the most common kind of assessment conducted (210 out of 777 assessments). A benchmark was conducted in 66 out of 777 assessments. The majority of assessments is not clearly classified (501 out of 777). This means that out of the 25591 observations, 15161 are not classified as either update or benchmark. The majority of assessments does not report a data source (545 out of 777 ).

We also have data on stock specific reference points such as MSYbtrigger, $B_{\text {lim }}, F_{\mathrm{MSY}}$, and $F_{\text {lim. }}$. MSYbtrigger, when reached, triggers the management action to fish at $F_{\mathrm{MSY}}$ to achieve a maximum sustainable yield (MSY) in the longrun. Fishing at $F_{\mathrm{MSY}}$ is one of the management objectives in the European Union and thus covers the majority of the stocks (51 out of 71 stocks). Fishing at $F_{\text {lim }}$ will lead to the biomass level of $B_{\text {lim }}$ which is the minimum size of a fish stock to ensure reproductive capacity. Thus, fishing above $F_{\lim }$ endangers the fish stock. For 49 out of 71 stock $B_{\lim }$ is reported. ICES introduced a buffer to avoid reaching $B_{\lim }$, namely the biomass precautionary reference point $B_{\mathrm{PA}}$. If the biomass drops below $B_{\mathrm{PA}}$ management action should be taken to reduce fishing pressure to avoid reaching $B_{\lim }$ [Lassen et al., 2013]. Reference points are fairly static 
values, but they are sometimes updated.

For each report year, we have one biomass estimate for each assessed year, which allows us to see how much the stock assessment has changed from one report year to another. We are interested in the inter-annual change of estimates depending on the report year. First, we measure the magnitude of the inter-annual change by converting the differences between estimates into relative changes. We use the absolute value of relative changes to measure the deviation between report years independent of the direction of the changes. The relative change $V_{i j t}$ is defined as

$$
V_{i j t}=\left|\frac{\left(S S B_{i j t}-S S B_{i j, t-1}\right)}{S S B_{i j, t-1}}\right|
$$

with $t$ being the report year, $j$ the assessed year and $i$ the stock assessed (fig. 4.2.1). Second, apart from the size of the inter-annual change we are also controlling for the direction of change since we hypothesize that an upward shift is stronger influenced by intuitive expert judgement than a downward shift. Combining the relative change and the direction of the change (Fig. 4.2.2), illustrates that not every fish stock was assessed every year. Naturally, number of assessed years increases with more recent report years.

To test our hypotheses we construct several variables. To differentiate between the different kinds of assessments we use indicator variables. We have a variable for update and one for benchmarking. We also have an indicator variable which takes the value one if the stock has been benchmarked before. We use two indicator variables to control for how the data was collected. We focus on two data sources, namely catches and scientific surveys. Due to the inconsistent reporting of the data sources we combine all the available data on discards, catches and landings in one variable named "catches", as it is not transparent when catches actually include discards and landings. The indicator variable for catches takes the value one if catches were part of the data source and the one for surveys takes the value one if surveys were part of the data source. We use interaction effects to determine the impact on inter-annual change when both data sources are used. Overall, we have 7062 estimates that either are based on catches, survey, or a combination of both.

In regard to the health of a fishery we focus on fishing pressure and biomass in relation to reference points [Ricard et al., 2011, Methot, 2015]. While we have different fishing pressure reference points in the data base, we use maximum sustainable yield ( $\left.F_{\mathrm{MSY}}\right)$. Since we do not have $F_{\mathrm{MSY}}$ for all years of each of these stocks and $F_{\mathrm{MSY}}$ is more or less static we use the average $F_{M S Y}$ per fish stock. Relative mortality is defined as fishing pressure divided by average $F_{\mathrm{MSY}}$. We use a continuous variable which indicates that the higher a ratio the higher is the pressure on the fish stock. A value above 1 indicates overfishing [Hilborn and Stokes, 2010]. In regard to biomass status we use $B_{\lim }$ as 
reference point since it is the most severe reference point. As in the case of $F_{\mathrm{MSY}}$, we do not have $B_{\text {lim }}$ for every fish stock, thus we use the average of $B_{\text {lim }}$ for each of the stocks. In line with Lindegren et al. [2009] we define the case when SSB is below $B_{\text {lim }}$ as critical.

To control for differences in information and learning, we include data on the duration of stock assessments, the exploitation range, recruitment range, and species interaction. We construct control variables in regard to measured SSB levels, recruitment, species interaction, and duration of assessments. The longer a stock has been assessed, the better is the understanding of the stock. Hence, we construct a variable which measures duration. This variable counts the difference between the first report year for a stock to the current report year. Since the data is incomplete the duration does not count the number of assessments conducted but measures the time difference between the first and the current report year. In a similar manner it is assumed that if a stock has experienced very low and very high SSBs we can better understand the underlying dynamics of a stock [Magnusson and Hilborn, 2007]. We construct variables for highest and lowest SSB which measure the highest/lowest SSB recorded up to year $j$ in report year $t$. We use the difference between highest and lowest SSB as an indicator for range. We also construct variables for highest and lowest recruitment per fish stock reported in year $j$ and report year $t$ from which we construct a range indicator for recruitment which is the difference between maximum recorded recruitment minus the minimum recruitment. The last control variable we use is species interaction. Here we measure the total SSB per year per ecosystem and divide it by the number of species assessed in the ecosystem. This way we are able to control for species interaction effects which might influence changes in SSB.

The compilation of fish stock assessments lead to a data base with 164 fish stocks. After combining the data base with the information on assessment models the data base consists of 102 stocks. Further data cleaning was necessary as not every assessment provides absolute SSB estimates and fishing pressure F. We drop all cases which do not have both (absolute SSB and F) available. Lastly, we drop all the cases for which we have only two or less assessments per fish stock. This leaves us with 71 fish stocks and 25591 observations. The data base is an unbalanced panel and table 4.A.1 provides a descriptive overview.

\section{Model}

Since the assessed years of a fish stock are not independent we use a linear fixed effect model in which we group assessed year and fish stocks. This allows us to account for structural differences between stock. We use report years (the year the assessment was conducted) as time variable $t, i$ denotes the fish stock and $j$ refers to the assessed year. In 
Table 4.A.1: Summary statistics

\begin{tabular}{lccccc}
\hline \hline \multicolumn{1}{c}{ Variable } & Obs & Mean & Std. Dev. & Min & Max \\
\hline fish stock & 25591 & & & 1 & 71 \\
report year & 25591 & & & 1988 & 2015 \\
assessed year & 25591 & & & 1946 & 2013 \\
sign of relative change $(1=$ neg) & 20994 & 0.459 & 0.498 & 0 & 1 \\
update & 25591 & 0.312 & 0.463 & 0 & 1 \\
benchmark & 25591 & 0.096 & .294 & 0 & 1 \\
critical stock status & 25591 & 0.101 & 0.301 & 0 & 1 \\
data source: catch & 25591 & 0.253 & 0.434 & 0 & 1 \\
data source: survey & 25591 & 0.15 & 0.357 & 0 & 1 \\
spawning stock biomass (SSB) & 25591 & 357174.7 & 903811.9 & 605 & $1.64 \mathrm{e}+07$ \\
relative change (abs) & 20994 & .042 & .115 & 0 & 8.71 \\
relative fishing pressure & 20221 & 1.796 & 1 & .001 & 23.287 \\
duration of stock assessments & 25591 & 9.304 & 5.769 & 1 & 28 \\
range of SSB & 25591 & 729560.5 & 1900273 & 1457 & $1.64 \mathrm{e}+07$ \\
range of recruitment & 25464 & 51236.17 & 200630.7 & 6.056 & 2005598 \\
species interaction & 25591 & 4549802 & $1.09 \mathrm{e}+07$ & 3707 & $1.31 \mathrm{e}+08$ \\
\hline \hline
\end{tabular}

each report year $t$ a time series is produced with estimates for previously assessed years $j$ for a given fish stock $i$. We start with a staggered difference in difference model with fixed effects of assessed year per stock to test the impact of benchmarking. The following model is estimated

$$
y_{i j t}=\alpha_{i j}+\sum_{k} \gamma_{k} D_{j i k}+\lambda_{t}+\epsilon_{i j t}
$$

with $y_{i j t}$ denoting the relative inter-annual change and $\lambda_{t}$ being an indicator variable for report years. $D_{j i k}$ is an indicator variable which equals one if an assessed year in a stock has been assessed by a benchmark in all report years when $k \geq t$ and $\epsilon_{i j t}$ being the error term. In order to control for the time variant idiosyncratic error we use a robust estimator which in our case is equivalent to a cluster estimator (clustered on assessed year of a fish stock). All econometric estimations were done with STATA. We used the $x$ treg, fe command for all our estimation since we are interested in the time-variant variables.

To test our hypotheses beyond the effect of the introduction of benchmarking we estimate the following model

$$
y_{i j t}=\alpha_{i j}+\beta \boldsymbol{X}_{i j t}+\lambda_{t}+\epsilon_{i j t}
$$

with $y_{i j t}$ being the relative change of estimated biomass in absolute values, $\boldsymbol{X}_{\boldsymbol{i j t}}$ the independent variables (kind of assessment, data source, stock status, and control variables), $\lambda_{t}$ are report year dummies, and the time variant idiosyncratic error $\epsilon_{i j t}$. 


\section{A.2 Supplementary Text}

We test the following hypotheses.

H1 Fiddling room increases fiddling - If there is room for human influence in the fish stock assessment, the assessment has a tendency towards the status quo.

H1a Updates show a stronger anchoring than benchmarks.

H1b 'Adequate weighting' increases anchoring in fish stock assessments.

H2 Experts' awareness of the impact of their work influences the assessment.

H2a If a fish stock is considered to be in a critical state there is a status quo dominance.

H2b Anchoring is stronger in an upward shift than in a downward shift.

When estimating the main model we also test whether the coefficients are robust, independent of the order they were estimated in (Tab. 4.A.4). We further conduct placebo tests in which we randomise the type of assessment while keeping everything else constant. In the first test (Tab. 4.A.5 columns 1 - 3) we randomly assign updates and benchmarks across report years and within fish stocks. Hence, the number of benchmarks and updates conducted per fish stock stays the same but we randomize the report year. In the second test (Tab. 4.A.5 columns 4 - 6) we randomise across stocks and within report years. We keep the number of updates and benchmarks per report year constant and randomly assign them to fish stocks. Most of the coefficients are statistically insignificant and the explained variation is the same as if the type of assessment had been ignored (Tab 4.A.6).

\section{A.3 Robustness checks}


Table 4.A.2: Robustness check. Different indicators for stock status.

\begin{tabular}{|c|c|c|c|c|}
\hline & $\begin{array}{c}(1) \\
\text { Relative Change } \\
\end{array}$ & $\begin{array}{c}(2) \\
\text { Relative Change } \\
\end{array}$ & $\begin{array}{c}(3) \\
\text { Relative Change } \\
\end{array}$ & $\begin{array}{c}(4) \\
\text { Relative Change }\end{array}$ \\
\hline $\begin{array}{l}\text { Type of Assessment } \\
\text { Update }\end{array}$ & $\begin{array}{c}-0.0140^{* * *} \\
(0.00212)\end{array}$ & $\begin{array}{c}-0.0130^{* * *} \\
(0.00208)\end{array}$ & $\begin{array}{c}-0.0115^{* * *} \\
(0.00253)\end{array}$ & $\begin{array}{c}-0.0136^{* * *} \\
(0.00256)\end{array}$ \\
\hline Benchmark & $\begin{array}{l}0.0880^{* * *} \\
(0.00362)\end{array}$ & $\begin{array}{l}0.0792^{* * *} \\
(0.00343)\end{array}$ & $\begin{array}{l}0.0859^{* * *} \\
(0.00452)\end{array}$ & $\begin{array}{l}0.0738^{* * *} \\
(0.00410)\end{array}$ \\
\hline $\begin{array}{l}\text { Health of Fishery } \\
\text { Critical stock status }\left(B_{\lim }\right)\end{array}$ & $\begin{array}{c}-0.0481^{* * *} \\
(0.0129)\end{array}$ & & $\begin{array}{c}-0.0587^{* * *} \\
(0.0166)\end{array}$ & \\
\hline Relative Fishing Pressure ( $\mathrm{F}_{\mathrm{MSY}}$ ) & $\begin{array}{r}-0.0266^{* * *} \\
(0.00592)\end{array}$ & $\begin{array}{r}-0.0144^{* *} \\
(0.00526)\end{array}$ & & \\
\hline Overfished (MSYbtrigger) & & $\begin{array}{l}-0.0175^{*} \\
(0.00692)\end{array}$ & & $\begin{array}{r}-0.0350^{* * *} \\
(0.00979)\end{array}$ \\
\hline Critical Fishing $\left(\mathrm{F}_{\text {lim }}\right)$ & & & $\begin{array}{l}-0.0261 \\
(0.0218)\end{array}$ & $\begin{array}{l}-0.0223 \\
(0.0207)\end{array}$ \\
\hline $\begin{array}{l}\text { Data Source } \\
\text { Catches }\end{array}$ & $\begin{array}{l}0.0323^{* * *} \\
(0.00448)\end{array}$ & $\begin{array}{l}0.0283^{* * *} \\
(0.00441)\end{array}$ & $\begin{array}{l}0.0102^{* *} \\
(0.00357)\end{array}$ & $\begin{array}{l}0.00320) \\
(0.00356)\end{array}$ \\
\hline Survey & $\begin{array}{l}0.0312^{* * *} \\
(0.00518)\end{array}$ & $\begin{array}{l}0.0317^{* * *} \\
(0.00516)\end{array}$ & $\begin{array}{c}0.00513 \\
(0.00676)\end{array}$ & $\begin{array}{c}0.00419 \\
(0.00683)\end{array}$ \\
\hline Catches X Survey & $\begin{array}{r}-0.0355^{* * *} \\
(0.00742)\end{array}$ & $\begin{array}{r}-0.0335^{* * *} \\
(0.00732)\end{array}$ & $\begin{array}{c}-0.0110 \\
(0.00880)\end{array}$ & $\begin{array}{c}0.0104 \\
(0.00864)\end{array}$ \\
\hline $\begin{array}{l}\text { Control Variables } \\
\text { Duration of Stock Assessment }\end{array}$ & $\begin{array}{l}-0.00142 \\
(0.00135)\end{array}$ & $\begin{array}{l}-0.00115 \\
(0.00135)\end{array}$ & $\begin{array}{r}-0.00225^{*} \\
(0.00101)\end{array}$ & $\begin{array}{c}-0.00275^{* *} \\
(0.00104)\end{array}$ \\
\hline Exploitation Range (SSB) & $\begin{array}{c}4.73 \mathrm{e}-09 \\
(5.70 \mathrm{e}-09)\end{array}$ & $\begin{array}{l}-7.21 \mathrm{e}-09 \\
(5.01 \mathrm{e}-09)\end{array}$ & $\begin{array}{l}2.10 \mathrm{e}-08^{*} \\
(8.42 \mathrm{e}-09)\end{array}$ & $\begin{array}{l}-5.26 \mathrm{e}-09 \\
(7.86 \mathrm{e}-09)\end{array}$ \\
\hline Recruitment Range & $\begin{array}{r}-0.00000547^{* * *} \\
(0.000000658)\end{array}$ & $\begin{array}{r}-0.00000202^{* * *} \\
(0.000000461)\end{array}$ & $\begin{array}{c}-0.00000673^{* * *} \\
(0.00000165)\end{array}$ & $\begin{array}{r}-0.00000437^{* *} \\
(0.00000148)\end{array}$ \\
\hline Species Interaction & $\begin{array}{c}-4.60 \mathrm{e}-10^{* * *} \\
(1.33 \mathrm{e}-10)\end{array}$ & $\begin{array}{l}-2.59 \mathrm{e}-10^{*} \\
(1.26 \mathrm{e}-10)\end{array}$ & $\begin{array}{l}-1.77 \mathrm{e}-10 \\
(1.79 \mathrm{e}-10)\end{array}$ & $\begin{array}{c}-4.19 \mathrm{e}-10^{* *} \\
(1.53 \mathrm{e}-10)\end{array}$ \\
\hline Fixed report year effect & $\sqrt{ }$ & $\sqrt{ }$ & $\sqrt{ }$ & \\
\hline Fixed assessed year per stock & $\sqrt{ }$ & $\sqrt{ }$ & $\sqrt{ }$ & \\
\hline Observations & 16735 & 15725 & 9736 & 9048 \\
\hline Adjusted $R^{2}$ & 0.189 & 0.158 & 0.180 & 0.167 \\
\hline
\end{tabular}

Robust standard errors in parentheses, clustered on assessed year per fish stock.

${ }^{*} p<0.05,{ }^{* *} p<0.01,{ }^{* * *} p<0.001$

Note: We tested whether the indicator used matters for the health of the fishery. We used MSYbtrigger to create an indicator variable which takes the value 1 if SSB is below the MSYbtrigger. Further, we used $B_{\text {lim }}$ to construct a continuous variable measuring the relative mortality. In (1) we provide the main regression used for the analysis for comparison, (2) uses indicators based upon MSY, (3) uses indicators based upon $\mathrm{B}_{\text {lim }}$ and $\mathrm{F}_{\text {lim }}$, and in (4) SSB status is based upon MSY and relative fishing pressure is based upon $\mathrm{F}_{\text {lim }}$. 
Table 4.A.3: Interaction of stock status with type of assessment and data source.

\begin{tabular}{|c|c|c|c|}
\hline & $\begin{array}{c}\text { (1) } \\
\text { Relative Change, full }\end{array}$ & $\begin{array}{c}(2) \\
\text { Relative Change, downward }\end{array}$ & $\begin{array}{c}\text { (3) } \\
\text { Relative Change, upward }\end{array}$ \\
\hline \multicolumn{4}{|l|}{ Type of Assessment } \\
\hline Update & $\begin{array}{c}-0.0111^{* * *} \\
(0.00199)\end{array}$ & $\begin{array}{r}0.00632^{* *} \\
(0.00226)\end{array}$ & $\begin{array}{c}-0.0190^{* * *} \\
(0.00343)\end{array}$ \\
\hline Benchmark & $\begin{array}{r}0.0836^{* * *} \\
(0.00374)\end{array}$ & $\begin{array}{r}0.0426^{* * *} \\
(0.00293)\end{array}$ & $\begin{array}{l}0.118^{* * *} \\
(0.00619)\end{array}$ \\
\hline \multicolumn{4}{|l|}{ Type of Assessment $\times$ Stock Status } \\
\hline Update $\times$ Critical Stock Status & $\begin{array}{c}-0.0406^{* * *} \\
(0.00917)\end{array}$ & $\begin{array}{l}-0.0216^{*} \\
(0.00995)\end{array}$ & $\begin{array}{c}-0.0669^{* * *} \\
(0.0162)\end{array}$ \\
\hline Benchmark $\times$ Critical Stock Status & $\begin{array}{l}0.0380^{*} \\
(0.0184)\end{array}$ & $\begin{array}{l}0.0399^{*} \\
(0.0190)\end{array}$ & $\begin{array}{l}-0.0245 \\
(0.0227)\end{array}$ \\
\hline \multicolumn{4}{|l|}{ Data Source } \\
\hline Catches & $\begin{array}{c}0.0307^{* * *} \\
(0.00466)\end{array}$ & $\begin{array}{r}0.0185^{* * *} \\
(0.00495)\end{array}$ & $\begin{array}{l}0.0268^{* * *} \\
(0.00604)\end{array}$ \\
\hline Survey & $\begin{array}{c}0.0330^{* * *} \\
(0.00580)\end{array}$ & $\begin{array}{c}0.0554^{* * *} \\
(0.00804)\end{array}$ & $\begin{array}{c}0.0360^{* * *} \\
(0.00801)\end{array}$ \\
\hline Catches $\times$ Survey & $\begin{array}{c}-0.0325^{* * *} \\
(0.00805)\end{array}$ & $\begin{array}{c}-0.0588^{* * *} \\
(0.00999)\end{array}$ & $\begin{array}{l}-0.0230^{*} \\
(0.0114)\end{array}$ \\
\hline \multicolumn{4}{|l|}{ Data Source $\times$ Stock Status } \\
\hline Catches $\times$ Stock Status & $\begin{array}{c}0.0162^{*} \\
(0.00775)\end{array}$ & $\begin{array}{c}0.0121 \\
(0.0137)\end{array}$ & $\begin{array}{l}-0.00532 \\
(0.00840)\end{array}$ \\
\hline Survey $\times$ Stock Status & $\begin{array}{c}-0.0466^{* *} \\
(0.0175)\end{array}$ & $\begin{array}{c}-0.0702^{* * *} \\
(0.0160)\end{array}$ & $\begin{array}{c}0.0604 \\
(0.0371)\end{array}$ \\
\hline Catches $\times$ Survey $\times$ Stock Status & $\begin{array}{c}-0.0221 \\
(0.0157)\end{array}$ & $\begin{array}{c}-0.00145 \\
(0.0191)\end{array}$ & $\begin{array}{l}-0.0215 \\
(0.0203)\end{array}$ \\
\hline \multicolumn{4}{|l|}{ Health of Fishery } \\
\hline Critical Stock Status & $\begin{array}{c}-0.0295^{* *} \\
(0.0114)\end{array}$ & $\begin{array}{c}0.0231 \\
(0.0128)\end{array}$ & $\begin{array}{l}-0.0365 \\
(0.0192)\end{array}$ \\
\hline Relative Fishing Pressure & $\begin{array}{c}-0.0261^{* * *} \\
(0.00589)\end{array}$ & $\begin{array}{c}0.00729 \\
(0.00543)\end{array}$ & $\begin{array}{c}-0.0551^{* * *} \\
(0.00987)\end{array}$ \\
\hline \multicolumn{4}{|l|}{ Control Variables } \\
\hline Duration of Stock Assessment & $\begin{array}{l}-0.00145 \\
(0.00135)\end{array}$ & $\begin{array}{c}-0.00215^{* * *} \\
(0.000221)\end{array}$ & $\begin{array}{l}-0.00133 \\
(0.00158)\end{array}$ \\
\hline Exploitation Range (SSB) & $\begin{array}{c}6.32 \mathrm{e}-09 \\
(5.79 \mathrm{e}-09)\end{array}$ & $\begin{array}{c}7.56 \mathrm{e}-09 \\
(5.00 \mathrm{e}-09)\end{array}$ & $\begin{array}{c}-1.56 \mathrm{e}-08^{*} \\
(7.68 \mathrm{e}-09)\end{array}$ \\
\hline Recruitment Range & $\begin{array}{c}-0.00000548^{* * *} \\
(0.000000663)\end{array}$ & $\begin{array}{c}-0.00000121^{* *} \\
(0.000000385)\end{array}$ & $\begin{array}{c}-0.00000561^{* * *} \\
(0.000000939)\end{array}$ \\
\hline Species Interaction & $\begin{array}{c}-4.24 \mathrm{e}-10^{* *} \\
(1.32 \mathrm{e}-10)\end{array}$ & $\begin{array}{c}2.59 \mathrm{e}-10 \\
(1.47 \mathrm{e}-10) \\
\end{array}$ & $\begin{array}{c}-8.05 \mathrm{e}-10^{* * *} \\
(1.68 \mathrm{e}-10) \\
\end{array}$ \\
\hline Fixed report year effect & $\sqrt{ }$ & $\sqrt{ }$ & $\sqrt{ }$ \\
\hline Fixed assessed year per stock & $\sqrt{ }$ & $\sqrt{ }$ & $\sqrt{ }$ \\
\hline Observations & 16735 & 7706 & 9029 \\
\hline Adjusted $R^{2}$ & 0.196 & 0.148 & 0.272 \\
\hline
\end{tabular}

\footnotetext{
Robust standard errors in parentheses, clustered on assessed year per fish stock.

${ }^{*} p<0.05,{ }^{* *} p<0.01,{ }^{* * *} p<0.001$

Note: Experts are under high pressure if they have to conduct a stock assessment for a fish stock that is considered to be overfished. In order to examine the behavioural response to this situation we estimated interaction effects between fish stock status and the type of assessment and with data source.
} 
Table 4.A.4: Robustness check. Sequential estimation of coefficients.

\begin{tabular}{|c|c|c|c|c|}
\hline & $\begin{array}{c}(1) \\
\text { Relative Change }\end{array}$ & $\begin{array}{c}(2) \\
\text { Relative Change }\end{array}$ & $\begin{array}{c}(3) \\
\text { Relative Change }\end{array}$ & $\begin{array}{c}(4) \\
\text { Relative Change }\end{array}$ \\
\hline \multicolumn{5}{|l|}{ Type of Assessment } \\
\hline Update & $\begin{array}{c}-0.0137^{* * *} \\
(0.00260)\end{array}$ & $\begin{array}{c}-0.0190^{* * *} \\
(0.00215)\end{array}$ & $\begin{array}{c}-0.0146^{* * *} \\
(0.00212)\end{array}$ & $\begin{array}{c}-0.0140^{* * *} \\
(0.00212)\end{array}$ \\
\hline Benchmark & $\begin{array}{c}0.0942^{* * *} \\
(0.00400)\end{array}$ & $\begin{array}{c}0.0881^{* * *} \\
(0.00386)\end{array}$ & $\begin{array}{c}0.0915^{* * *} \\
(0.00391)\end{array}$ & $\begin{array}{c}0.0880^{* * *} \\
(0.00362)\end{array}$ \\
\hline \multicolumn{5}{|l|}{ Health of Fishery } \\
\hline Critical Stock Status & & $\begin{array}{c}-0.0438^{* * *} \\
(0.0124)\end{array}$ & $\begin{array}{c}-0.0444^{* * *} \\
(0.0123)\end{array}$ & $\begin{array}{c}-0.0481^{* * *} \\
(0.0129)\end{array}$ \\
\hline Relative Fishing Pressure & & $\begin{array}{c}-0.0150^{* *} \\
(0.00509)\end{array}$ & $\begin{array}{c}-0.0182^{* * *} \\
(0.00513)\end{array}$ & $\begin{array}{c}-0.0266^{* * *} \\
(0.00592)\end{array}$ \\
\hline \multicolumn{5}{|l|}{ Data Source } \\
\hline Catches & & & $\begin{array}{l}0.0297^{* * *} \\
(0.00414)\end{array}$ & $\begin{array}{c}0.0323^{* * *} \\
(0.00448)\end{array}$ \\
\hline Survey & & & $\begin{array}{l}0.0347^{* * *} \\
0.0347^{* * *}\end{array}$ & $\begin{array}{l}0.0312^{* * *} \\
0.0312^{* * *}\end{array}$ \\
\hline Catches X Survey & & & $\begin{array}{c}-0.0368^{* * *} \\
(0.00706)\end{array}$ & $\begin{array}{c}-0.0355^{* * *} \\
(0.00742)\end{array}$ \\
\hline \multicolumn{5}{|l|}{ Control Variables } \\
\hline Duration of Stock Assessment & & & & $\begin{array}{l}-0.00142 \\
(0.00135)\end{array}$ \\
\hline Exploitation Range (SSB) & & & & $\begin{array}{c}4.73 \mathrm{e}-09 \\
(5.70 \mathrm{e}-09)\end{array}$ \\
\hline Recruitment Range & & & & $\begin{array}{c}-0.00000547^{* * *} \\
(0.000000658)\end{array}$ \\
\hline Species Interaction & & & & $\begin{array}{c}-4.60 \mathrm{e}-10^{* * *} \\
(1.33 \mathrm{e}-10)\end{array}$ \\
\hline Fixed report year effect & $\sqrt{ }$ & $\sqrt{ }$ & $\sqrt{ }$ & $\sqrt{ }$ \\
\hline Fixed assessed year per stock & $\sqrt{ }$ & $\sqrt{ }$ & $\sqrt{ }$ & $\sqrt{ }$ \\
\hline Observations & 20994 & 16767 & 16767 & 16735 \\
\hline Adjusted $R^{2}$ & 0.104 & 0.164 & 0.172 & 0.189 \\
\hline
\end{tabular}

Robust standard errors in parentheses, clustered on assessed year per fish stock.

${ }^{*} p<0.05,{ }^{* *} p<0.01,{ }^{* * *} p<0.001$

Note: In order test the robustness of the coefficients we run sequential estimations. We run the regression in every possible order and all were robust. This table is one example. 


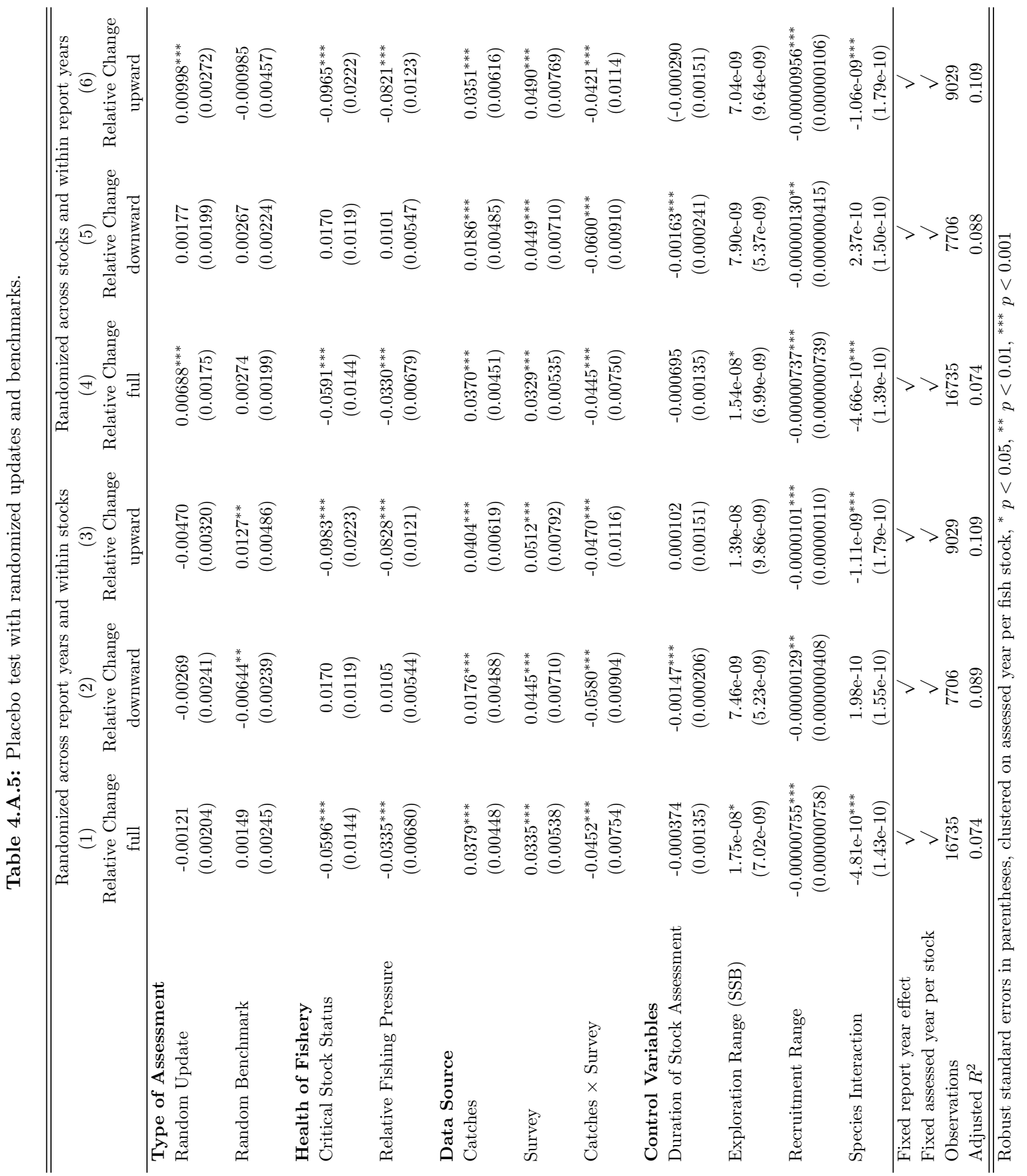


We conduct a placebo test to ensure that our results are solid. We are particularly interested in the type of assessment variables. We conduct two tests. In the first one we randomize the type of assessment across report years but within fish stocks (table 4.A.5 column 1 - 3). This yields insignificant coefficients and an adjusted $R^{2}$ as high as if the type of assessment is excluded. In the second test we randomized the type of assessment across fish stocks and within report years (table 4.A.5 column 4 -6). Again, we mostly have insignificant coefficients and adjusted $R^{2}$ as low as if we excluded the type of assessment (table 4.A.6).

Table 4.A.6: The basic model without updates and benchmarks.

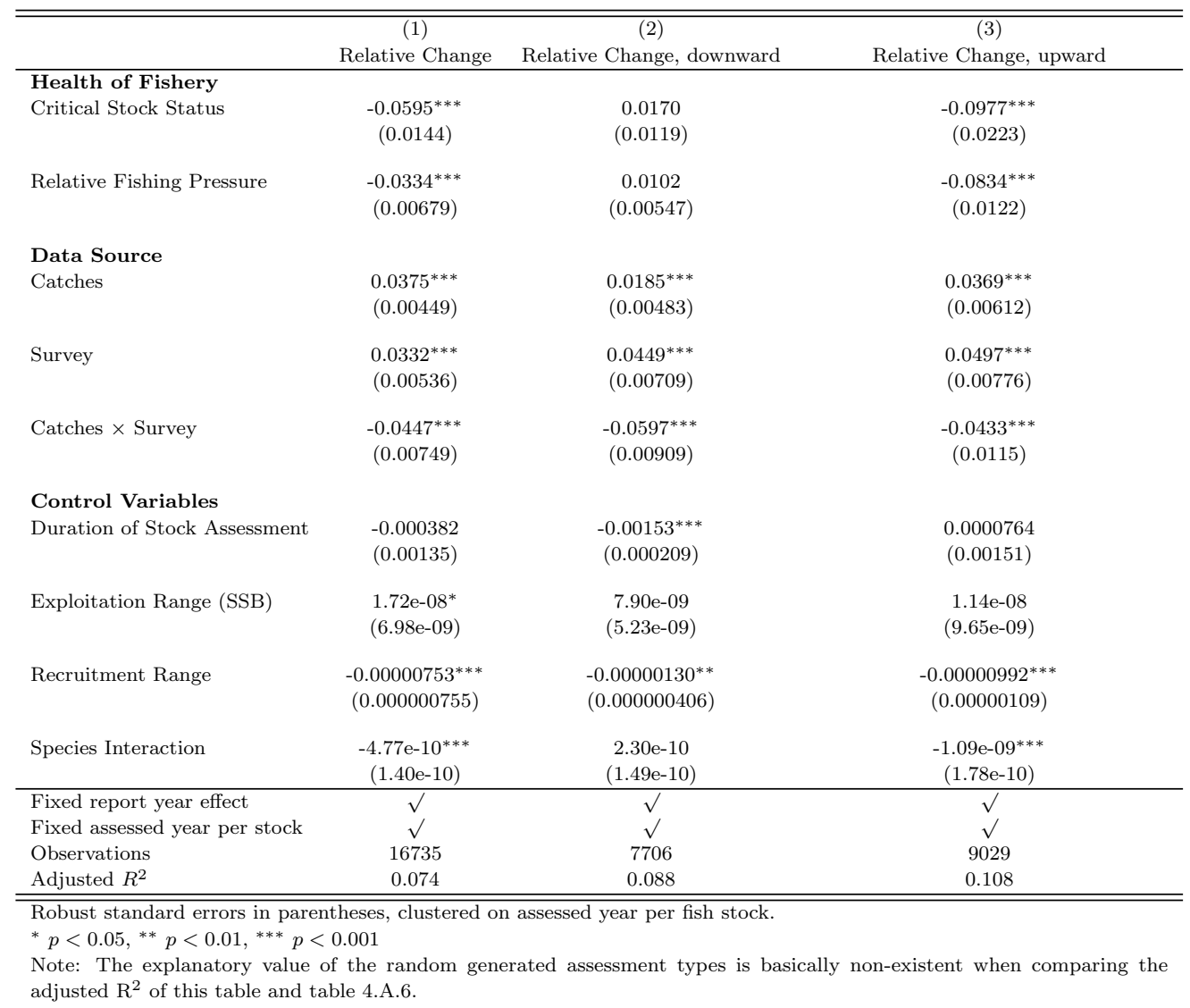




\section{Chapter 5}

\section{Sticky institutions may prevent adaptation of fisheries to climate change}

This chapter is based on a manuscript under review at Marine Policy, Schuch, E., Gabbert, S. and Richter, A. (2020). Sticky institutions may prevent adaptation of fisheries to climate change. 


\section{Abstract}

Fisheries management has to deal with uncertainty about composition and location of fish stock. Climate change dynamics cause stocks to shift polewards. This may cause management decisions to be less effective if institutions are sticky, i.e. unable to adapt to those changes. This paper analyses fisheries management in Europe which relies on scientific advice feeding into the management decision process. The spatial boundaries of fish stocks are, depending on the institution, defined as scientific areas and management areas. It is shown that updating scientific information on the stock composition and location leads to changes in scientific areas, while management areas are often not adjusted. This causes an institutional mismatch which violates the self-imposed good governance principles of the EU. We use the North Sea and the Western horse mackerel stocks to gain some insights in the process of renegotiating new management areas and national fisheries quotas. We find that the distributional questions of allocating quota are a key obstacle towards an adjustment of management areas. We suggest two modes of action: either the EU needs to implement a mechanism on how to adapt management areas or ICES, provider of scientific information, could adjust scientific information presentation to facilitate its use.

Keywords: Climate change; sticky institutions; fisheries management; and scientific information 


\subsection{Introduction}

Marine systems are complex adaptive systems where both the ecological system and the governance system are changing over time. While the understanding of the mechanisms of ecological change has become better and better, relatively little is known about the institutional changes that govern marine systems. Specifically, institutional dynamics can be slow and path-dependent, which is described by Young (2010) as follows: 'institutions are sticky; they often remain in place long after mismatches between regimes and the biophysical and socioeconomic settings with which they interact become severe and widely understood, at least among specialists' [Young, 2010]. In fisheries, this may be problematic for at least two reasons. First, governance arrangements may adjust too slowly to respond adequately to environmental changes, which is particularly dangerous if certain thresholds have been passed, thereby endangering sustainable resources management [Gibbs, 2008, Winter et al., 2020, Scheffer et al., 2003, Young, 2017, Martin et al., 2020]. Second, there may occur a misfit, also called mismatch, between the governance mechanisms and ecosystem functioning [Galaz et al., 2008, Crowder et al., 2006, Folke et al., 2007, Bodin et al., 2014, Treml et al., 2015, Ekstrom and Crona, 2017]. This is particularly challenging in marine systems, where jurisdictional boundaries often do not align with boundaries of fish stocks [Pinsky et al., 2018]. In many of those cases, strategies have emerged over time on how to agree on the distribution of fish stocks among countries. However, climate change induces continuous range shifts, which alter historically observed spatial patterns of fish stocks. One example is that with rising water temperatures the stocks start to migrate out of their traditional habitats towards the poles [Pinsky et al., 2018, Fossheim et al., 2015, Pinsky and Fogarty, 2012, Reiss et al., 2009, Cheung et al., 2009, Perry et al., 2005]. These distribution shifts can challenge international cooperation on the management of fisheries and can even lead to conflicts between countries [Spijkers and Boonstra, 2017, Pinsky et al., 2018, Østhagen et al., 2020]. In this paper we focus on cooperation within the institutional setting of the European Union (EU) and the challenges distribution shifts pose for the institution itself.

The decision making system in the EU is multi-institutional, multinational, and highly political. Even though the EU strives for ecosystem based management, defining fishing quotas based on single stocks for individual countries has been the default allocation strategy. The two main institutions involved in the decision making process in the European Common Fisheries Policy (CFP) are the Council of the European Union (Council) and the Commission of the European Communities (Commission). The Council encompasses the ministers from the EU member states and is the main legislator in the area of fisheries. The Commission can initiate, draft, and propose legislative acts in regard to the CFP. Any legislative measure proposed by the Commission has to be 
approved by the Council as well as by the European Parliament under the co-decision mechanism [Hegland and Raakjær, 2008].

The CFP states that in order to achieve 'conservation and sustainable exploitation of fisheries resources' the 'best available scientific advice' has to be taken into account [European Parliament and Council of the Eurpean Union, 2013]. This scientific advice is produced by the International Council for the Exploration of the Sea (ICES), an intergovernmental scientific network [Stange, 2017]. The scientific advice delivered by ICES is based upon biological and ecological information, but the CFP also requires the consideration of technical and economic advice. The Scientific, Technical and Economic Committee on Fisheries (STECF), the Commission's (independent) scientific advisory committee, expands the advice of ICES by including socio-economic considerations [Casey et al., 2016].

An essential obstacle in the fisheries management process of the European Union is that there exists a fundamental difference between scientific and management areas of stock. Scientific areas refer to the habitat of a stock. Hence, their location is to a certain degree flexible as areas are closely aligned with the stock, its genetic composition, and its potential spatial movement. The management areas, in contrast, are based upon biological as well as economic factors, and on political and administrative constraints [Reiss et al., 2009]. While the main constraint with regard to defining the scientific area is the validity of scientific information, the management area faces political constraints, which makes adjustments be a difficult and time consuming process. As a consequence, scientific areas, which can be changed according to best available knowledge, are therefore not necessarily identical with the management areas.

For various reasons, the European fisheries management system, in its current form, has been working sub-optimally. A key obstacle has been the interplay between scientific and policy institutions in the EU fisheries management system. For instance, Delaney and Hastie (2007) and Schwach et al. (2007) argued that scientific institutions such as ICES and the STECF, and policy and administrative institutions such as the Council, operate under different role identities, causing them to prioritise different aspects in the entire management process [Delaney and Hastie, 2007, Schwach et al., 2007]. This has hampered scientists to effectively explain research results, to learn from and to further adapt the advice system. Furthermore, it has induced a shift in the 'ethos of science', moving from traditional academic science towards contextualized, policy-driven science [Msomphora, 2016]. Daw \& Gray (2005) and Cardianle et al. (2017) considered the limited scope of fisheries research and large uncertainties underlying to crucial parameters such as stock growth and species mortality a major cause of the insufficient 
transformation of scientific knowledge (e.g. about the size and the location of fish stocks) into practical policy outcomes such as fishing quotas [Daw and Gray, 2005, Cardinale et al., 2017].

The focus of this paper is on the implications of the inert reactivity of governance institutions to new scientific information regarding stock location and composition, which may be altered by climate change dynamics. Under climate change, fish stocks will continue to move towards the poles in the coming years. Consequently, an increasing divergence of the location of fish stocks and management areas is to be expected. Specifically, this will be the case if climate change alters the composition of the stock, which is typically revealed by genomics research. If fish stocks shift faster than governance institutions can adapt, an institutional mismatch may occur, leading to unsustainable exploitation of stocks, which may even cause fisheries management in Europe to collapse [Niiranen et al., 2018]. While there are ample studies documenting how fish stocks may respond to climate change, evidence how this may affect the functioning of institutional systems is largely lacking. The aims of this paper are, therefore, twofold. First, we analyse how ecological changes such as climate change can affect the functioning of institutions if these are unable to adapt within sufficient time. In particular, we focus on problems in the institutional system for setting total allowable catch (TAC) in the EU that could lead to inadequate responses to distribution shifts of fish stocks. We use the EU as an example for a supranational management system in which there is a system to cooperatively manage fisheries which is not adequately equipped to deal with such distribution shifts, and we show that the self-imposed good governance principles by the EU can be violated as a result of an institutional mismatch. Second, we look at the different parts of the fisheries management system in the EU and explore their ability to flexibly adjust to distribution shifts of fish stock by adjusting management areas and the corresponding allocation of national fishing quotas. We use horse mackerel in the North Sea and the Atlantic as an illustrative case study.

The remainder of the paper is organised as follows: section 5.2 provides an overview over the European fisheries management system with a special focus on the setting of TACs, section 5.3 discusses the reasons and implications of a spatial mismatch as well as the costs associated with a realignment of the areas, in section 5.4 we use the horse mackerel case to gain insight into the factors which make institutions sticky, in section 5.5 we discuss the implications of our findings and section 5.6 concludes. 


\subsection{European Fisheries Management}

The EU manages fisheries under the Common Fisheries Policy (CFP) with the goal to 'make fisheries environmentally, economically and socially sustainable' [European Commission and others, 2016]. The EU's aim is that 'by 2020 at the latest all fish stocks should be exploited at a level that will let them produce the maximum sustainable yield for the long term (MSY). This means taking the highest catches possible without affecting future productivity of the stocks' [European Commission and others, 2016]. To maximise long-term yield of a fish stock solid scientific evidence is needed. Taking the best available scientific advice as a basis for defining management measures is one of the Common Fisheries Policy's (CFP) principles of good governance. Such measures include setting fishing opportunities and monitoring their efficiency in delivering policy objectives and targets' [European Commission, 2018]. Within the CFP, scientific information is generated as follows. First, biological information is provided by ICES which then is expanded upon by the STECF including the economic and societal impact of TACs (see figure 5.2.1). Those scientific TACs are communicated to DG MARE, the administrative body of the Commission working on maritime issues. DG MARE consults advisory councils (AC) and negotiates with non-EU states. Based upon this input DG MARE proposes TACs which can be used for management decision-making [Carpenter et al., 2016, Wilson, 2010, Holm and Nielsen, 2004]. The proposed TACs are sent to AGRIFISH which consists of the agricultural and fisheries ministers of the member states of the EU. The Council decides upon the final size of TACs which are to be implemented which we refer to as 'agreed TAC' [Stange, 2017, Casey et al., 2016].

The agreed TAC is the total quantity of biomass to be fished in the management area and has to be converted into quotas for the individual EU member states. Certain member states have fishing rights in this area. How to assign the agreed TAC to a management area that is then allocated between EU member states is determined by the 'relative stability' principle. The relative stability principle has been part of the CFP since its introduction. It determines the shares of an agreed TAC that each member state receives. The relative stability principle is based on three aspects, (i) historical catches, (ii) the maintenance of fisheries-dependent communities as established in the 'Hague preferences', and (iii) the compensation of jurisdictional losses after the introduction or extension of Exclusive Economic Zones (EEZ) by non-members. The historic catches are based on the reference period from 1973 to 1978. The Hague preferences refer to preferential treatment of regions whose dependence upon fishing is above average [Hoefnagel et al., 2015, Carpenter et al., 2016, Hegland and Raakjær, 2008, Nielsen and Holm, 2007]. Apprehending that it may be impossible to reach a new agreement once the negotiations are opened the relative stability principle has been considered an 'untouchable institutional principle' [Holm and Nielsen, 2004]. At the same time, it has been acknowledged that the relative stability 


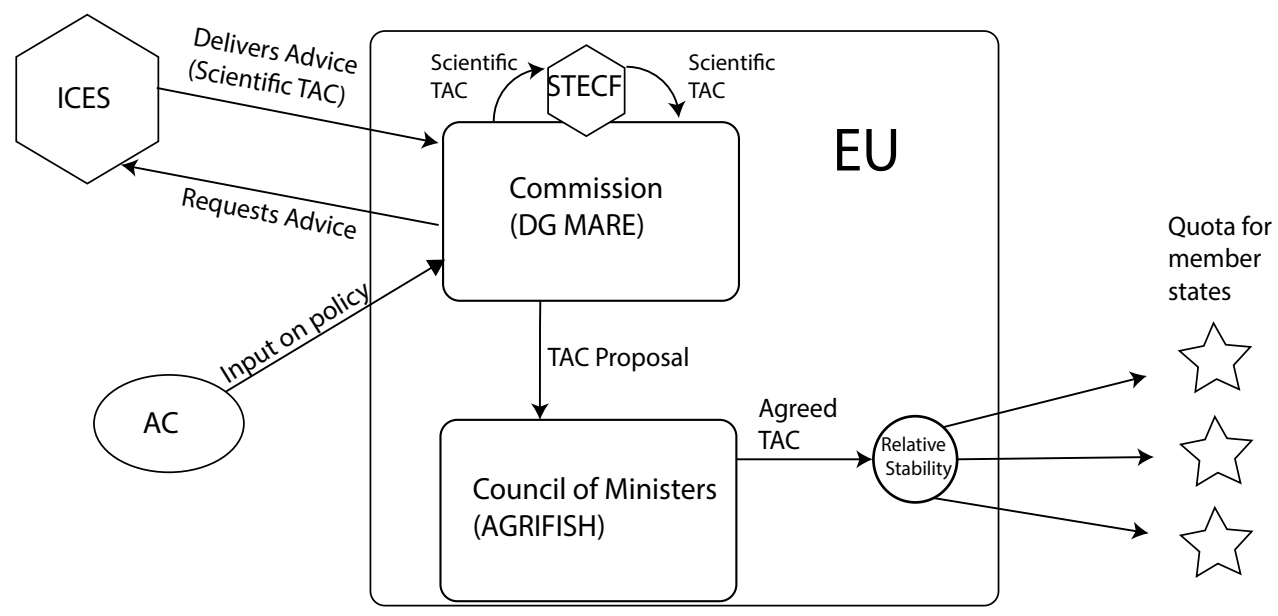

Figure 5.2.1: EU Decision making system for quota setting in the European Union. Hexagons $=$ scientific bodies, rectangles $=$ political $/$ administrative bodies, ellipse $=$ stakeholder bodies, circle $=$ institutional constraint, and star $=$ policy outcome. ICES = International Council for the Exploration of the Sea, STECF = Scientific, Technical and Economic Committee for Fisheries, $\mathrm{AC}=$ Advisory Council.

principle is an impediment to a better management system [Khalilian et al., 2010]. Due to the relative stability principle the management areas are paramount to the fisheries management process in the same way as the scientific areas are essential to the provision of scientific advice.

\subsubsection{The Role of ICES}

ICES describes itself as 'a global organization that develops science and advice to support the sustainable use of the oceans' with the goal 'to provide the best available science for decision-makers to make informed choices on the sustainable use of the marine environment and ecosystems' [ICES, 2018]. In the strategic plan for 2014 - 2018 ICES identified four main pillars for their work: (1) building a foundation of science, (2) producing information and advice that decision-makers need, (3) underpinning science and advice through data and information service, and (4) supporting the organization through the work of the secretariat. In respect to the second pillar the goal is to 'evaluate and advise on options for the sustainable use and the protection of marine ecosystems' [ICES, 2014].

ICES produces advice upon request of clients such as the European Union or the North East Atlantic Fisheries Commission (NEAFC). Frequently, these are standing requests 
such as stock assessments and corresponding advice on total allowable catch required by the EU to set the annual fishing quotas [ICES, 2016]. These TACs are based upon predefined areas (see figure 5.2.2). We refer to these areas as 'scientific areas' since they are the basis for the scientific advice of ICES. The main part of the recurring advice are single stock assessments (the focus of this paper), but also information on mixedfisheries and ecosystem based approaches [ICES, 2018]. Since this advice is given in form of total allowable catch (TAC) estimates and is based upon scientific areas we refer to the corresponding TAC as 'scientific TAC'. The underlying principle is to deliver 'best available science', i.e. the most accurate stock assessment upon which the scientific TAC is based, which will, ultimately, be converted into best management practices.

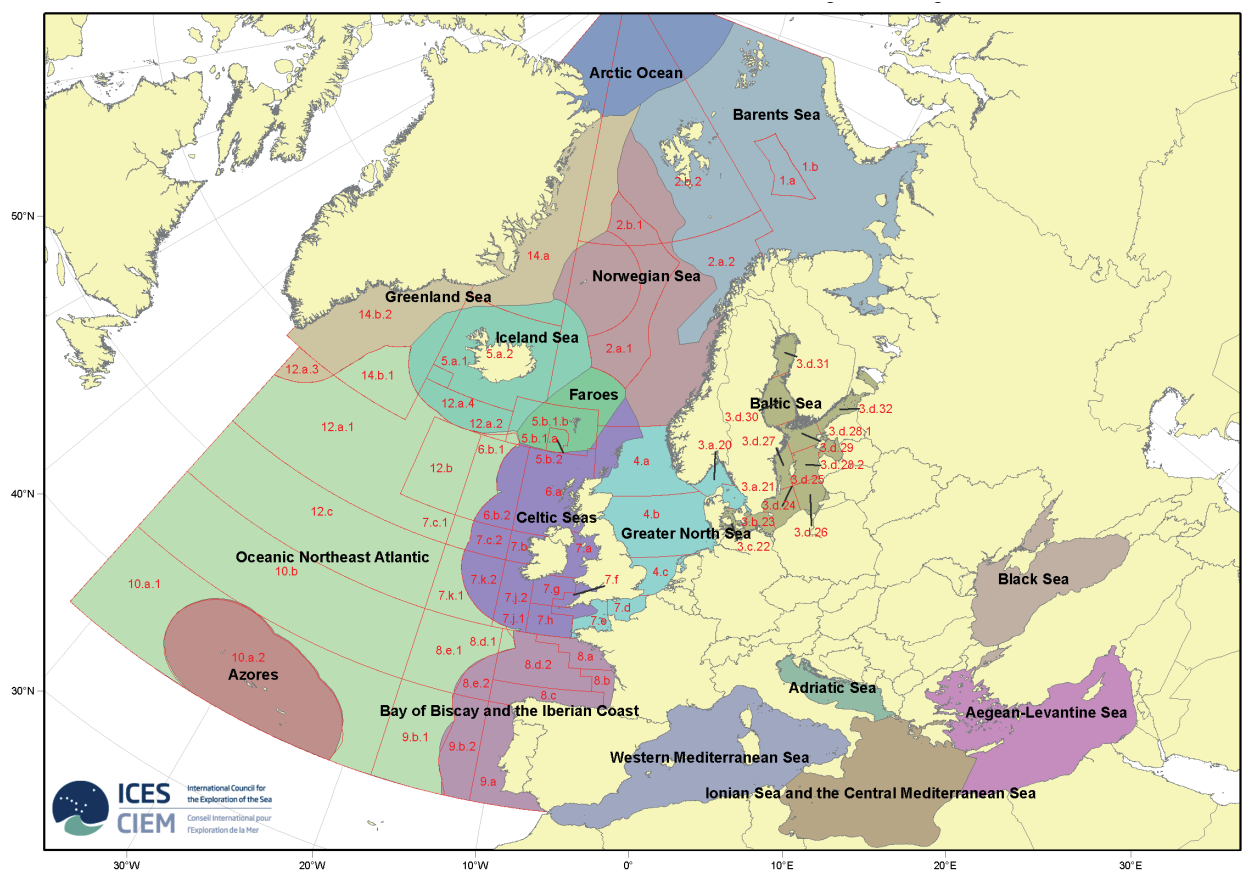

Figure 5.2.2: Division of scientific areas (red lines) and ecoregions (coloured regions) taken from the ICES homepage [ICES, 2017]. ICES provides management advice based upon these scientific areas in form of a scientifically determined total allowable catch (TAC). 


\subsection{Institutional mismatch}

\subsubsection{Reasons for changing the scientific area}

As discussed above, the management areas used in European fisheries management result from a transformation of scientific areas accounting for economic and political factors. Yet, fish populations adapt to changing environments. One of the biggest drivers is climate change which causes fish populations to shift towards the poles [Pinsky et al., 2018, Poloczanska et al., 2016]. Obviously, the increase in temperature does not affect all stocks in the same way. Rather, some stocks have a comparatively high thermal tolerance, a low dispersal capacity and a low ability to exploit new resources. These shift less quickly than stocks with a lower thermal tolerance, high dispersal capacity, and a high ability to exploit new resources. Any combination of these factors is possible, yielding different rates of distribution shifts [Fossheim et al., 2015]. While the speed and degree of distribution shifts differ between stocks, there is ample evidence that all marine stocks shift towards the poles [Fossheim et al., 2015, Pinsky et al., 2018, Pinsky and Fogarty, 2012]. Even fish stocks less affected by temperature will move north eventually following their prey [Kortsch et al., 2015]. Perry et al. (2005) studied the effect of climate change on exploited as well as unexploited stocks in the North Sea. They found that out of the 36 stocks investigated, 21 had reacted to climate change with a distribution shift [Perry et al., 2005]. This inevitably affects fishing grounds in the European Union. Besides shifting distribution ranges, climate change can impact fish populations in multiple ways such as recruitment failure and increased productivity [Fossheim et al., 2015, Reiss et al., 2009, Perry et al., 2005]. In addition to the spatial distribution of stocks the genetic composition of a stock can change over time [Reiss et al., 2009]. Scientific advances in genomics allow for clear differentiation between genetically different stocks which used to be considered as one fish stock. New insights from genomics and distribution shifts due to climate change are the main factors calling for a modification of scientific and management areas.

Genomics has developed rapidly in recent years and may have lead to modification of scientific areas [Hedeholm et al., 2016]. Understanding the genome of a fish stock gives important information about the stock structure, which may allow for more precise stock assessments and also more sustainable management of stocks [Casey et al., 2016]. An example is the cod fishery in Greenland that has been managed as a single stock prior to 2012. Since then, two different TACs are provided, one for the inshore and one for the outshore stock. Establishing two different TACs was facilitated by the fact that only one country (Greenland) exploited the stock [Hedeholm et al., 2016]. Recent research however indicates that the stock structure is even more complex, consisting of four substocks [Bonanomi et al., 2015, Therkildsen et al., 2013]. Hence, while the assessment of two TACs seemed innovative and appropriate in 2012, it may prove to be outdated in the 
near future and, consequently, may need to be revised. Distribution shifts of fish stocks as well as changes in the stock composition can induce a revision of scientific areas.

\subsubsection{Sticky institutions and the corresponding mismatch in the management system}

New information over stock location and stock structure would require also an adjustment of the management system. If this does not happen, the scientific and the management area can diverge over time. Such mismatch between the scientific and the management area of fish stock occurs if (i) scientific area, (ii) management area, and (iii) fish stock location are not aligned, i.e. congruent. Figure 5.3.1 shows schematically different possible situations of the fisheries management system. In the ideal case (A), the scientific and the management area are aligned and the fish stock is also in that area. In this case, the scientific TAC can be easily converted into national fishing quotas. New information may indicate that the fish stock is not completely in the scientific and management area, but these two areas are aligned (B). This would, for example, be the case if a fish stock shifted polewards due to climate change. In this case, the national quotas are still determined via the relative stability principle even tough the stock is partially located outside that area and can, therefore, not harvested by national fleets. However, the rigid structure of relative stability lacks a mechanism to flexibly adapt to 'an unpredictable but continuously changing ecosystem' [Schwach et al., 2007].

Situation (C) depicts the case where the scientific area is adapted to match the location of the fish stock, but the management area is not, due to the inflexibility caused by institutional and political constraints. As a result, the scientific TAC needs to be converted into the agreed TAC and it is unclear how to divide the quota over countries. This is the case the paper focuses on. Clearly, the three cases depicted in Figure 1.3 do not claim to be exhaustive, several other cases may exist where the scientific and the management area do not (fully) match the position of the stock, keeping also in mind that stock assessments are subject to considerable data and model uncertainty. The mismatch between the scientific and the management area and the spatial position of the stock as illustrated in case B and $\mathrm{C}$ has clear implications for fisheries management: A change of the scientific area requires consensus among scientists involved in the provision of the scientific advice. Given the potential impact of changes in stock assessments on the allocation of the TAC, changes in stock assessments are usually adopted only of scientific evidence is sufficiently robust. Also, different working groups with their own working culture, tradition and composition of scientists having various roles lead to complex institutional dynamics [Dankel et al., 2012]. Still, there is an ongoing discourse about modification of scientific areas. The change of the management area, in contrast, is more convoluted given that it has immediate implications for national fishing quotas and requires a renegotiation of the relative stability key. Since the relative stability principle is the backbone of the common fisheries 


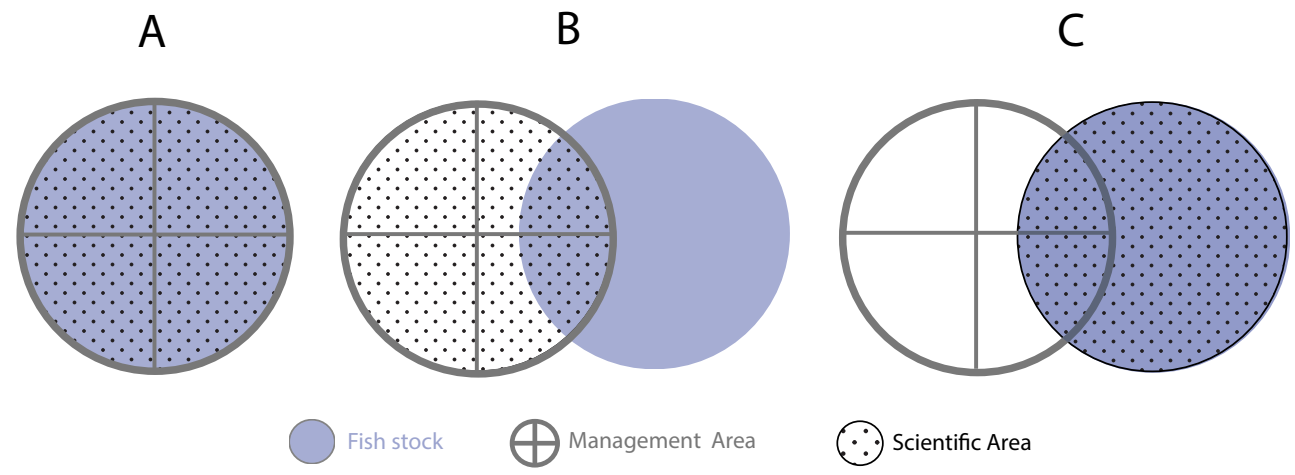

Figure 5.3.1: Institutional mismatch. The black dotted area depicts the scientific area, the grey circle the management area and the purple area indicates the location of the fish stock. The division of the management area represents the sharing of the TAC according to the relative stability key. (A) Perfect alignment of scientific area, management area, and fish stock. (B) Management and scientific area are aligned but fish stock is not completely covered. (C) Scientific area matches the fish stock, but mismatch with management area occurs.

policy, decision makers are reluctant to open this sharing rule up for discussions since there is a risk of not agreeing on a new sharing rule [Holm and Nielsen, 2004]. Also, the time frame is an important factor, since the renegotiation process of the management area takes most likely even more time than the changing of the scientific area. Hence, there is a risk of science outpacing the political realm. Since there is no defined mechanism indicating when on how management areas to adjust, responsible institutions in the EU (AGRIFISH and DG MARE) are lacking an effective and efficient procedure of resolving a mismatch.

\subsubsection{Consequences of the mismatch}

A mismatch between the scientific and the management area may impact the (perceived) quality of governance, i.e. the principles how decisions are adopted [Griffin, 2008]. The European Union has defined five principles for good governance, which are transparency, participation, accountability, effectiveness, and coherence. These principles also apply to the CFP [Griffin, 2010]. Good governance in the CFP requires a clear definition of responsibilities at Union, regional, national and local level, the use of best available scientific advice, following a long-term perspective, administrative cost efficiency as well as taking into account regional disparities and consistency with other EU policies [European Parliament and Council of the Eurpean Union, 2013]. In the following part we analyse how a mismatch between scientific and management area may violate the principles of good governance in different respects. 


\section{Loss of transparency and coherence}

Transparency refers to a policy process that can be followed and understood by the public, while coherence implies consistency across sectoral boundaries [Heldeweg, 2005, Griffin, 2008]. A mismatch as discussed in Section 1.3.2 requires that - under defined conditions - the scientific TAC needs to be converted into the agreed management TAC. Since the areas are not equivalent, it needs to be decided how to calculate and allocate the TAC from the scientific area. So far, there is no clearly defined process how this should be done. So far, the conversion process occurs behind closed doors in the AGRIFISH meetings. Thus, it remains a black box which factors steer the conversion. Agreement on the conversion can involve trading political favours between countries within the realm of fisheries. Since the AGRIFISH meetings are between fisheries and agricultural ministers of the member states [Carpenter et al., 2017] such trading can also extend to other policy areas such as agriculture. This, in turn, goes at the expense of transparency and coherence. It also violates the principle of clear separation of responsibilities between member state and the EU. Ultimately, the lack of transparency and the deviation from predefined institutional rules may, in the long term, hamper cooperation between members states. Moreover, it can undermine public trust in the functioning of EU institutions [De Vos and Van Tatenhove, 2011].

\section{Loss of accountability}

Given the opaque process of converting the scientific TAC into the agreed TAC, and the risk of mismatches between both, it remains intransparent for the public who is responsible for the setting of the agreed TAC. The accountability of the distribution of quotas is further reduced if member states of the European Union engage in quota swapping. Quotas assigned to one country through the relative stability key can be swapped with other member states. There are rules on how this is to be done but the process is still complex and therefore difficult to follow for outsiders [Hoefnagel et al., 2015]. This is further convoluted by the fact that the quota that is agreed on on paper is higher than the potential catch in that area, often referred to as 'paper fish'. If an assigned quota is not fished by the country because it is too high to be profitable, countries use them to swap with other countries or use them as currency to negotiate additional quotas for different fish stocks. It is expected that a potential mismatch of scientific and management area aggravates the problem of 'paper fish', and also undermines accountability. While the quota swaps satisfy principle of administrative cost efficiency in the short run, there is a risk that they undermine accountability and also trust in the long run.

\section{Reduced effectiveness of sustainable fisheries management}

The CFP has the clear goal to manage fish stocks sustainably, so policies should be implemented in a timely and effective manner. There are various reasons why fisheries 
management is expected to be less effective if there is a mismatch between areas. The management of fish stocks is based on reference points which typically set management targets as well as safe biological limits of harvesting. These reference points are calculated for a given stock in a fixed geographical location. If the fish stock shifts out of this predefined area the reference points are no reliable tools for management anymore. As a result, there is a risk of either overexploiting or underexploiting the stock, both leading to economic losses in the long run [Link et al., 2011]. In particular, if the fish moves out of a management area, there is a risk of overfishing, as the stock can now also be caught outside that area. This could imply that the quotas are fully fished in the management area and on top of that fished in neighbouring management areas [Pinsky and Fogarty, $2012]$.

The EU introduced a landings obligation in 2017 which means that everything that has been caught also needs to be landed [Borges, 2018]. This has implications for mismatches between scientific and management areas, since stocks that migrated into another region might be caught there as by-catch. Since the quota in these areas may be low, stocks can become a 'choke species'. This implies that vessels either have to halt fishing activity even if they still have quota for the target species, or discard the fish illegally [Baudron and Fernandes, 2015, Baudron et al., 2019]. If the stock is no longer (exclusively) located in the management areas, and fishers are aware of this, they may be inclined to fish the stock in the part of the scientific area that is not covered by the management area. In such case, they would still have to take 'accounting trips' to the management area in order to camouflage that the catch was caught outside that area. These actions of behaviour impede a successful long-term management of the fish stocks. They also undermine the principles of effectiveness, accountability, as well as transparency and coherence.

\subsection{Resolving the institutional mismatch - The horse mackerel case}

In European fisheries management mismatches between scientific and management areas are not uncommon [Carpenter et al., 2017]. Moreover, as discussed above, they can be expected to become more relevant in the future due to climate change [Pinsky and Fogarty, 2012]. So far, there has been, to the best of our knowledge, only one case in the European Union - i.e. the case of horse mackerel - in which the management area has been adjusted to the scientific area. The main reason for a mismatch of the scientific and the management area in this case was new genetic information. It became apparent that two stocks of the same species had been genetically misspecified. We use this case 
as an example to evaluate the process and to exemplify different obstacles associated with resolving the mismatch. We discuss the process in light of the governance principles introduced before.

\subsubsection{Background of the mismatch}

The two Horse mackerel stocks for which the management areas were adjusted are the North Sea stock (along the coasts of France, Germany, Denmark, Sweden, Norway, and the United Kingdom) and the Western stock (along the coasts of France, Norway, Ireland, and the United Kingdom).

The first scientific assessment that became publicly available for those stocks is from 1999 in which ICES pointed out that the management areas for the North Sea as well as the Western stock do not match the scientific areas ${ }^{1}$ [ICES, 1999a]. The management area for the Western stock did not cover the division IIa and IVa, but did cover all of division VII while the scientific area did not include division VIId [Council of the European Union, 1999, ICES, 1999a]. Hence, the scientific TAC for the North Sea stock included the division VIId but excluded the division IIa and IVa [Council of the European Union, 1998, 1999]. Figure 5.4.1 provides an overview of the three divisions which were to be changed to realign scientific and management areas. The first publicly available assessments for the North Sea and the Western stocks already indicated a lack of transparency and effectiveness.

First, the status of the North Sea stock was a concern. ICES stated clearly that the rising exploitation rate of the stock and the extensive fishing of juveniles was problematic for the sustainability of the stock. Second, it was noted that the stock was migrating out of the North Sea and mingled with the Western stock [ICES, 1999b]. The Western stock was also considered to be outside safe biological limits. Also for that stock, there was a major concern about the increased fishing of juveniles in the areas VIIe\&f. Part of the overfishing of the stock was due to a distribution shift which lead to an increased fishing pressure since new fleets started to also fish the Western stock [ICES, 1999a]. The effectiveness of the management was severely undermined by the mismatch. From 2000 onwards, efforts were made to disentangle the horse mackerel stocks with the aid of genetic markers and biological tags [Abaunza et al., 2008]. While the differences between the northern boundary of the Western stock and the North Sea stock were clearly defined, uncertainty about the southern boundaries (VIId, English Channel) of the two stocks remained due to a lack of samples [Abaunza et al., 2008]. This lack of conclusive science turned out to be a big hindrance in the realignment of the management areas.

\footnotetext{
${ }^{1}$ The management area also did not cover the Western part of division IIIa, but this division was of no major concern to any party involved.
} 


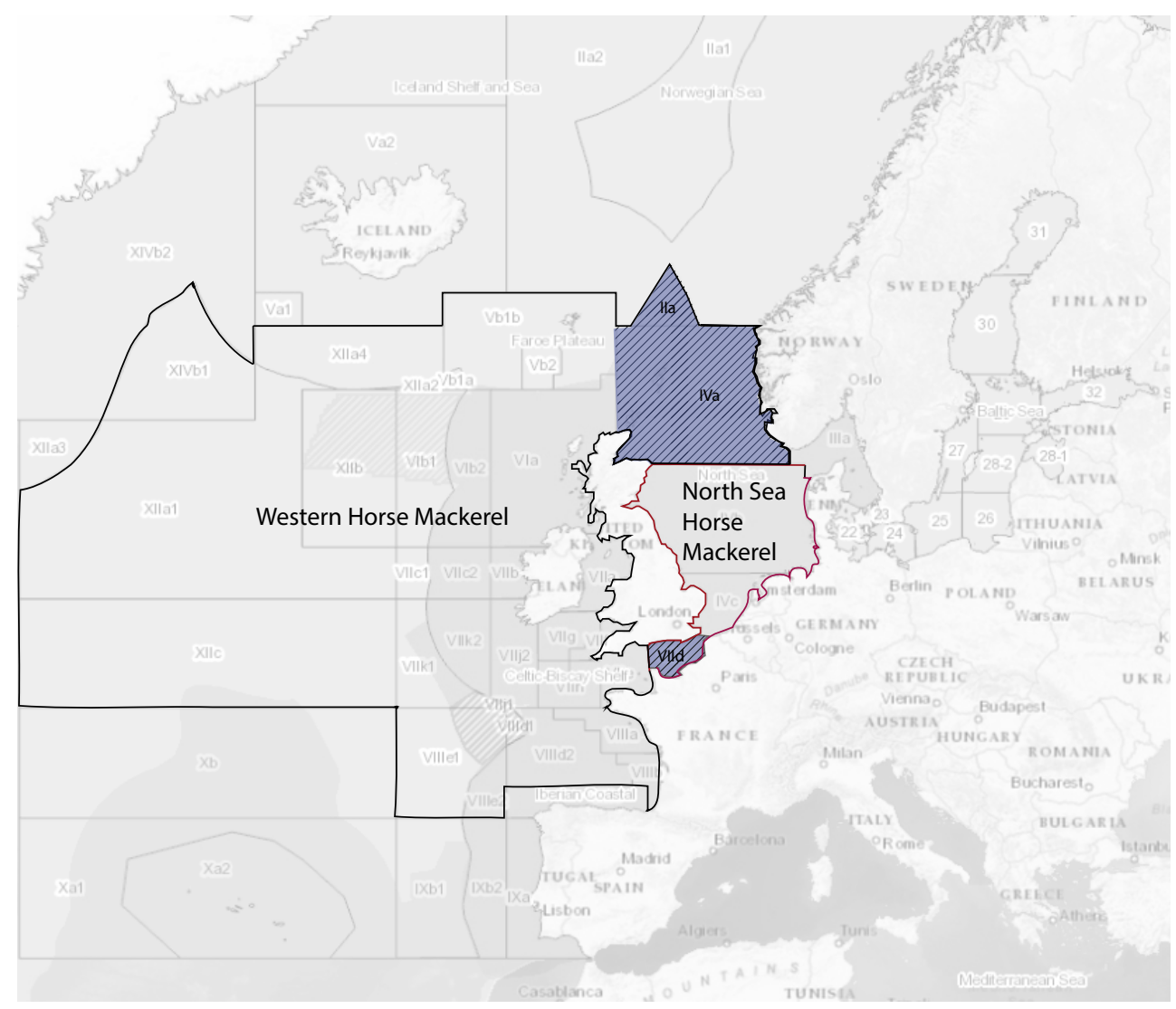

Figure 5.4.1: The mismatch between management and scientific areas for the Western and the North Sea stock of horse mackerel in 1999. The black line indicates the scientific area for the Western horse mackerel stock and the pink line the North Sea horse mackerel stock. The two purple areas indicate the regions where the management and the scientific areas were not aligned. Management considered the division IIa and IVa to be part of the North Sea stock and VIId as part of the Western stock.

\subsubsection{Process of the renegotiation}

The alignment of the scientific and management area was a lengthy process, starting in 1999 and ending in 2010 with aligned areas and recalculated national quotas. Table 5.4.1 provides a brief overview over the process and the involved actors. The EU upheld the principle of participation by involving stakeholders such as the industry seated in the Advisory Councils (ACs). In the following, we focus on the main steps that were taken over the years, and in particular on the recalculation of the national quotas. 
Table 5.4.1: Timeline of the main steps from the first official mismatch between scientific and management area for the North Sea and the Western stock of horse mackerel to the aligned areas and accepted quotas.

\begin{tabular}{|c|c|c|c|c|c|c|}
\hline 1999 & 2005 & 2006 & 2007 & 2008 & 2009 & 2010 \\
\hline $\begin{array}{l}\text { First offi- } \\
\text { cial record } \\
\text { of mis- } \\
\text { match } \\
\text { between } \\
\text { manage- } \\
\text { ment and } \\
\text { scientific } \\
\text { area }\end{array}$ & $\begin{array}{l}\text { Advisory } \\
\text { Council } \\
(\mathrm{AC}) \text { Ini- } \\
\text { tiative to } \\
\text { align areas } \\
\text { as part } \\
\text { of a mul- } \\
\text { tiannual } \\
\text { manage- } \\
\text { ment plan }\end{array}$ & $\begin{array}{l}\text { AC dis- } \\
\text { cussions } \\
\text { on how to } \\
\text { align areas }\end{array}$ & $\begin{array}{l}\text { Proposal of } \\
\text { alignment } \\
\text { send to } \\
\text { European } \\
\text { Commis- } \\
\text { sion and } \\
\text { ICES }\end{array}$ & $\begin{array}{l}\text { Biggest } \\
\text { problem } \\
\text { of imple- } \\
\text { mentation } \\
\text { of man- } \\
\text { agement } \\
\text { plan: con- } \\
\text { solidation } \\
\text { of scientific } \\
\text { and man- } \\
\text { agement } \\
\text { area } \\
\text { European } \\
\text { Commis- } \\
\text { sion asks } \\
\text { AC for } \\
\text { advice, but } \\
\text { AC refuses } \\
\text { to discuss } \\
\text { quotas }\end{array}$ & $\begin{array}{l}\text { European } \\
\text { Commis- } \\
\text { sion sends } \\
\text { proposal } \\
\text { of aligned } \\
\text { areas to } \\
\text { European } \\
\text { Council } \\
\text { without re- } \\
\text { distributed } \\
\text { quotas } \\
\text { Commission } \\
\text { circulates } \\
\text { proposal } \\
\text { for recal- } \\
\text { culation } \\
\text { of quotas } \\
\text { asking for } \\
\text { input of } \\
\text { member } \\
\text { states } \\
\text { Several } \\
\text { member } \\
\text { states voice } \\
\text { concerns } \\
\text { and provide } \\
\text { alternative } \\
\text { solutions }\end{array}$ & $\begin{array}{l}\text { First record } \\
\text { of aligned } \\
\text { manage- } \\
\text { ment and } \\
\text { scientific } \\
\text { area with } \\
\text { new quotas }\end{array}$ \\
\hline \multicolumn{7}{|c|}{ Involved Actors } \\
\hline EU, ICES & $\mathrm{AC}$ & $\mathrm{AC}$ & $\begin{array}{l}\text { AC, EU, } \\
\text { ICES }\end{array}$ & $\mathrm{AC}, \mathrm{EU}$ & $\begin{array}{l}\text { EU, France, } \\
\text { UK, } \\
\text { Nether- } \\
\text { lands, } \\
\text { Spain, } \\
\text { Ireland }\end{array}$ & $\mathrm{EU}$ \\
\hline
\end{tabular}




\section{Alignment of the scientific and the management areas}

In 2004 the Council of the European Union established the Advisory Councils (ACs) to allow for stakeholder participation in the CFP [Council of the European Union, 2004]. In 2005, the Pelagic AC agreed with ICES that the management area should be changed to match the scientific area [Pelagic AC, 2005]. The alignment of scientific and management area was to be part of a longterm management plan for horse mackerel for which the Pelagic AC kept pushing [Pelagic AC, 2006a]. In November 2006 the first unofficial draft of a management plan for horse mackerel was discussed and one of the main issues to be solved was the discrepancy between scientific and management area [Pelagic AC, 2006b, 2007b]. In July 2007 the Pelagic AC proposed the management plan to the European Commission which was based upon the scientific areas, thus assuming that management and scientific areas are aligned but without discussing the implications for the national quotas [Pelagic AC, 2007a]. Stakeholders as well as ICES agreed on the need to increase the effectiveness of the CFP by aligning the areas.

The implementation of the management plan proved difficult since the question of how to adjust national quotas due to a change in management areas had not been solved [Pelagic AC, 2008a]. The Commission wrote a non-paper, an unofficial and non-binding discussion paper, in which it discussed the calculation of new national quotas for the changed management areas. The Pelagic AC was asked to provide input but declined since they considered this a 'political issue, which should be left to the Member States to be resolved' [Pelagic AC, 2008b]. The Commission stressed that 'relevant stakeholders' would have to get involved in the coming weeks to find a solution but since there was no agreement on the new distribution key yet, the TAC and the corresponding management area for 2009 would be the same as in 2008 [European Commission, 2009b].

In April 2009, the Commission sent the proposal for the multiannual management plan of horse mackerel to the Council of the European Union without having solved the recalculation of national quotas. The proposal stated that 'the management TAC shall be calculated taking into account recent scientific advice on appropriate catch levels' [European Commission, 2009a]. In the annex of the proposal, the Commission presented the problem of the mismatch. The Commission pointed out that science-based management of the fish stocks was impossible given the mismatch. Moreover, the proposal stated which divisions had to be reassigned to other management areas to be in line with the scientific areas. The Commission also presented the changes in the agreed TAC (the TAC for the Western stock will be increased while the one for the North Sea stock will be reduced). What the Commission failed to address was how this would translate into national quotas [European Commission, 2009a]. Thus, while the Commission clearly acknowledged that the mismatch was in contrast to the good governance principle of effectiveness, the 
failure to make use of the best available scientific advice, and the resulting problems of implementing a long-term management strategy, there was still no clear path on how to solve the issue.

\section{Recalculation of the quotas}

While the official proposal did not quantify the new national quotas, the Commission circulated a non-paper (DS 621/09) among the member states in which the exact calculation was discussed. The Commission proposed to use the 10 year period between 1997 - 2006 as basis for the calculations. The North Sea stock was used to clarify the process.

The recalculation of the quota for each member state meant that agreement needed to be reached on a new sharing rule of the agreed TAC which proved to be complex. While the Commission stated that it 'calculates the fishing possibilities that each MS [member state] has in the average catches in the division to be transferred', this principle was not applied. The benchmark of what was fished under the old management regime could be based on either calculating the average quota per country, or average catch, which were different (see table 5.A.1). Using catches as a benchmark for calculating the new relative stability key would probably have been more transparent, since it would reflect the catches after quota-swapping and without quota that only existed on paper, the so-called 'paper fish'. Using the average quota as a basis would ensure that the new sharing rule was closer to the old one and perhaps easier to implement. While the realignment of the areas would increase transparency and effectiveness of the CFP, the recalculation of the relative stability key was still a hurdle that needed to be taken.

The Commission proposed to calculate the average fishing possibilities per member state and division. The idea was to transfer national fishing possibilities per division to the new management area (fishing possibilities of VIId are added, fishing possibilities of IVa and IIa are deducted from the average quota in the old North Sea management area) [European Commission, 2008]. The Commission asked for input of the member states. Depending on the fishing behaviour of a country there was a clear preference for either catches or quotas as basis for the calculations. Countries that did not fish their full quota advocated for quota as basis for the calculation while countries engaged in quota swaps to increase their national quotas advocated for using catches as the basis for calculation (see table 5.A.2 for input by member states). Ireland advocated to base the calculation on catch instead of quotas. This would have the advantage that the new relative stability key would be based on fish that had actually been caught by the countries. Thereby, 'paper fish' would be eliminated which would increase transparency considerably. In contrast, Spain was a strong supporter of basing the new quotas on the old quotas to keep the 
original relative stability key. The main concerns in regard to the proposal referred to the scientific accuracy of the division of the two stocks and whether quotas or catches should be used as a basis. In regard to VIId, several countries proposed a flexibility clause to be able to catch part of the Western under the North Sea quota and/or part of the North Sea quota under the Western quota, depending on the time of the year. This request was granted as a political compromise, though it reduced transparency of the CFP. Division VIId highlights the importance of robust scientific advice for the management and its adaptation.

\subsubsection{Final relative stability key}

The first official quotas for 2010 were made public in January 2010 [Council of the European Union, 2010b]. France, Germany, the Netherlands, and United Kingdom had the right to declare $5 \%$ of their quota for the North Sea stock fished in division VIId under the quota for the Western stock. Denmark, Germany, France, Ireland, the Netherlands, Sweden, and the United Kingdom had the possibility to declare up to $5 \%$ of their quota for the Western stock fished in division IIa and IVa under the North Sea stock [Council of the European Union, 2010c, European Commission, 2010].

The redistribution of the divisions IIa, IVa, and IIVd were not without consequences for the relative stability key. Table5.4.2 shows the changes for the individual stocks. The main part of the TAC for the North Sea stock was and still is the quota for Denmark. Yet, the relative size of the Danish quota was reduced by around 20 percentage points. In contrast to Denmark, the Netherlands' share of the North Sea TAC was increased by about the same amount. The other countries kept their share more or less constant with maybe a 1 or 2 percentage point change. The changes to the relative stability key in the Western stock were smaller. While Ireland increased its share by about 3 percentage points, the Dutch share decreased by about 5 percentage points. Combining the two quotas it becomes apparent that the relative stability key remained more or less stable (table 5.4.2). The biggest decrease in quota shares was experienced by Denmark with -1.589 percentage points while Ireland was the country with the biggest increase in quota $(+0.248$ percentage points). So while we do see an adjustment in the management areas to match the scientific areas, none of the countries had to give up a lot of its quota for horse mackerel. It seems that the guiding principle was 'to focus most on minimizing short-term losses and maintaining agreed quota shares' [Schwach et al., 2007]. The final compromise was accepted, so it can be seen as a success, though it was also a missed opportunity to establish a more transparent and effective system on how to handle adaptations within the system. The horse mackerel case could, finally, be resolved because it only required a division of biomass (North Sea and Western horse mackerel) into two quotas. Given the stickiness of the institutions involved, a case which also involves a re-distribution of stocks between countries will likely be much more challenging, since it can be expected 
Table 5.4.2: Changes in the relative stability key for the North Sea stock and the Western stock. Numbers indicate percentage of total quota per fish stock and year (rounded). We use the official quotas to calculate the relative stability key for the years 2008 [Council of the European Union, 2008] and 2010 [Council of the European Union, 2010a]. We see that while there were changes in the single stock distribution, the relative share for both stocks did not change much (biggest difference DK loosing $1.6 \%$ ).

\begin{tabular}{lccccccc}
\hline \hline \multirow{2}{*}{ Country } & \multicolumn{2}{c}{ North Sea } & \multicolumn{3}{c}{ Western } & \multicolumn{3}{c}{ Stocks combined } \\
& $\mathbf{2 0 0 8}$ & $\mathbf{2 0 1 0}$ & $\mathbf{2 0 0 8}$ & $\mathbf{2 0 1 0}$ & $\mathbf{2 0 0 8}$ & $\mathbf{2 0 1 0}$ & $\Delta$ \\
& $\%$ & $\%$ & $\%$ & $\%$ & $\%$ & $\%$ & \\
\hline Belgium & 0.156 & 0.109 & 0 & 0 & 0.028 & 0.024 & -0.004 \\
Denmark & 67.709 & 47.601 & 9.073 & 9.938 & 19.714 & 18.126 & -1.589 \\
Germany & 5.106 & 4.202 & 7.252 & 7.755 & 6.863 & 6.982 & 0.119 \\
Spain & 0 & 0.885 & 9.904 & 10.577 & 8.107 & 8.470 & 0.363 \\
France & 0.107 & 3.949 & 4.792 & 3.991 & 3.942 & 3.982 & 0.040 \\
Ireland & 3.930 & 2.994 & 23.610 & 25.826 & 20.039 & 20.863 & 0.824 \\
Netherlands & 10.983 & 28.659 & 34.601 & 31.114 & 30.315 & 30.580 & 0.265 \\
Portugal & 0 & 0.100 & 0.958 & 1.019 & 0.785 & 0.819 & 0.035 \\
Sweden & 2.015 & 0.171 & 0 & 0.428 & 0.366 & 0.372 & 0.006 \\
United Kingdom & 9.995 & 11.328 & 9.808 & 9.352 & 9.842 & 9.782 & -0.060 \\
\hline Agreed TAC (in t) & 37230 & 43854 & 167920 & 157881 & 205150 & 201735 & \\
\hline \hline
\end{tabular}

that some countries will have to give up a part of their quota while others will receive additional quota.

\subsection{Discussion}

So far, the common fisheries policy of the EU has been relying on a rather static governance system. While it adheres to the good governance principles of administrative cost efficiency, it lacks a clear and transparent mechanism of adjusting the management TAC when new information on the size and location of stocks has become available. This institutional stickiness can induce a mismatch between the scientific and the management area. Besides hampering EU institutions to adequately react to ecological changes with sufficient flexibility, it can also negatively affect the relations between EU member states and other countries. For instance, with stocks shifting towards the poles, conflicts about fish can arise with non-EU countries such as Norway and Iceland.

Obviously, overcoming the stickiness is challenging in several respects. However, this paper has provided several important lessons that may help overcoming those challenges. First, information can reflect most recent scientific insights but is less valuable to 
decision makers in the policy arena. Hence, a change of the scientific area may be considered 'best' by researchers (e.g. in ICES) but be qualified 'sub-optimal' in terms of management goals and policy preferences. As the horse-mackerel case illustrates, changing procedures to account for the best scientific advice is very time- and resource consuming since the adjustments are done on a case-by-case basis rather than through a predefined process. This is neither efficient, nor does it ensure good long-term planning. In line with the four pillars of ICES as explained in Section 1.2.1, the challenge is to broaden the ambition of providing 'best' science towards providing 'most useful' advice that is tailored to governance needs, which could be based on species rather than on stocks.

Second, defining a mechanism for adjusting management areas also requires a debate about when new information should trigger adjustments. Considering that even the best and most up-to-date scientific knowledge remains subject to different types of uncertainty, and considering the distributional impacts of adjustments of management areas, new information has to be sufficiently robust to warrant a change in the management system. But the level of robustness is often subjective and open for interpretation.

Third, the expected distributional impacts of any changes, i.e. change in quota, have been the overriding institutional constraint, potentially stalling any meaningful attempts to create a system where individual countries are worse off even if it is collectively beneficial. Especially in a multi actor setting like the EU, establishing predefined rules would help to not get bogged down in lengthy negotiations and unclear responsibilities as laid bare in the horse mackerel case. ICES could play a larger role in making distributional implications transparent in their advice, also when proposing a change in the management system.

Fourth, a predefined mechanism bears the risk to create one-size fits all solutions and ignore their context-dependence. This requires to think ahead about which components of such mechanism should be kept flexible and which should be cast in stone. Closely related to this, and as illustrated by the horse mackerel case, countries tend to argue opportunistically, trying to create the most beneficial agreement for their national fishers. Hence, a system for flexible adjustments of management areas should contain a 'veil of ignorance', i.e. EU member states should adopt decisions without knowing whether it will apply to a fish stock in their own portfolio. In general, using catches as basis for the calculations would improve transparency since it would respect the idea of giving rights to those who have been traditionally fishing, and avoiding the problem with 'paper fish', i.e. quota that only exists on paper. A mechanism to compensate losers of a potential change may help to make an agreement that avoids too severe distributional repercussions. 
Fifth, having a predefined mechanism that steers the redistribution of the newly agreed TAC among EU member states would eliminate the need for deals behind closed doors in the AGRIFISH meetings. Being able to pinpoint on who is responsible within the system would increase trust in the institution and thus establish a stronger sense of legitimacy of the policy. Also, establishing a dynamic system that continuously aligns the management area to the scientific area would eliminate incentives to mask fishing outside designated locations, which may happen if the best fishing locations are not where vessels hold their quota. The horse mackerel case - as complex and convoluted as it was - has been the only case in the EU where the management areas have finally been adjusted. In the context of climate change dynamics future cases will probably be even more complex and difficult if the current regime will be maintained. While we can only speculate about the overall welfare effects, a predefined mechanism for adjusting management areas would increase transparency, decrease administrative costs, and would therefore improve the efficiency and effectiveness of the CFP. This is a pre-requisite for building trust in the European fisheries policy and longterm management.

\subsection{Conclusion}

Climate change impacts fisheries management and will continue to do so. Yet, institutions may be sticky and do not respond swiftly and appropriately to those ecological changes. In this paper, we investigate the case of a potential mismatch between scientific areas and management areas. Originally, the best available science referred to the most detailed knowledge on a fish stock that at the same time was exactly the knowledge needed for the system to run smoothly. Also, the principle of separating scientific advice from the realm of politics and management (see figure 5.2.1) was well intended, as it strengthens transparency and the independence of advice, and is an important cornerstone of sustainable fisheries management. However, in this paper we have indicated a potential weakness, as there is no mechanism in place to ensure that institutions co-evolve with the ecosystem that is governed. As a result, over time, new scientific insights have emerged that cannot be translated into management because of too sticky institutions. This stickiness leads to a violation of the self-imposed principles of good governance, especially effectiveness, transparency, and accountability. The biggest direct danger is probably the erosion of trust of stakeholders and the broader public in the fisheries system, which is notoriously difficult to built and almost impossible to recover if lost. We used the realignment of the management areas of the North Sea and Western horse mackerel stocks as a case to gain some insights in the process and the associated obstacles of changing management areas. We see that the negotiations are slow (ten years from the first officially documented mismatch between scientific and management area) and primarily driven by distributional questions about how to divide the total quota. 
Considering that the European Union provides a framework for countries to cooperate on fisheries management with the declared aim of achieving sustainability, it is plausible that those distribution shifts are even harder to manage in areas where such an institutional setting is missing. But what is also clear is that the current system is not equipped to deal with distribution changes in a coherent and transparent way. The current system is too static to adapt to these changes. What would be urgently needed, therefore, is a streamlined process on how to adapt management and scientific areas and the corresponding national quotas following-up on new and better knowledge on stock composition and spatial distribution. 



\section{Appendix}

\section{A Appendix}

Table 5.A.1: Commission proposal on how to calculate the new quotas for the agreed TAC of Horse Mackerel in the North Sea [European Commission, 2008].

\begin{tabular}{|c|c|c|c|c|c|c|c|}
\hline & $\begin{array}{l}\text { Average } \\
\text { Quota } \\
\text { in old } \\
\text { Northern } \\
\text { manage- } \\
\text { ment area } \\
\text { (tons) }\end{array}$ & $\begin{array}{l}\text { Quota to } \\
\text { be trans- } \\
\text { ferred from } \\
\text { Western } \\
\text { area (aver- } \\
\text { age catches } \\
\text { VIId) }\end{array}$ & $\begin{array}{l}\text { Quota to be } \\
\text { transferred } \\
\text { to West- } \\
\text { ern area } \\
\text { (division } \\
\text { IVa) }\end{array}$ & $\begin{array}{l}\text { Quota to be } \\
\text { transferred } \\
\text { to West- } \\
\text { ern area } \\
\text { (division } \\
\text { IIa) }\end{array}$ & $\begin{array}{l}\text { Net trans- } \\
\text { fer, adding } \\
\text { the ra- } \\
\text { tios of the } \\
\text { transfer } \\
\text { quotas to } \\
52599 \mathrm{t}\end{array}$ & $\begin{array}{l}\text { New quotas } \\
\text { for the new } \\
\text { manage- } \\
\text { ment area } \\
\text { (IVbc and } \\
\text { VIId) }\end{array}$ & $\begin{array}{l}\text { New quota } \\
\text { key }\end{array}$ \\
\hline NL & 5896.35 & 6838.808 & 3034.995 & 92.258 & $7.06 \%$ & 9607.902 & $21.61 \%$ \\
\hline $\mathrm{IE}$ & 2109.2199 & 4666.556 & 1085.667 & 33.002 & $6.75 \%$ & 5657.106 & $12.72 \%$ \\
\hline ES & 0 & 1957.565 & 0 & 0 & $3.72 \%$ & 1957.565 & $4.40 \%$ \\
\hline FR & 57.858 & 947.198 & 29.781 & 0.905 & $1.74 \%$ & 974.370 & $2.19 \%$ \\
\hline PT & 0 & 189.447 & 0 & 0 & $0.36 \%$ & 189.447 & $0.43 \%$ \\
\hline $\mathrm{DE}$ & 2740.407 & 1433.436 & 1410.555 & 42.878 & $-0.04 \%$ & 2720.411 & $6.12 \%$ \\
\hline DK & 36345.909 & 1793.377 & 18708.134 & 568.693 & $-33.24 \%$ & 18862.459 & $42.41 \%$ \\
\hline UK & 5365.098 & 1938.610 & 2761.548 & 83.946 & $-1.72 \%$ & 4458.214 & $10.03 \%$ \\
\hline $\mathrm{BE}$ & 84.158 & 0 & 43.3184 & 1.316 & $-0.08 \%$ & 39.523 & $0.09 \%$ \\
\hline Total & 52599 & 19765 & 27074 & 823 & $-15,46 \%$ & 44467 & $100 \%$ \\
\hline
\end{tabular}




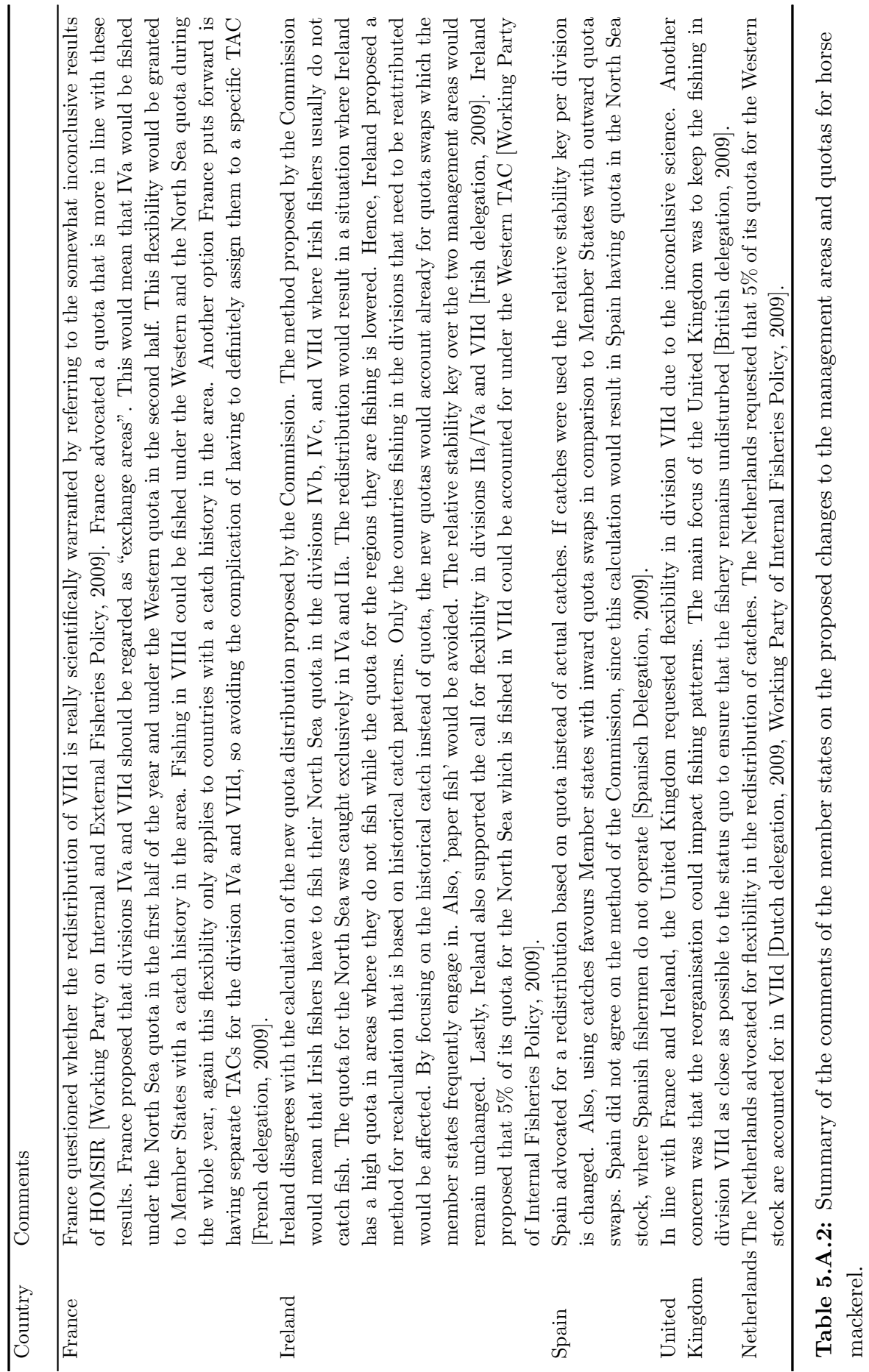


Chapter 6

Synthesis 


\subsection{Introduction}

The study of natural resource management has a long tradition, analysing the different management challenges across all scales, from individuals to households, villages, countries, to supranational institutions [Fulton et al., 2011, Østhagen et al., 2020, Spijkers and Boonstra, 2017, Mendenhall et al., 2020, Mina et al., 2016, Cason and Gangadharan, 2015, Noussair et al., 2015, Ratner and Allison, 2012, Symes and Hoefnagel, 2010, Symes, 2007, 2009, Dankel et al., 2012, Soomai, 2017]. Natural resources are part of a social-ecological system [Ostrom, 2010, 2009, Berardo and Lubell, 2016, Carlisle and Gruby, 2019]. To fully understand the system, knowledge about the resource and its dynamics is needed as well as an understanding of human behaviour, and a grasp on the institutions (formal as well as informal) governing the interactions between resource and humans. I focus on fisheries management to analyse parts of the social-ecological system in depth. Challenges in fisheries management are the different uncertainties. There are uncertainties associated with the natural resource such as the estimation of abundance, the growth rate, well as as the determination of the exact location [Lee et al., 2012, Walters, 2004, Kehler et al., 2002, Myers and Barrowman, 1995, Marshall et al., 2006, Methot et al., 2011, Deroba and Miller, 2016, Francis, 2016, Soria et al., 1996, Fallon et al., 2015]. These uncertainties play a role for formal as well as informal institutions managing fisheries. Formal institutions like the European Union need to account for these uncertainties when determining the national fishing quotas [Symes, 2007, Wilson, 2010, Galland et al., 2018, Hauge, 2011, Link et al., 2012]. Informal institutions, often relying on cooperation between fishers, also need to consider this lack of knowledge. Yet, there are further uncertainties to be considered in these informal institutions. When relying on the cooperation between a group of fishers, fishers have to reflect on how cooperative the other ones will be [Fehr and Fischbacher, 2003, Fischbacher et al., 2012, Charness and Villeval, 2009, Bouma et al., 2008, Ockenfels and Weimann, 1999, Gneezy et al., 2015, Anderson et al., 2004, Kocher et al., 2015]. Will they try to achieve the best outcomes for the whole group of fishers (social optimum) or will they try to maximise individual benefits only. This social uncertainty is typical for a social dilemma in which individual versus group interests need to be balanced. Cooperation can be even more complicated if the strategy to reach the social optimum is not clear ex-ante but rather depends on the cooperative level of the other fishers [Dannenberg et al., 2015, Tavoni et al., 2011, Barrett and Dannenberg, 2014, İriş et al., 2019, Au, 2004]. Both, formal and informal institutions have to handle ecological changes, e.g. distribution shifts of fish stocks or changes in the growth rate, caused by climate change [Reiss et al., 2009, Spijkers and Boonstra, 2017, Mantilla, 2018]. This interplay of factors is governed by sets of social rules and norms. Focussing on formal and informal institutions and their ability to provide a framework within which a successful resource management can take place, yields insights into reasons for shortcomings in natural resource management. Identifying these weaknesses can help to improve the management system. 


\subsection{Overview of results}

An exhaustive analysis of the various challenges arising from the interplay between human behaviour, external influences, and institutions would be beyond the scope of this thesis. I therefore focus on selected challenges that are not only interesting from a methodological perspective, but also particularly pressing from a social and environmental perspective. I use a combination of experimental economics, surveys, and econometrics (primary and secondary data) to analyse the behaviour of resource users and experts in informal and formal institutions. The main topics explored are the role of information and uncertainty in fisheries and in how far these influence human behaviour. Of particular interest is the study of cooperative behaviour. This is often studied in linear settings, yet most natural resources have nonlinear dynamics. I concentrate on thresholds since these are widely applicable to natural resources but also to climate change scenarios [Gibbs, 2008, Scheffer et al., 2003, Young, 2017, Martin et al., 2020, Sguotti et al., 2019, Winter et al., 2020, Milinski et al., 2008, Barrett and Dannenberg, 2012]. To analyse cooperation under uncertainty of fishers I use experiments. The research was done in rural Cambodia with fishers and farmers who rely on cooperation on a daily basis to manage natural resources. I start with a comparison between the standard linear public good game and a threshold public good game to assess in how far results from linear public good games might be applicable to the management of resources with a threshold. Chapter 2 explores how cooperation in informal institutions is impacted by uncertainty and which strategies resource users use to determine how cooperative they are. In general, decision-making in a linear public good game is less complex than in a threshold public good game since there is only social uncertainty (how much do the other resource users contribute) present. In the threshold public good game there is an additional layer of uncertainty, since the social optimal contribution level depends on the contributions of the other resource users. I refer to this as strategic uncertainty. I find that if there is only social uncertainty, individual preferences such as risk aversion, cooperative behaviour types, as well as trust explain a large part of the contribution level. With the added complexity of strategic uncertainty, these factors become less important. Rather, people tend to reduce these complex cooperation problem into a coordination problem. The threshold point seems to act as a focal point, so people coordinate contributions intuitively to reach the threshold by equal contributions.

The entanglement of uncertainty and information is a frequent feature of fisheries management. Chapter 3 scrutinizes how fishers cooperative behaviour changes depending on the way the management problem is presented to them. Further, I analyse which impact the different decision frames have on the anticipated cooperative behaviour of the other fishers. To analyse the influence of information on cooperation under uncertainty, I manipulate the presentation of the decision problem (framing) in the threshold public 
good game. I run the threshold game as a public good and a public bad game. While some natural resources are usually associated with a public good (e.g. maintaining an irrigation infrastructure), others are frequently regarded a pubic bad (e.g. avoiding a fish stock collapse). While previous framed threshold games have been done in the lab [Sonnemans et al., 1998, Fosgaard et al., 2014, Kotani et al., 2008, 2014, Iturbe-Ormaetxe et al., 2011], I show that a framing effect in threshold games also exists outside the lab for a population that is used to managing nonlinear natural resources on a daily basis. People are more cooperative if they hope to achieve a public good in contrast to avoiding a public bad. At the same time they seem to rely on the other resource users to be more cooperative when trying to avoid negative consequences than when achieving a joint positive result. The effect of framing on cooperation is in line with the results published earlier in the literature; the effect that framing has on people's beliefs, however, is novel. Previous framed linear public good games found that believed contributions of the other research users are higher in the public good frame [Dufwenberg et al., 2011] just as in framed threshold public good games [Sonnemans et al., 1998, Fosgaard et al., 2014]. Neither the literature nor the experimental setup provide an explanation for the observed framing effect on beliefs. Thus, further research is needed to determine the channels how framing impacts beliefs and how sensitive these effects are to culture and social norms.

Decision-making under uncertainty poses different difficulties in informal and formal institutions. Formal institutions have clear rules on how to manage the natural resources. The European Union has a sophisticated science-based management system to distribute quotas for fish stocks between its member states [Stange, 2017, Cash and Clark, 2001]. An essential component of this management system are fish stock assessments. These stock assessments are conducted on an annual basis and provide estimates on the abundance of the fish stock and how many tons of fish in total are to be shared out as quota to the different member states [European Parliament and Council of the Eurpean Union, 2013, Stange, 2017, Casey et al., 2016, Delaney and Hastie, 2007, Schwach et al., 2007, Daw and Gray, 2005, Cardinale et al., 2017, Carpenter et al., 2016, Wilson, 2010, Holm and Nielsen, 2004]. In chapter 4 the focus is on the experts conducting these stock assessments. Up to now there is hardly any research on how the stock assessment experts make decisions in a realm of such high uncertainties and also high stakes. Chapter 4 zooms in on the role of experts in fish stock assessments and how their intuitive judgement calls are influenced by heuristics. By compiling the stock assessments, including the full time series provided by the models, I analyse which parts of the assessments are influenced by intuitive judgement calls of experts. When information is uncertain, experts use heuristics. I find a strong overemphasis of previous results, whenever there is uncertainty. This overemphasis is caused by anchoring. The overemphasis of previous results is particularly strong when fish stocks are considered to be endangered. Overall, there is a pattern that fish stock assessment experts prefer to be cautious when uncertainties are high to avoid negative 
impacts on fish stocks. I show that stock assessments are indeed influenced by intuitive judgements of experts. Yet, further research is needed to test which factors apart from anchoring and external pressure influence expert judgements and which are the main drivers.

These stock assessment are the backbone of the European common fisheries policy. They provide the total allowable catch for a fish stock which is to be divided into national fishing quotas. The stock assessment refers to a spatial area, just as the division of the total allowable catch into national quotas is tied to a predefined area. In chapter 5 I use the spatial aspect of the management system to assess how the EU is handling new ecosystem dynamics caused by climate change. Of particular interest is the assessment of the flexibility of the EU to incorporate new scientific information into the management process. Using fish stock distribution changes as an example it becomes clear that the institutional dynamics are slow and path-dependent, which Young [2010] describes as 'sticky institutions'. Sticky institutions 'often remain in place long after mismatches between regimes and the biophysical and socioeoconomic settings with which they interact become severe and widely understood, at least among specialists' [Young, 2010]. The EU is too sticky to adjust the definition of the management areas to match the fish stock distribution. This inflexibility is mainly caused by the relative stability principle which defines how the total allowable catch is divided into national quotas. The value of the scientific information provided by the fish stock assessment experts is reduced since the static setting of the EU does not allow to make full use of the information in management. As a result, the EU violates its self-imposed good governance principles. Given that the distribution shifts will continue it is essential that the EU adjust its management system to allow for a smooth integration of this new information. One way of achieving this could be to agree on an institutional level on the mode of recalculation of the quotas for when climate change induces fish stock distribution shifts out of the predefined management area.

A key objective of this thesis is to gain insights into individual decision-making under uncertainty in fisheries management. By applying a combination of experimental economics, surveys, and econometrics I find that resource users as well as experts have mechanisms on how to handle the uncertainty inherent in fisheries management. If the uncertainty is due to the actions of the other members with whom the resource is managed (in a linear public good game), I find that social norms and individual preferences play a strong role in steering cooperation. This is in line with previously reported results in the literature. If there is more than one kind of uncertainty (e.g. the threshold game with its strategic uncertainty), the resource users reduce the game to a coordination game. They focus on reaching the threshold. Thus, one coping mechanism with uncertainty is to reduce the complexity of the decision framework. If the game is reduced to 'reaching the threshold' people manage a pretty high success rate. In this 
case, the coordination overrides the impact of social norms and individual preferences observed in linear public good games to a large extent (chapter 2). In the experimental setup the size of the fish stock is known. In reality, it is impossible to know the precise size of a fish stock and its location. Yet, policy requires an exact estimate of stock, provided by fish stock assessment experts, in order to assign 'safe' quotas to member states which is hardly possible. Analysing the decision-making of these experts has been neglected so far and my study is only a starting point for this kind of research (chapter 4). I find patterns in their intuitive judgement calls that are caused by stress and publicity, as well as anchoring. Clearly, experts providing stock assessments try to avoid estimation errors. By analysing human behaviour and different kinds of uncertainty (social, strategic, resource) it is clear that there is not only one way of handling uncertainty. Rather, I find three main coping strategies depending on the kind of uncertainty. If only social uncertainty is present people use social norms and individual preferences as guides. If also strategic uncertainty is present the complex cooperation problem is reduced to a more manageable coordination problem. In the case of inherent resource uncertainty, one strategy people follow is "better safe than sorry" and become very cautious.

Another objective of this thesis is to scrutinize the role of information in fisheries management. While chapter 2 analyses contribution strategies in linear and threshold public good games, chapter 3 focuses more on the role of information in fisheries management. I use framing to test to what extent the formulation of the management problem impacts its solution. I find higher success rates (reaching the threshold) in the public good framing than in the public bad framing. This effect is driven by two factors, i) the higher contributions in the public good framing and ii) the high expectations people place on the cooperation of the other fishers in the public bad framing. Here, the strategic uncertainty of the threshold game does play a significant role, since basing one's own contributions on the believed contributions of the other resource users has a very high chance of not reaching the threshold, if people overestimate the partners contributions (chapter 3). Overall, the threshold public good game is mainly influenced by the fact that people seem to use the threshold as a focal point for their contribution strategies and that the people who base their contributions an what they believe the other group members will contribute run the risk of overestimating these contributions in the public bad framing. Complementary to analysing individual behaviour in informal institutions, I explore formal institutions and their impact on natural resource management. Specifically, I analyse how the EU as an example for a supranational institution integrates new information regarding ecosystem dynamics in order to adapt decisions on the allocation of national fishing quotas among member states (chapter 5). Natural resources are inherently dynamic but climate change will accelerate these dynamics further. Thus, institutions are needed that are able to adapt to those changes in an effective way. Given that distribution shifts of fish stocks are already happening and 
are expected to continue to do so, I focus on the spatial aspect of the common fisheries policy. ICES, a scientific organization, is contracted to provide estimates of the total allowable catch of a fish stock to the EU. If the fish stock shifts towards the pole, the total allowable catch (TAC) also applies to a new area (the one where the stock is) but it has become apparent, that the EU fails to properly account for those shifts. Rather, the TAC is shared via a rule of thumb between the countries that have traditionally quotas for this fish stock. By failing to account for those distribution shifts, the EU ignores willingly part of the scientific information bordering on the absurd given the importance the EU attaches to the idea of employing a science-based management system.

\subsection{Contribution, limitations, and implications for future research}

This thesis contributes to the vast research on natural resource management by zooming in on the entanglement of uncertainty, information, and behaviour. I show that humans have different mechanisms on how to handle uncertainty, depending on the kind of uncertainty they encounter. Further, getting as much information as possible of the best scientific standard is crucial in an uncertain environment like fisheries management. Especially in fisheries management, uncertainty and information are co-dependent since the uncertainty cannot be resolved completely. While in fish stock assessments information (the advice feeding into the management system) is created out of uncertain data points, these fish stock assessments are then used to guide policy. The use of information on an institutional level is far from ideal since the EU is lacking the flexibility to incorporate scientific information if it is not provided in a standardised way. Lastly, I show that the framing of a resource management problem influences cooperation and that this effect also exists outside the lab.

Yet, there remain a lot of open questions still to be analysed. My research on threshold public good games so far only focuses on certain thresholds. Yet, it has been shown that the uncertainty of thresholds, or the uncertainty of the damage to be experienced when failing to reach the threshold, reduces cooperation [Dannenberg and Gallier, 2019, Dannenberg et al., 2015, Kotani et al., 2014, McBride, 2010, Suleiman et al., 2001, Milinski et al., 2008, Barrett and Dannenberg, 2014]. While the effect of an uncertain threshold in a framed experiment has been analysed earlier [Kotani et al., 2014, Iturbe-Ormaetxe et al., 2011, Cartwright et al., 2019], these were done in a binary setup. Thus, either people contribute a predefined amount to the public good or they contribute nothing. What remains to be explored is the effect that threshold uncertainty has in a framed game with discrete distribution steps like the one designed 
for this thesis. By allowing people to choose their contribution level freely, we can assess their cooperative behaviour in a more realistic setting than in the previously used "all or nothing" decision framework. By only having one threshold level (50\% of endowment) in the experimental setting I am not able to differentiate clearly the effect of coordination (the threshold acts as a focal point) and the natural tendency to contribute around $40-50 \%$ of the endowment [Ledyard, 1995, Fehr and Fischbacher, 2003, Burton-Chellew and West, 2013, Fischbacher et al., 2001]. While the results from the linear public good game indicate that our study population does not use the 40 - $50 \%$ of endowment as a main contribution strategy, further research is needed that looks at the effect of different threshold levels. Also, it has been shown that the size of the public good has an effect on cooperation [Dannenberg and Gallier, 2019]. This is particularly interesting in a framed threshold game to test for the effect of loss aversion.

By framing the beliefs in the threshold game, I found that the framing effect on contributions is in line with the previously reported results in the literature but the beliefs are not. In general, beliefs are often elicited but are not analysed in depth. While Dufwenberg et al. [2011] and Cubitt et al. [2011] elicit beliefs in a framed linear public good game, Sonnemans et al. [1998] and Fosgaard et al. [2014] elicit beliefs in a framed threshold game. While Cubitt et al. [2011] find no framing effect on beliefs, Dufwenberg et al. [2011], Fosgaard et al. [2014], Sonnemans et al. [1998] find that beliefs are higher in the public good treatment. Yet, these threshold games only allow for binary choices of contributing or refraining to contribute. The decision to be made in the experiment used in this thesis was more complex but also more realistic. The design used in this thesis does not allow to analyse how beliefs were formed. Thus, future research should focus more on determinants of beliefs and how they might be impacted differently, depending on the framing. In order to get the full picture, running a framed linear public good game with framed believes would provide useful to be able to clearly pinpoint to the different mechanism between the different framings as well as the different games (linear versus threshold). These studies should be done in the lab as well as in the field to account for the role of social norms and cultural differences in natural resource management.

Traditionally the focus has been on resource users when decision-making in fisheries management has been studied whilst the role of experts has been somewhat neglected. Yet, it has been established that experts and their judgements are essential in natural resource management and thus the potential biases need to be accounted for [Martin et al., 2012, McBride et al., 2012, Sinkey, 2015, Montibeller and Winterfeldt, 2015]. This analysis has been mainly lacking in fisheries management. While Chrysafi et al. [2019] made a start to analyse biases in fisheries experts decision-making when assessing data-poor stocks, the role of experts in standard fish stock assessments has, so far, been ignored. In this thesis I show that fish stock experts use intuitive judgement 
which distorts fish stock assessments systematically. This should be followed up by further research focussing on disentangling the different factors. Designing a set of experiments that allows to separate what exactly causes the anchoring (stress, reputational concerns, cognitive biases) will help to reduce these effects in expert judgements.

Neither resource users nor experts act in a void, rather, they are always embedded in institutional settings, formal or informal, that influence their behaviour, just as the institutions are shaped by humans. Understanding formal and informal institutions, their potential short-comings, as well as the interactions between different layers of the socialecological system should be on the top of the research agenda for this and next generations in natural resource management. Since natural resource management in social-ecological systems is strongly influenced by local and cultural conditions, focussing on understanding these conditions is urgently required to make natural resource use sustainable. 


\section{References}

M. Aanesen and C. W. Armstrong. The political game of european fisheries management. Environmental and Resource Economics, 63(4):745-763, 2016.

P. Abaunza, A. Murta, N. Campbell, R. Cimmaruta, A. Comesaña, G. Dahle, M. G. Santamaría, L. Gordo, S. Iversen, K. MacKenzie, et al. Stock identity of horse mackerel (trachurus trachurus) in the northeast atlantic and mediterranean sea: Integrating the results from different stock identification approaches. Fisheries Research, 89(2):196209, 2008.

L. R. Anderson, J. M. Mellor, and J. Milyo. Social capital and contributions in a publicgoods experiment. American Economic Review, 94(2):373-376, 2004.

J. Andreoni. Warm-glow versus cold-prickle: the effects of positive and negative framing on cooperation in experiments. The Quarterly Journal of Economics, 110(1):1-21, 1995.

W. Au. Criticality and environmental uncertainty in step-level public goods dilemmas. Group Dynamics: Theory, Research, and Practice, 8(1):40, 2004.

M. Barange, G. Merino, J. Blanchard, J. Scholtens, J. Harle, E. Allison, J. Allen, J. Holt, and S. Jennings. Impacts of climate change on marine ecosystem production in societies dependent on fisheries. Nature Climate Change, 4(3):211-216, 2014.

S. Barrett and A. Dannenberg. Climate negotiations under scientific uncertainty. Proceedings of the National Academy of Sciences, page 201208417, 2012.

S. Barrett and A. Dannenberg. Sensitivity of collective action to uncertainty about climate tipping points. Nature Climate Change, 4(1):36, 2014.

A. Baudron, T. Brunel, M.-A. Blanchet, M. Hidalgo, G. Chust, E. Brown, K. Kleisner, C. Millar, B. MacKenzie, N. Nikolioudakis, et al. Changing fish distributions challenge the effective management of european fisheries. Ecography, 2019.

A. R. Baudron and P. G. Fernandes. Adverse consequences of stock recovery: European hake, a new "choke" species under a discard ban? Fish and Fisheries, 16(4):563-575, 2015 .

R. Berardo and M. Lubell. Understanding what shapes a polycentric governance system. Public Administration Review, 76(5):738-751, 2016. 
O. Bodin, B. Crona, M. Thyresson, A.-L. Golz, and M. Tengo. Conservation success as a function of good alignment of social and ecological structures and processes. Conservation Biology, 28(5):1371-1379, 2014.

S. Bonanomi, L. Pellissier, N. O. Therkildsen, R. B. Hedeholm, A. Retzel, D. Meldrup, S. M. Olsen, A. Nielsen, C. Pampoulie, J. Hemmer-Hansen, M. S. Wisz, P. Grønkjær, and E. E. Nielsen. Archived dna reveals fisheries and climate induced collapse of a major fishery. Scientific Reports, 5(1):15395, Oct. 2015.

L. Borges. Setting of total allowable catches in the 2013 EU common fisheries policy reform: possible impacts. Marine Policy, 91:97-103, 2018.

J. Bouma, E. Bulte, and D. van Soest. Trust and cooperation: Social capital and community resource management. Journal of environmental economics and management, 56(2):155-166, 2008.

British delegation. 14738/09 PECHE 287 + ADD 1 - COM(2009) 553 final + Annexes, 2009.

M. A. Burgman. Trusting Judgements: How to Get the Best out of Experts. Cambridge University Press, Cambridge, 2015.

M. N. Burton-Chellew and S. A. West. Prosocial preferences do not explain human cooperation in public-goods games. Proceedings of the National Academy of Sciences, 110(1):216-221, 2013.

C. B. Cadsby and E. Maynes. Voluntary provision of threshold public goods with continuous contributions: experimental evidence. Journal of Public Economics, 71(1):53-73, 1999.

J. C. Cárdenas, L. A. Rodriguez, and N. Johnson. Collective action for watershed management: field experiments in colombia and kenya. Environment and Development Economics, 16(3):275-303, 2011.

J.-C. Cárdenas, M. A. Janssen, M. Ale, R. Bastakoti, A. Bernal, J. Chalermphol, Y. Gong, H. Shin, G. Shivakoti, Y. Wang, et al. Fragility of the provision of local public goods to private and collective risks. Proceedings of the National Academy of Sciences, 114 (5):921-925, 2017.

M. Cardinale, G. C. Osio, and G. Scarcella. Mediterranean sea: A failure of the european fisheries management system. Frontiers in Marine Science, 4:72, 2017.

K. Carlisle and R. L. Gruby. Polycentric systems of governance: A theoretical model for the commons. Policy Studies Journal, 47(4):927-952, 2019.

G. Carpenter, R. Kleinjans, S. Villasante, and B. C. O'Leary. Landing the blame: The influence of EU member states on quota setting. Marine Policy, 64:9-15, 2016.

S. R. Carpenter, W. A. Brock, G. J. Hansen, J. F. Hansen, J. M. Hennessy, D. A. Isermann, E. J. Pedersen, K. M. Perales, A. L. Rypel, G. G. Sass, et al. Defining a safe operating 
space for inland recreational fisheries. Fish and Fisheries, 18(6):1150-1160, 2017.

E. Cartwright, A. Stepanova, and L. Xue. Impulse balance and framing effects in threshold public good games. Journal of Public Economic Theory, 2019.

J. Casey, E. Jardim, and J. T. Martinsohn. The role of genetics in fisheries management under the E.U. common fisheries policy. Journal of Fish Biology, 89(6):2755-2767, 12 2016.

D. Cash and W. C. Clark. From science to policy: Assessing the assessment process. John F. Kennedy School of Government Faculty Research Working Papers Series RWP01$045,2001$.

T. N. Cason and L. Gangadharan. Promoting cooperation in nonlinear social dilemmas through peer punishment. Experimental Economics, 18(1):66-88, 2015.

G. Charness and M.-C. Villeval. Cooperation and competition in intergenerational experiments in the field and the laboratory. American Economic Review, 99(3):956-78, 2009.

W. W. Cheung, V. W. Lam, J. L. Sarmiento, K. Kearney, R. Watson, and D. Pauly. Projecting global marine biodiversity impacts under climate change scenarios. Fish and fisheries, 10(3):235-251, 2009.

C. Chou. The local governance of common pool resources: The case of irrigation water in Cambodia. Cambodia Development Resource Institute Phnom Penh, 2010.

C. Chou, P. Nang, I. Whitehead, P. Hirsch, and A. Thompson. Decentralised governance of irrigation water in Cambodia: Matching principles to local realities. CDRI, 2011.

A. Chrysafi, J. M. Cope, and A. Kuparinen. Eliciting expert knowledge to inform stock status for data-limited stock assessments. Marine Policy, 101:167-176, 2019.

L. C. Coffman and M. Niederle. Pre-analysis plans have limited upside, especially where replications are feasible. Journal of Economic Perspectives, 29(3):81-98, 2015.

Council of the European Union. Council regulation (EC) no 45/98 of 19 december 1997. Journal of the European Communities, 1998.

Council of the European Union. Council regulation (EC) no 48/1999. Official Journal of the European Communities, 1999.

Council of the European Union. Council decision of 19 july 2004 establishing regional advisory councils under the common fisheries policy. (2004/585/EC). Official Journal of the European Union, 2004.

Council of the European Union. Council regulation (EC) no 40/2008. Official Journal of the European Union, 2008.

Council of the European Union. Council regulation (EU) no 219/2010. Official Journal of the European Union, 2010a. 
Council of the European Union. Council Regulation fixing for 2010 the fishing opportunities for certain fish stocks and groups of fish stocks, applicable in EU waters and, for EU vessels, in waters where catch limitations are required and amending Regulations (EC) No 1359/2008, (EC) No 754/2009, (EC) No 1226/2009 and EC No 1287/2009. Official Journal of the European Union, 2010b.

Council of the European Union. Council regulation (EU) no 219/2010 of 15 march 2010 amending regulation (EU) no 53/2010 as regards the fishing opportunities for certain fish stocks and following the conclusion of the bilateral fisheries arrangements for 2010 with Norway and the Faroe Islands. Official Journal of the European Union, 2010c.

C. Cox and B. Stoddard. Framing and feedback in social dilemmas with partners and strangers. Games, 6(4):394-412, 2015.

C. A. Cox. Decomposing the effects of negative framing in linear public goods games. Economics Letters, 126:63-65, 2015.

L. B. Crowder, G. Osherenko, O. R. Young, S. AiramÃAC, E. A. Norse, N. Baron, J. C. Day, F. Douvere, C. N. Ehler, B. S. Halpern, S. J. Langdon, K. L. McLeod, J. C. Ogden, R. E. Peach, A. A. Rosenberg, and J. A. Wilson. Resolving mismatches in U.S. ocean governance. Science, 313(5787):617, 2006.

R. P. Cubitt, M. Drouvelis, and S. Gächter. Framing and free riding: emotional responses and punishment in social dilemma games. Experimental Economics, 14(2):254-272, 2011.

D. J. Dankel, R. Aps, G. Padda, C. Röckmann, J. P. van der Sluijs, D. C. Wilson, and P. Degnbol. Advice under uncertainty in the marine system. ICES Journal of Marine Science, 69(1):3-7, 2012.

D. J. Dankel, K. Stange, and K. N. Nielsen. What hat are you wearing? on the multiple roles of fishery scientists in the ices community. ICES Journal of Marine Science, 73 (2):209-216, 2015.

A. Dannenberg and C. Gallier. The choice of institutions to solve cooperation problems: A survey of experimental research. ZEW-Centre for European Economic Research Discussion Paper, (19-021), 2019.

A. Dannenberg, A. Löschel, G. Paolacci, C. Reif, and A. Tavoni. On the provision of public goods with probabilistic and ambiguous thresholds. Environmental and Resource Economics, 61(3):365-383, 2015.

T. Daw and T. Gray. Fisheries science and sustainability in international policy: a study of failure in the european union's common fisheries policy. Marine Policy, 29(3):189-197, 2005.

B. I. De Vos and J. P. Van Tatenhove. Trust relationships between fishers and government: New challenges for the co-management arrangements in the dutch flatfish industry. 
Marine Policy, 35(2):218-225, 2011.

A. E. Delaney and J. E. Hastie. Lost in translation: Differences in role identities between fisheries scientists and managers. Ocean \& Coastal Management, 50(8):661-682, 2007.

J. J. Deroba and T. J. Miller. Correct in theory but wrong in practice: Bias caused by using a lognormal distribution to penalize annual recruitments in fish stock assessment models. Fisheries Research, 176:86-93, 2016.

M. Dickey-Collas, M. A. Pastoors, and O. A. Van Keeken. Precisely wrong or vaguely right: simulations of noisy discard data and trends in fishing effort being included in the stock assessment of north sea plaice. ICES Journal of Marine Science, 64(9):1641-1649, 2007.

M. Dufwenberg, S. Gächter, and H. Hennig-Schmidt. The framing of games and the psychology of play. Games and Economic Behavior, 73(2):459-478, 2011. ISSN 08998256 .

Dutch delegation. 14738/09 PECHE 287 + ADD - COM(2009) 553 final + Annexes Subject: Proposal for a Council Regulation fixing for 2010 the fishing opportunities for certain fish stocks and groups of fish stocks, applicable in Community waters and, for Community vessels, in waters where catch limitations are required., 2009.

J. A. Ekstrom and B. I. Crona. Institutional misfit and environmental change: A systems approach to address ocean acidification. Science of The Total Environment, 576:599608, 2017.

B. Englich and K. Soder. Moody experts - how mood and expertise influence judgmental anchoring. Judgment and Decision making, 4(1):41, 2009.

European Commission. Non-paper: Review of the TAC-areas for horse mackerel, 2008.

European Commission. Proposal for a Council regulation establishing a multi-annual plan for the western stock of Atlantic Horse Mackerel and the fisheries exploiting that stock. Technical Report Interinstitutional File: 2009/0057 (CNS), European Commission, 2009a.

European Commission. Pelagic RAC recommendations on horse mackerel, sprat and some shared stocks. Your letters - references PRAC0848/AC and 0809PRAC10/A, 2009b.

European Commission. Proposal for a Council regulation amending regulation (EU) no $23 / 2010$ as regards the fishing opportunities for certain fish stocks and following the conclusion of the bilateral fisheries arrangements for 2010 with Norway and the Faroe Islands, 2010.

European Commission. Scientific advice on managing fish stocks, 2018. URL https: //ec.europa.eu/fisheries/cfp/fishing_rules/scientific_advice_en.

European Commission and others. Facts and figures on the common fisheries policy-basic statistical data, 2016. URL https://ec.europa.eu/fisheries/publications/ 
facts-and-figures-common-fisheries-policy-basic-statistical-data-2_en.

European Parliament and Council of the Eurpean Union. Regulation (EU) no 1380/2013. Official Journal of the European Union, 2013. URL http://eur-lex.europa.eu/ legal-content/EN/TXT/PDF/?uri=CELEX:32013R1380\&from=EN.

N. G. Fallon, M. A. Collins, C. T. Marshall, and P. G. Fernandes. Assessing consistency of fish survey data: uncertainties in the estimation of mackerel icefish (champsocephalus gunnari) abundance at south georgia. Polar Biology, 39(4):593-603, oct 2015.

F. Fallucchi, R. A. Luccasen, and T. L. Turocy. Identifying discrete behavioural types: A re-analysis of public goods game contributions by hierarchical clustering. Journal of the Economic Science Association, pages 1-17, 2018.

FAO. The state of world fisheries and aquaculture - meeting the sustainable development goals. CA0191EN/1/07.18, 2018.

E. Fehr and U. Fischbacher. The nature of human altruism. Nature, 425(6960):785, 2003.

A. C. Finlayson and B. J. McCay. Crossing the threshold of ecosystem resilience: the commercial extinction of northern cod. Linking social and ecological systems: management practices and social mechanisms for building resilience. Cambridge University Press, Cambridge, UK, pages 311-337, 1998.

U. Fischbacher, S. Gächter, and E. Fehr. Are people conditionally cooperative? Evidence from a public goods experiment. Economics letters, 71(3):397-404, 2001.

U. Fischbacher, S. Gächter, and S. Quercia. The behavioral validity of the strategy method in public good experiments. Journal of Economic Psychology, 33(4):897-913, 2012.

C. Folke, L. Pritchard, F. Berkes, J. Colding, and U. Svedin. The problem of fit between ecosystems and institutions: Ten years later. Ecology and Society, 12(1), 2007.

T. R. Fosgaard, L. G. Hansen, and E. Wengström. Understanding the nature of cooperation variability. Journal of Public Economics, 120:134-143, 2014.

T. R. Fosgaard, L. G. Hansen, and E. Wengström. Cooperation, framing, and political attitudes. Journal of Economic Behavior 63 Organization, 158:416-427, 2019.

M. Fossheim, R. Primicerio, E. Johannesen, R. B. Ingvaldsen, M. M. Aschan, and A. V. Dolgov. Recent warming leads to a rapid borealization of fish communities in the arctic. Nature Climate Change, 5(7):673, 2015.

R. C. Francis. Explaining bias caused by the wrong recruitment penalty in stock assessment models. Fisheries Research, 181:114-115, 2016.

French delegation. 14738/09 PECHE 287 + ADD 1 - Com(2009) 553 final + annexes. subject: Proposal for a Council regulation fixing for 2010 the fishing opportunities for certain fish stocks and groups of fish stocks, applicable in community waters and for Community vessels, in waters where catch limitations are required, 2009. 
H. Fujimoto and E.-S. Park. Framing effects and gender differences in voluntary public goods provision experiments. The Journal of Socio-Economics, 39(4):455-457, 2010.

E. A. Fulton, A. D. M. Smith, D. C. Smith, and I. E. van Putten. Human behaviour: the key source of uncertainty in fisheries management. Fish and Fisheries, 12(1):2-17, Mar. 2011.

A. Furnham and H. C. Boo. A literature review of the anchoring effect. The journal of socio-economics, 40(1):35-42, 2011.

S. Gächter, F. Kölle, and S. Quercia. Reciprocity and the tragedies of maintaining and providing the commons. Nature human behaviour, 1(9):650, 2017.

V. Galaz, P. Olsson, T. Hahn, C. Folke, and U. Svedin. Institutions and Environmental Change Principal Findings, Applications, and Research Frontiers, chapter The problem of fit among biophysical systems, environmental and resource regimes, and broader governance systems: insights and emerging challenges, pages 147-182. The MIT Press, Cambridge, USA, 2008.

G. R. Galland, A. E. Nickson, R. Hopkins, and S. K. Miller. On the importance of clarity in scientific advice for fisheries management. Marine Policy, 87:250-254, 2018.

E. J. Garrity. Individual transferable quotas (ITQ), rebuilding fisheries and short-termism: How biased reasoning impacts management. Systems, 8(1):7, 2020.

A. Gibbs, Mark; Cole. Ecological Economics of the Oceans and Coasts, chapter Oceans and Coasts as Complex Adaptive Systems, pages 74-92. Edward Elgar Publishing, Inc., 2008.

G. Gigerenzer and W. Gaissmaier. Heuristic decision making. Annual Review of Psychology, 62(1):451-482, 2011.

G. Gigerenzer and P. M. Todd. Simple heuristics that make us smart. Oxford University Press, USA, 1999.

T. Gilovich, D. Griffin, and D. Kahneman. Heuristics and biases: The psychology of intuitive judgment. Cambridge university press, 2002.

U. Gneezy and J. Potters. An experiment on risk taking and evaluation periods. The Quarterly Journal of Economics, 112(2):631-645, 1997.

U. Gneezy, A. Leibbrandt, and J. A. List. Ode to the sea: Workplace organizations and norms of cooperation. The Economic Journal, 126(595):1856-1883, 2015.

S. J. Goerg and G. Walkowitz. On the prevalence of framing effects across subject-pools in a two-person cooperation game. Journal of Economic Psychology, 31(6):849-859, 2010 .

L. Griffin. The north sea fisheries crisis and good governance. Geography Compass, 2(2): 452-475, 2008. 
L. Griffin. The limits to good governance and the state of exception: a case study of North Sea fisheries. Geoforum, 41(2):282-292, 2010.

R. Hagafors. When experts are influential: Comparisons with respect to success and consistency in judgment tasks. Scandinavian Journal of Psychology, 24(1):293-301, 1983.

K. H. Hauge. Uncertainty and hyper-precision in fisheries science and policy. Futures, 43 (2):173-181, 2011.

R. B. Hedeholm, R. B. Jacobsen, and E. E. Nielsen. Learning from 'apparent consensus' in tac disputes: Exploring knowledge overlaps in lek and genetic categorization of atlantic cod. Marine Policy, 69:114-120, 2016.

T. J. Hegland and J. Raakjær. Recovery Plans and the Balancing of Fishing Capacity and Fishing Possibilities: Path Dependence in the Common Fisheries Policy, pages 131-160. 2008.

M. Heldeweg. Towards good environmental governance in europe. European Energy and Environmental Law Review, 14(1):2-24, 2005.

J. Henrich, R. Boyd, S. Bowles, C. Camerer, E. Fehr, H. Gintis, and R. McElreath. In search of homo economicus: behavioral experiments in 15 small-scale societies. American Economic Review, 91(2):73-78, 2001.

W. Hichri. Interior collective optimum in a voluntary contribution to a public-goods game. Applied Economics Letters, 11(3):135-140, Feb. 2004.

R. Hilborn and K. Stokes. Defining overfished stocks: Have we lost the plot [definiendo stocks sobrepescados: Ä¿se ha perdido el argumento?]. Fisheries, 35(3):113-120, 2010.

E. Hoefnagel, B. de Vos, and E. Buisman. Quota swapping, relative stability, and transparency. Marine Policy, 57:111-119, 2015.

P. Holm and K. Nielsen. The TAC machine. appendix b, working document 1 in ICES, 2004, report of the Working Group for Fisheries Systems (WGFS). Annual Report, pages $40-51,2004$.

ICES. Western horse mackerel (Trachurus trachurus) (Divisions IIa, IVa, Vb, VIa, VIIa-c,e-k, VIIIa,b,d,e). Technical report, 1999a.

ICES. North Sea horse mackerel (Trachurus trachurus) (Division IIIa (eastern part), Divisions IVb,c, VIId). Technical report, ICES, 1999b.

ICES. Introduction to Benchmarks at ICES. Technical report, International Council for the Exploration of the Sea (ICES), 2013.

ICES. Implementing the ICES strategic plan 2014 - 2018, 2014. URL http://www.ices. $\mathrm{dk} /$ explore-us/what-we-do/Pages/Our-strategy.aspx.

ICES. ICES Advice Basis, 2016. URL http://www.ices.dk/sites/pub/Publication\% 
20Reports/Advice/2016/2016/Introduction_to_advice_2016.pdf.

ICES. Map of Ecoregions with ICES Areas, 2017. URL http://ices.dk/data/Documents/ Maps/ICES-Ecoregions-hybrid-statistical-areas.png.

ICES. Who we are, 2018. URL http://www.ices.dk/explore-us/who-we-are/Pages/ Who-we-are.aspx.

ICES. Administrative Agreement (AA) between the European Commission and the International Council for the Exploration of the Sea International Council for the Exploration of the Sea. Technical report, 2018. URL http://www.ices.dk/explore-us/ Documents/Cooperation\%20agreements/EU/2018_ICES_EC_AA_signed_WEB.pdf.

M. Ichinokawa, H. Okamura, and Y. Takeuchi. Data conflict caused by model misspecification of selectivity in an integrated stock assessment model and its potential effects on stock status estimation. Fisheries Research, 158:147-157, 2014.

D. İriş, J. Lee, and A. Tavoni. Delegation and public pressure in a threshold public goods game. Environmental and Resource Economics, 74(3):1331-1353, 2019.

B. H. Iris Bohnet, Fiona Greig and R. Zeckhauser. Betrayal aversion: Evidence from Brazil, China, Oman, Switzerland, Turkey, and the United States. American Economic Review, 98(1):294-310, 2008.

Irish delegation. 9003/09 PECHE 103 - COM(2009) 189 final - Subject: Proposal for a Council Regulation establishing a multi-annual plan for the western stock of Atlantic horse mackerel and the fisheries exploiting the stock., 2009.

E. T. Isaksen, K. A. Brekke, and A. Richter. Positive framing does not solve the tragedy of the commons. Journal of Environmental Economics and Management, 95:45-56, 2019 .

I. Iturbe-Ormaetxe, G. Ponti, J. Tomás, and L. Ubeda. Framing effects in public goods: Prospect theory and experimental evidence. Games and Economic Behavior, 72(2): 439-447, 2011.

O. P. Jensen, T. A. Branch, and R. Hilborn. Marine fisheries as ecological experiments. Theoretical Ecology, 5(1):3-22, 2012.

K. F. Johnson, C. C. Monnahan, C. R. McGilliard, K. A. Vert-pre, S. C. Anderson, C. J. Cunningham, F. Hurtado-Ferro, R. R. Licandeo, M. L. Muradian, K. Ono, C. S. Szuwalski, J. L. Valero, A. R. Whitten, and A. E. Punt. Time-varying natural mortality in fisheries stock assessment models: identifying a default approach. ICES Journal of Marine Science, 72(1):137-150, apr 2014.

D. Kahneman. Thinking, Fast and Slow. Farrar, Straus and Giroux: New York, NY, USA, 2011.

K. S. Kassam, K. Koslov, and W. B. Mendes. Decisions under distress: Stress profiles influence anchoring and adjustment. Psychological science, 20(11):1394-1399, 2009. 
D. G. Kehler, R. A. Myers, and C. A. Field. Measurement error and bias in the maximum reproductive rate for the ricker model. Canadian Journal of Fisheries and Aquatic Sciences, 59(5):854-864, may 2002.

N. L. Kerr. Motivation losses in small groups: A social dilemma analysis. Journal of Personality and Social Psychology, 45(4):819-828, 1983.

M. Khadjavi and A. Lange. Doing good or doing harm: experimental evidence on giving and taking in public good games. Experimental Economics, 18(3):432-441, Sep 2015.

S. Khalilian, R. Froese, A. Proelss, and T. Requate. Designed for failure: A critique of the Common Fisheries Policy of the European Union. Marine Policy, 34(6):1178-1182, 2010 .

D. C. Kingsley. Peer punishment across payoff equivalent public good and common pool resource experiments. Journal of the Economic Science Association, 1(2):197-204, 2015.

G. Kirchgässner and U. K. Müller. Are forecasters reluctant to revise their predictions? some german evidence. Journal of Forecasting, 25(6):401-413, 2006.

M. G. Kocher, P. Martinsson, D. Matzat, and C. Wollbrant. The role of beliefs, trust, and risk in contributions to a public good. Journal of Economic Psychology, 51:236-244, 2015.

S. Kortsch, R. Primicerio, M. Fossheim, A. V. Dolgov, and M. Aschan. Climate change alters the structure of arctic marine food webs due to poleward shifts of boreal generalists. Proceedings of the Royal Society B: Biological Sciences, 282(1814):20151546, 2015.

K. Kotani, K. Tanaka, and S. Managi. Further investigations of framing effects on cooperative choices in a provision point mechanism. Economics Bulletin, 3(51):1-9, 2008.

K. Kotani, K. Tanaka, and S. Managi. Cooperative choice and its framing effect under threshold uncertainty in a provision point mechanism. Economics of Governance, 15 (4):329-353, 2014.

S. B. Kraak, N. Daan, and M. A. Pastoors. Biased stock assessment when using multiple, hardly overlapping, tuning series if fishing trends vary spatially. ICES Journal of Marine Science, 66(10):2272-2277, 2009.

S. B. Kraak, C. J. Kelly, E. A. Codling, and E. Rogan. On scientists' discomfort in fisheries advisory science: the example of simulation-based fisheries management-strategy evaluations. Fish and Fisheries, 11(2):119-132, 2010.

K. Kupferschmidt. How the pandemic made this virologist an unlikely cult figure. Science., 2020. doi: doi:10.1126/science.abc5095.

J. Kurien. Community fisheries organizations of cambodia. sharing processes, results and lessons learned in the context of the implementation of the ssf guideline. (FAO Fisheries and Aquaculture Circular No. 1138), 2017. 
S. F. Kvamsdal, A. Eide, N.-A. Ekerhovd, K. Enberg, A. Gudmundsdottir, A. H. Hoel, K. E. Mills, F. J. Mueter, L. Ravn-Jonsen, L. K. Sandal, J. E. Stiansen, and N. Vestergaard. Harvest control rules in modern fisheries management. Elementa: Science of the Anthropocene, 4:000114, jul 2016.

H. Lassen, C. Kelly, and M. Sissenwine. ICES advisory framework 1977-2012: from Fmax to precautionary approach and beyond. ICES Journal of Marine Science, 71(2): 166-172, 092013.

F. G. Laxe. Dysfunctions in common fishing regulations. Marine Policy, 34(1):182-188, 2010.

J. O. Ledyard. Public goods: A survey of experimental research. Princeton University Press, Princeton, 1995.

H.-H. Lee, M. N. Maunder, K. R. Piner, and R. D. Methot. Can steepness of the stockrecruitment relationship be estimated in fishery stock assessment models? Fisheries Research, 125-126:254-261, 2012.

M. Lindegren, C. Möllmann, A. Nielsen, and N. C. Stenseth. Preventing the collapse of the baltic cod stock through an ecosystem-based management approach. Proceedings of the National Academy of Sciences, 106(34):14722-14727, aug 2009.

E. Lindkvist, Örjan Ekeberg, and J. Norberg. Strategies for sustainable management of renewable resources during environmental change. Proceedings of the Royal Society B: Biological Sciences, 284(1850):20162762, 2017.

J. Link, T. Ihde, C. Harvey, S. Gaichas, J. Field, J. Brodziak, H. Townsend, and R. Peterman. Dealing with uncertainty in ecosystem models: The paradox of use for living marine resource management. Progress in Oceanography, 102:102-114, 2012.

J. S. Link, J. A. Nye, and J. A. Hare. Guidelines for incorporating fish distribution shifts into a fisheries management context. Fish and Fisheries, 12(4):461-469, 2011.

A. Magnusson and R. Hilborn. What makes fisheries data informative? Fish and Fisheries, 8(4):337-358, 2007.

C. Mantilla. Environmental uncertainty in commons dilemmas: A survey of experimental research. International Journal of the Commons, 12(2), 2018.

C. T. Marshall, C. L. Needle, A. Thorsen, O. S. Kjesbu, and N. A. Yaragina. Systematic bias in estimates of reproductive potential of an atlantic cod (gadus morhua) stock: implications for stock-recruit theory and management. Canadian Journal of Fisheries and Aquatic Sciences, 63(5):980-994, 2006.

R. Martin, M. Schlüter, and T. Blenckner. The importance of transient social dynamics for restoring ecosystems beyond ecological tipping points. Proceedings of the National Academy of Sciences, 117(5):2717, 2020.

T. G. Martin, M. A. Burgman, F. Fidler, P. M. Kuhnert, S. Low Choy, M. McBride, 
and K. Mengersen. Eliciting expert knowledge in conservation science. Conservation Biology, 26(1):29-38, 2012.

M. McBride. Threshold uncertainty in discrete public good games: an experimental study. Economics of governance, 11(1):77-99, 2010.

M. F. McBride, S. T. Garnett, J. K. Szabo, A. H. Burbidge, S. H. M. Butchart, L. Christidis, G. Dutson, H. A. Ford, R. H. Loyn, D. M. Watson, and M. A. Burgman. Structured elicitation of expert judgments for threatened species assessment: a case study on a continental scale using email. Methods in Ecology and Evolution, 3(5):906-920, 10 2012.

E. Mendenhall, C. Hendrix, E. Nyman, P. M. Roberts, J. R. Hoopes, J. R. Watson, V. W. Lam, and U. R. Sumaila. Climate change increases the risk of fisheries conflict. Marine Policy, 117:103954, 2020.

R. D. Methot, I. G. Taylor, and Y. Chen. Adjusting for bias due to variability of estimated recruitments in fishery assessment models. Canadian Journal of Fisheries and Aquatic Sciences, 68(10):1744-1760, oct 2011.

R. D. Methot, Jr. Prioritizing fish stock assessments. techreport NMFS-F/SPO-152, U.S. Dep. Commer., NOAA, 2015.

M. Milinski, R. D. Sommerfeld, H.-J. Krambeck, F. A. Reed, and J. Marotzke. The collective-risk social dilemma and the prevention of simulated dangerous climate change. Proceedings of the National Academy of Sciences, 105(7):2291-2294, 2008.

J. S. A. Mina, D. A. R. Fernández, A. A. Ibarra, and N. Georgantzis. Economic behavior of fishers under climate-related uncertainty: Results from field experiments in Mexico and Colombia. Fisheries Research, 183(Supplement C):304-317, 2016.

G. Montibeller and D. Winterfeldt. Cognitive and motivational biases in decision and risk analysis. Risk Analysis, 35(7):1230-1251, 72015.

M. R. Msomphora. The role of science in fisheries management in Europe: from mode 1 to mode 2. Maritime Studies, 15(3):1 - 23, 2016.

R. A. Myers and N. J. Barrowman. Time series bias in the estimation of density-dependent mortality in stock-recruitment models. Canadian Journal of Fisheries and Aquatic Sciences, 52(1):223-232, jan 1995.

K. N. Nielsen and P. Holm. A brief catalogue of failures: Framing evaluation and learning in fisheries resource management. Marine Policy, 31(6):669-680, 2007.

S. Niiranen, A. Richter, T. Blenckner, L. C. Stige, M. Valman, and A.-M. Eikeset. Global connectivity and cross-scale interactions create uncertainty for blue growth of arctic fisheries. Marine Policy, 87:321-330, 2018.

W. D. Nordhaus. Forecasting efficiency: concepts and applications. The Review of Economics and Statistics, 69(4):667-674, 1987. 
C. N. Noussair, D. van Soest, J. Stoop, et al. Cooperation in a dynamic fishing game: A framed field experiment. American Economic Review, 105(5):408-413, 2015.

A. Ockenfels and J. Weimann. Types and patterns: an experimental East-West-German comparison of cooperation and solidarity. Journal of Public Economics, 71(2):275-287, 1999.

S. Oskamp. Overconfidence in case-study judgments. Journal of consulting psychology, 29(3):261, 1965.

A. Østhagen, J. Spijkers, and O. A. Totland. Collapse of cooperation? the north-atlantic mackerel dispute and lessons for international cooperation on transboundary fish stocks. Maritime Studies, pages 1-11, 2020.

E. Ostrom. Governing the Commons: The Evolution of Institutions for Collective Action. Cambridge University Press, 1990.

E. Ostrom. A general framework for analyzing sustainability of social-ecological systems. Science, 325(5939):419-422, 2009.

E. Ostrom. Beyond markets and states: polycentric governance of complex economic systems. American Economic Review, 100(3):641-72, 2010.

M. Ottaviani and P. N. Sørensen. Professional advice. Journal of Economic Theory, 126 (1):120-142, 2006.

M. C. Palmer and C. Demarest. Getting to good enough: Performance of a suite of methods for spatially allocating fishing effort to management areas. Fisheries Research, 204:26-32, 2018.

E.-S. Park. Warm-glow versus cold-prickle: a further experimental study of framing effects on free-riding. Journal of Economic Behavior \& Organization, 43(4):405-421, 2000.

M. Pastoors. Evaluation of the performance of stock assessments in the northeast atlantic using a new metric for historical retrospective analyses. Working Paper, 2020.

M. R. Payne, L. W. Clausen, and H. Mosegaard. Finding the signal in the noise: objective data-selection criteria improve the assessment of western baltic spring-spawning herring. ICES Journal of Marine Science, 66(8):1673-1680, jul 2009.

Pelagic AC. Minutes of the meeting of Working Groups 1 and 2 of the Pelagic RAC, 2005. URL https://pelagic-ac.org/pracmeetings/pastmeetings/2005.

Pelagic AC. Minutes of the Pelagic RAC Working Groups meeting on Wednesday 21 June 2006, 2006a. URL https://pelagic-ac.org/pracmeetings/pastmeetings/2006.

Pelagic AC. Minutes of the Pelagic RAC Working Groups I and II meeting on 3 November 2006, 2006b. URL https://pelagic-ac.org/pracmeetings/pastmeetings/2006.

Pelagic AC. Minutes of the Pelagic RAC Executive Committee meeting, 2007a. URL https://pelagic-ac.org/pracmeetings/pastmeetings/2007. 
Pelagic AC. Minutes of the Pelagic RAC Working Groups I and II, 2007b. URL https: //pelagic-ac.org/pracmeetings/pastmeetings/2007.

Pelagic AC. Minutes of the Pelagic RAC Working Groups meeting, 2008a. URL https: //pelagic-ac.org/pracmeetings/pastmeetings/2008.

Pelagic AC. P-RAC response to horse mackerel non-paper and recommendation on sprat., 2008b. URL https://pelagic-ac.org/pracmeetings/pastmeetings/2008.

L. Perera. Factors affecting the formation of FWUCs in institution building for PIMD in Cambodia: Two case studies, volume 113. IWMI, 2006.

A. L. Perry, P. J. Low, J. R. Ellis, and J. D. Reynolds. Climate change and distribution shifts in marine fishes. Science, 308(5730):1912-1915, 2005.

M. L. Pinsky and M. Fogarty. Lagged social-ecological responses to climate and range shifts in fisheries. Climatic Change, 115(3-4):883-891, 2012.

M. L. Pinsky, G. Reygondeau, R. Caddell, J. Palacios-Abrantes, J. Spijkers, and W. W. L. Cheung. Preparing ocean governance for species on the move. Science, 360(6394):11891191, 2018.

E. S. Poloczanska, M. T. Burrows, C. J. Brown, J. García Molinos, B. S. Halpern, O. Hoegh-Guldberg, C. V. Kappel, P. J. Moore, A. J. Richardson, D. S. Schoeman, and W. J. Sydeman. Responses of marine organisms to climate change across oceans. Frontiers in Marine Science, 3:62, 2016.

S. Prediger. How does income inequality affect cooperation and punishment in public good settings? Technical report, Joint discussion paper series in economics, 2011.

B. B. C. P. M. K. N. J. Ratner, B.D. and E. Allison. Strengthening governance across scales in aquatic agricultural systems, 2012.

H. Reiss, G. Hoarau, M. Dickey-Collas, and W. J. Wolff. Genetic population structure of marine fish: mismatch between biological and fisheries management units. Fish and Fisheries, 10(4):361-395, 2009.

D. Ricard, C. Minto, O. P. Jensen, and J. K. Baum. Examining the knowledge base and status of commercially exploited marine species with the RAM legacy stock assessment database. Fish and Fisheries, 13(4):380-398, aug 2011.

A. Richter, E. Schuch, and T. Nhim. Cooperation under uncertainty in natural resource management. OSF. March 3. doi:10.17605/OSF.IO/U3GC8., 2020.

D. Rustagi, S. Engel, and M. Kosfeld. Conditional cooperation and costly monitoring explain success in forest commons management. Science, 330(6006):961-965, 2010.

M. Scheffer, F. Westley, and W. Brock. Slow response of societies to new problems: Causes and costs. Ecosystems, 6(5):493-502, 2003.

V. Schwach, D. Bailly, A.-S. Christensen, A. E. Delaney, P. Degnbol, W. L. T. van Densen, 
P. Holm, H. A. McLay, K. N. Nielsen, M. A. Pastoors, S. A. Reeves, and D. C. Wilson. Policy and knowledge in fisheries management: a policy brief. ICES Journal of Marine Science, 64(4):798-803, 2007.

C. Sguotti, S. A. Otto, R. Frelat, T. J. Langbehn, M. P. Ryberg, M. Lindegren, J. M. Durant, N. Chr. Stenseth, and C. Möllmann. Catastrophic dynamics limit atlantic cod recovery. Proceedings of the Royal Society B, 286(1898):20182877, 2019.

M. Sinkey. How do experts update beliefs? Lessons from a non-market environment. Journal of Behavioral and Experimental Economics, 57:55-63, 2015.

M. Sithirith. The governance of wetlands in the tonle sap lake, Cambodia. Journal of Environmental Science and Engineering B, 4(6), 2015.

J. Sonnemans, A. Schram, and T. Offerman. Public good provision and public bad prevention: The effect of framing. Journal of Economic Behavior \& Organization, 34 (1):143-161, 1998.

S. S. Soomai. The science-policy interface in fisheries management: Insights about the influence of organizational structure and culture on information pathways. Marine Policy, 81:53-63, 2017.

M. Soria, P. Fréon, and F. Gerlotto. Analysis of vessel influence on spatial behaviour of fish schools using a multi-beam sonar and consequences for biomass estimates by echo-sounder. ICES Journal of Marine Science, 53(2):453-458, 1996.

Spanisch Delegation. Note in regard to "Proposal for a Council Regulation establishing a multiannual plan for the western stock of Atlantic horse mackerel and the fisheries exploiting that stock", 2009.

J. Spijkers and W. J. Boonstra. Environmental change and social conflict: the northeast Atlantic mackerel dispute. Regional Environmental Change, 17(6):1835-1851, 2017.

J.-C. D. Sreyphea Chap, Panha Touch. Fisheries reforms and right-based fisheries: insights from community fisheries across cambodia, 2016.

K. Stange. Knowledge production at boundaries: An inquiry into collaborations to make management plans for European fisheries. phdthesis, 2017.

K. Starcke and M. Brand. Decision making under stress: a selective review. Neuroscience E Biobehavioral Reviews, 36(4):1228-1248, 2012.

D. H. Steele, R. Andersen, and J. M. Green. The managed commercial annihilation of northern cod. Newfoundland and Labrador Studies, 1992.

R. Suleiman, D. V. Budescu, and A. Rapoport. Provision of step-level public goods with uncertain provision threshold and continuous contribution. Group Decision and Negotiation, 10(3):253-274, 2001.

U. R. Sumaila, W. W. Cheung, V. W. Lam, D. Pauly, and S. Herrick. Climate change 
impacts on the biophysics and economics of world fisheries. Nature climate change, 1 (9):449-456, 2011.

W. J. Sutherland and M. Burgman. Policy advice: use experts wisely. Nature, 526(7573): 317-318, 2015.

D. Symes. Fisheries management and institutional reform: a European perspective. ICES Journal of Marine Science, 64(4):779-785, 2007.

D. Symes. Reform of the European Union's Common Fisheries Policy: Making fisheries management work. Fisheries Research, 100(2):99-102, 2009.

D. Symes and E. Hoefnagel. Fisheries policy, research and the social sciences in Europe: Challenges for the 21st century. Marine Policy, 34(2):268-275, 2010.

N. N. Taleb. The black swan: The impact of the highly improbable, volume 2. Random house, 2007.

A. Tavoni, A. Dannenberg, G. Kallis, and A. Löschel. Inequality, communication, and the avoidance of disastrous climate change in a public goods game. Proceedings of the National Academy of Sciences, 108(29):11825-11829, 2011.

N. O. Therkildsen, J. Hemmer-Hansen, R. B. Hedeholm, M. S. Wisz, C. Pampoulie, D. Meldrup, S. Bonanomi, A. Retzel, S. M. Olsen, and E. E. Nielsen. Spatiotemporal snp analysis reveals pronounced biocomplexity at the northern range margin of atlantic cod gadus morhua. Evolutionary Applications, 6(4):690-705, 2013.

E. A. Treml, P. I. J. Fidelman, S. Kininmonth, J. A. Ekstrom, and r. Bodin. Analyzing the (mis)fit between the institutional and ecological networks of the Indo-West Pacific. Global Environmental Change, 31:263-271, 2015.

A. Tversky and D. Kahneman. The framing of decisions and the psychology of choice. Science, 211(4481):453-458, 1981.

G. Vaidyanathan. Inner workings: Climate change complicates fisheries modeling and management. Proceedings of the National Academy of Sciences, 114(32):8435-8437, 2017.

A. J. Van de Kragt, J. M. Orbell, and R. M. Dawes. The minimal contributing set as a solution to public goods problems. American Political Science Review, 77(1):112-122, 1983.

D. van Soest, J. Stoop, and J. Vyrastekova. Toward a delineation of the circumstances in which cooperation can be sustained in environmental and resource problems. Journal of Environmental Economics and Management, 77:1-13, 2016.

M. Voors, E. Bulte, A. Kontoleon, J. A. List, and T. Turley. Using artefactual field experiments to learn about the incentives for sustainable forest use in developing economies. American Economic Review, 101(3):329-33, 2011. 
C. Walters. Simple representation of the dynamics of biomass error propagation for stock assessment models. Canadian Journal of Fisheries and Aquatic Sciences, 61(7):10611065, jul 2004.

C. Werthmann, A. Weingart, and M. Kirk. Common-pool resources-a challenge for local governance. CAPRi Working Paper, 2010.

M. Willinger and A. Ziegelmeyer. Framing and cooperation in public good games: an experiment with an interior solution. Economics letters, 65(3):323-328, 1999.

D. C. Wilson. The paradoxes of transparency: Science and the ecosystem approach to fisheries management in Europe. Amsterdam University Press, 2010.

A.-M. Winter, A. Richter, and A. M. Eikeset. Implications of allee effects for fisheries management in a changing climate: evidence from atlantic cod. Ecologcal Applications, 30(1):e01994, 2020.

Working Party of Internal Fisheries Policy. Outcome of Proceedings: Proposal for a Council Regulation establishing a multi-annual plan for the western stock of Atlantic horse mackerel and the fisheries exploiting that stock. 12461/09, 2009.

Working Party on Internal and External Fisheries Policy. 14738/09 PECHE $287+$ ADD 1 - $\operatorname{COM}(2009) 553$ final + Annexes- Subject: Proposal for a Council Regulation fixing for 2010 the fishing opportunities for certain fish stocks and groups of fish stocks, applicable in Community waters and, for Community vessels, in waters where catch limitations are required. Technical report, European Commission, 2009.

O. R. Young. Institutional dynamics: Resilience, vulnerability and adaptation in environmental and resource regimes. Global Environmental Change, 20(3):378-385, 2010.

O. R. Young. Governing complex systems: social capital for the anthropocene. MIT Press, 2017. 

Appendices 



\title{
Appendix A
}

\section{Experimental Instructions}

\author{
Instructions Field study Cambodia
}

The text in [] is only for instructions and at no case to be read out.

\section{[Introduction and Verbal Consent Form]}

Our names are Tum Nhim and Esther Schuch. We are PhD students at Wageningen University in the Netherlands. Together with our study supervisor, Andries Richter, we are conducting a research study with about 300 villagers in Kampong Chhnang province, Cambodia. Our study aims to understand livelihood improvements such as those related to farming and fishing.

We would like to invite you to participate in this study by attending today's meeting. We will give you all necessary information about this study, and then you can decide if you want to participate in this study or not.

- The meeting has two parts and takes about three hours. The first part is you play five decision games upon which you may win some money. The second part is we ask you some questions about the daily livelihood of your own household.

- Participating in this meeting, you will get paid (i) 4000 Riels for your effort to come here; (ii) from one random game out of the five, depending on what you decide individually; and (iii) 6000 Riels for your effort to stay until the end of the meeting. All of the payment is paid once at the end of the meeting, and is sponsored by the European Union.

- Your answers to the question and your decisions in the game will not have any consequences on your daily livelihood. They are all kept confidential and will be stored safely and anonymously at Wageningen University's database. The results of the study may be published, but your names will not be used.

- Your participation is purely voluntary and you are free to leave at any time or skip any questions if you feel you want to, for whatever reasons. Doing so will not have 
any negative consequences for you.

- There are no correct or incorrect responses, so please express your opinions freely. If you have any questions, concerns or requests, feel free to ask us at any time. We will try our best to address them.

If you have any questions regarding this research or your rights as a research study participant, you may contact Mr. Tum Nhim at the phone number: 017886785.

I repeat again, please do not hesitate to ask any questions. Until now, do you have any questions?

Before we start the games, we will give each of you an identification card. Please keep it with you all the time, do not lose it.

[distribute the ID cards]

\section{A.1 Instructions for the risk elicitation}

Now we read the instructions and give examples for the first task. Then, we will do a test to see if you understand the task or not. Once we are sure you understand your task, you will begin the actual decision. Now I explain your task.

For this task, we give each participant an endowment of 6000 Riels, containing 6 bills of 1000 Riel. [show the notes] With this endowment of 6000 Riels, you have to decide how much you want to put in the white envelope and how much you want to put in the green envelope. [show both envelopes]. For the white envelope, the amount of money you put in you will get for sure. For example, if you put in 1000 Riels, you will get 1000 Riels for sure. If you put in 6000 Riels, you will get 6000 Riels for sure.

The green envelope is different. For every bill you put in the green envelope, you may get it tripled or you get zero Riel. If you put 1000 Riels in the green envelope, you may get 3000 Riels or you get zero Riel. If you put in 6000 Riels in the green envelope you may get 18000 Riels or you get zero Riel. To know whether you get the money tripled or get zero Riel, we will flip the coin. If the coin shows head [show coin's head], you will get the money you put in tripled. If the coin shows tail [show coin's tail], you will get zero Riel.

What you will earn from this task is your return from the white envelope plus the return from the green envelope.

You can put all the 6 bills in the white envelope or all the bills in the green envelope, or some in the white and some in the green.

[Example]

Now we will provide you with an example of how it is done in practice. Please note that since this is an example, we will tell you how many bills to put in the green envelope. For the actual task, you will have to decide this on your own, without any help from us.

[Randomly select a player and give him six bills of 1000 Riels . Please make sure that each time YOU tell the person how much he should put into the 
green envelope. Do not allow the player to take the decision because this may influence the decision of other potential players.]

[Record the coin tosses]

Suppose you are the participant in this task. Now we give you an endowment of 6000 Riels, containing six bills of 1000 Riels.

Now let us assume that out of six bills, you put zero in the green envelope. Please put zero bills in the green envelope and the remaining in the white envelope. [Ask the group; Can you tell me how many Riels are in the green envelope? How many Riels are in the white envelope? [Flip the coin and show the result to the participants]. Now the coin shows [head/tail]. How much will you get from the green envelope? You get nothing from it because you put in nothing. Have you understood this? How much do you get from the white envelope? [6000]. How much do you get in total? [6000] Do you have any questions?

[If it is understood, please ask the person to take bills out of the envelopes. If it is not understood, repeat this example again]

Please take the bills out of the envelopes again. Now, let us assume that out of 6 bills you put 2 bills in the green envelope. Please put two bills in the green envelope and the remaining in the white envelope. [Ask the group;]. How many bills are in the green envelope? How many bills are in the white envelope? [Flip the coin and show the result to the participants]. Now the coin shows [head/tail]. How much will you get from the green envelope (tripled or nothing?)? You thus get [6000/0 Riels]. How much do you get from the white envelope? [4000]. How much do you get in total? $[4000 / 10000]$

Do you have any questions?

[If it is understood, please ask the person to take bills out of the envelopes again]

Please take the bills out of the envelopes again. Now, let us assume that out of 6 bills you put 4 bills in the green envelope. Please put four bills in the green envelope and the remaining in the white envelope. [Ask the group;]. How many bills are in the green envelope? How many bills are in the white envelope? [Flip the coin and show the result to the participants]. Now the coin shows [head/tail]. How much will you get from the green envelope then (tripled or nothing?)? You thus get [12000/0 Riels].How much do you get from the white envelope? [2000]. How much do you get in total? [2000/14000]

Do you have any questions?

[If it is understood, please ask the person to take bills out of the envelopes again]

Please take the bills out of the envelopes again. Now, let us assume that out of 6 bills you put 6 in the green envelope. Please put six bills in the green envelope and the remaining 
in the white envelope. [Ask the group;]. How many bills are in the green envelope? How many bills are in the white envelope? [Flip the coin and show the result to the participants]. Now the coin shows [head/tail]. How much will you get from the green envelope then (tripled or nothing?)? You thus get [18000/0 Riels]. How much do you get from the white envelope? [0]. How much do you get in total? [0/18000] Have you understood this part? Do you need additional examples? [If yes, select another person and repeat the examples in the same order.]

\section{Control questions}

Now we will ask you two questions which each of you have to answer privately. To answer these two questions we will provide you each with two pieces of paper. We will ask you the questions and then you will answer by ticking the box next to the correct answer [show how the paper looks and which boxes to tick]. The answer has only two choices. It is either white envelope [point to the picture] or the green envelope [point to the picture]. We will collect the pieces of paper to see whether you answered correctly. In order to make sure each of you answers privately, please put up the card board boxes.

[Show the participants how to set up the card board boxes. Distribute the pieces of paper. Make sure everyone has two pieces of paper and the card board boxes up].

1 From which of the envelope will you get the same amount of money as what you put in for sure?

Please tick the correct answer. Once you ticked the box, please fold the paper inward. We will then come to collect it and continue to the next question.

2 From which envelope will you get a return of three times of what you put in or you get nothing?

Please tick the correct answer. Once you ticked the box, please fold the paper inward. We will then come to collect it and continue to the next question.

[Collect the pieces of paper ] We will now provide you each with 6000 Riel and the two envelopes. Now please decide how many bills you put in the white envelope, and how many in the green envelope. Please don't leave any money out of the envelopes. Remember, it is your own choice how you want to distribute the 6000 Riels. If you have finished putting the bills into the envelopes, please signal the instructor. We then come and collect the envelopes. After all the tasks have been completed each of you will role a die to decide which task will be paid out. If this task is chosen you will flip the coin to determine whether the money in the green envelope is tripled or zero.

[Collect the envelopes ]. 


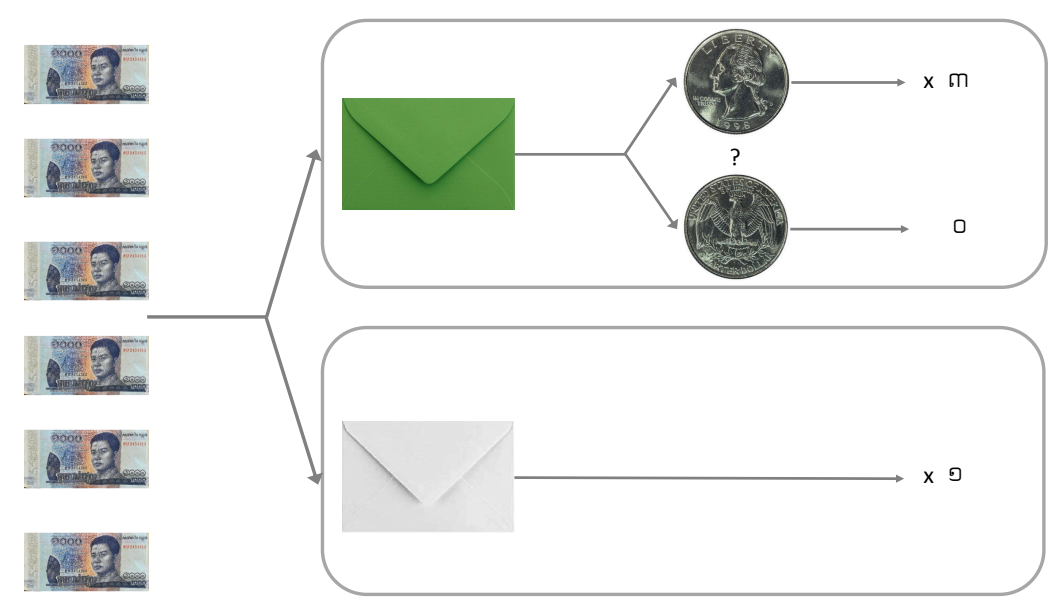

Figure A.1.1: Poster aid for the risk elicitation.

\section{A.2 Instructions for the linear Public Good game}

Now we will read the instructions and give examples for the second task. Once we are sure that you understand your task, we will begin.

In this task, we will divide you into groups of two: you and another person in your community. You will not come to know to which group you belong. Likewise, you will not come to know the identity of the other member of your group. Similarly, he will not come to know your identity either.

We will give each of you an endowment of 6000 Riels, containing six bills of 1000 Riels. With this endowment of 6000 Riels, you have to decide how much you want to keep for yourself and how much you want to contribute to a group fund. The group fund is the money contributed by you and your partner. The difference between the money you keep for yourself and the group fund is that the money you keep to yourself remains the same, but the group fund is increased. For every 1000 Riel in the group fund, there will be 500 Riel added. After the money in the group fund has been increased, the total money will be divided equally between you and your partner, irrespective of how much you or your partner have put into the group fund [Please repeat this again].

Please note that, when you make the actual decision, the money you want to keep for yourself is to be put in the white envelope [show the white envelope], and the money you want to contribute to the group fund is to be put in the green envelope [show the 
green envelope]. With this endowment of 6000 Riels, you are free to contribute whatever amount to the group fund, without knowing how much your partner would contribute.

Examples:

[Have an assistant showing with the money what is actually happening. Put money on the green envelope, add the correct amount, divide into two piles] Now my assistant will demonstrate you some examples how the return from the group fund work.

1 If both group members put zero Riels each in the group fund, [ask the group] how much will be in the group fund? There will be zero Riels in the group fund. [ask the group] By how much will the group fund be increased? The group fund will be increased by zero Riel. [Ask the group] How much is in total in the group fund? In total the group fund contains now zero Riel. [Ask the group] How much does each member get from the group fund? Each gets zero Riel from the group fund.

2 If both group members put 3000 Riels each in the group fund, [ask the group] how much will be in the group fund? There will be 6000 Riels in the group fund. [ask the group] By how much will the group fund be increased? The group fund will be increased by 3000 Riel. [Ask the group] How much is in total in the group fund? In total the group fund contains now 9000 Riel. [Ask the group] How much does each member get from the group fund? Each gets 4500 Riel from the group fund.

3 If both group members put 6000 Riels each in the group fund, [ask the group] how much will be in the group fund? There will be 12000 Riels in the group fund. [ask the group] By how much will the group fund be increased? The group fund will be increased by 6000 Riel. [Ask the group] How much is in total in the group fund? In total the group fund contains now 18000 Riel. [Ask the group] How much does each member get from the group fund? Each gets 9000 Riel from the group fund.

Have you understood this part? Do you have any questions? If there are no questions we continue with the examples.

[EXAMPLES]

Now we will show you with examples how the task is done in practice. In these examples you can see the decision of both participants. In the actual task, you will not know what the other person in your group decides. [Randomly select 2 players and give each of them six bills of $1000 \mathrm{Riel}$ and a white and a green envelope. Assign who takes the role as participant I \& II. Please make sure that each time YOU tell the persons on how much he should put into the project. Do not allow the players to take the decision because this may influence the decision of other potential players.] In the following we give you two examples. 


\section{Example 1:}

Suppose you two are in the same group who perform this task. As mentioned before, each of you receives an endowment of 6000 Riels. Member I decides to contribute 4000 Riel into the group fund and keeps 2000 Riels for himself. Member I, please put 4000 Riels on top of the green envelope, and the remaining 2000 Riel on top of the white envelope.

Now suppose that member II decides that he contributes zero Riel to the group fund and keeps 6000 Riels for himself. Member II, please put zero Riel on top of the green envelope, and 6000 Riels on top of the white envelope.

[Ask the group;]

Now, can you tell me how much did member I put in the green envelope?[Take the money out and put it on the table] How much did he put in the white envelope? [Take the money out and put it on the table]

How much did member II put in the green envelope? [Take the money out and put it on the table] How much did he put in the white envelope? [Take the money out and put it on the table]

How much money is in the group fund before it is increased? [Count the bills for everyone to see]. We have 4000 Riels in the green envelopes. By how much will the group fund be increased? [Put another 2000 Riels on the project fund pile and count each pile for people to see]. This will be increased by 2000 Riel. In total there are now 6000 Riels in the group fund Finally, how much does each member get from the group fund then? [Divide the pile into two piles of 3000]

Each member will thus get 3000 Riels from the group fund since the group fund has to be equally divided regardless how much each contributes.

[Ask the group]

How much does member I get in total? To know how much he earns, we count the money in his green and white envelopes.

Member I keeps 2000 Riels for himself (in his white envelope) and gets 3000 Riels from the group fund (in his green envelope). In total, member I gets 5000 RielS.

[Ask the group;

How much does member II get in total? To know how much he earns, we count the money in his green and white envelopes.

member II keeps 6000 Riels for himself (in his white envelope) and gets 3000 Riels from the group fund (in his green envelope). In total member II gets 9000 RielS.

[Ask the group;

Can you tell me, who earned more? Member I or member II?[member 2]

[Randomly select 2 players and give each of them six bills of 1000 Riel and a white and a green envelope. Assign who takes the role as participant I \& II. Please make sure that each time YOU tell the persons on how much he should put into the project. Do not allow the players to take the decision because this may influence the decision of other potential players.] 


\section{Example 2:}

Now suppose that member I decides that he contributes 5000 Riel into the group fund and keeps 1000 Riels for himself. Member I, please put 5000 Riels on top of the green envelope, and 1000 Riels on top of the white envelope.

Now suppose that member II decides that he contributes 3000 Riels to the group fund and keeps 3000 Riels for himself. Member II, please put 3000 Riels on top of the green envelope and the remaining 3000 Riels on top of the white envelope.

[Ask the group;]

Now, can you tell me how much money did member I put in the green envelope?[Take the money out and put it on the table] How much did he put in the white envelope? [Take the money out and put it on the table]

How much did member II put in the green envelope? [Take the money out and put it on the table] How much did he put in the white envelope? [Take the money out and put it on the table]

How much money is in the group fund before it is increased?[Count the bills for everyone to see]. We have 8000 Riel in the green envelopes. By how much will the group fund be increased? [Put another 4000 Riels on the group fund pile and count each pile for people to see]. This will be increased by 4000 Riel. In total there are now 12000 Riels in the group fund.

Finally, how much does each member get from the group fund then? [Divide the pile into two piles of 6000$]$

Each member will thus get 6000 Riels from the group fund since the group fund has to be equally divided regardless how much each contributes.

\section{[Ask the group]}

How much did member I get in total? To know how much he earns, we count the money in his green and white envelopes.

Member I keeps 1000 Riels for himself (in his white envelope) and gets 6000 Riels from the group fund (in his green envelope). In total, member I gets 7000 Riels.

[Ask the group;]

How much does member II get in total? To know how much he earns, we count the money in his green and white envelopes.

Member II keeps 3000 Riels for himself (in his white envelope) and gets 6000 Riels from the group fund (in his green envelope). In total member II gets 9000 Riel.

[Ask the group; ]

Can you tell me, who earned more? Participant I or participant II? [member 2]

Are there any questions? Do you need more examples? [If more examples are needed pick two other participants and do the examples again. If not, collect the money and proceed.]

Please remember that any money that you put into the group fund is first increased by half and then divided equally with your partner. Any amount that you keep for yourself remains the same. If you keep 1000 Riels for yourself, it remains 1000 Riels. It neither 


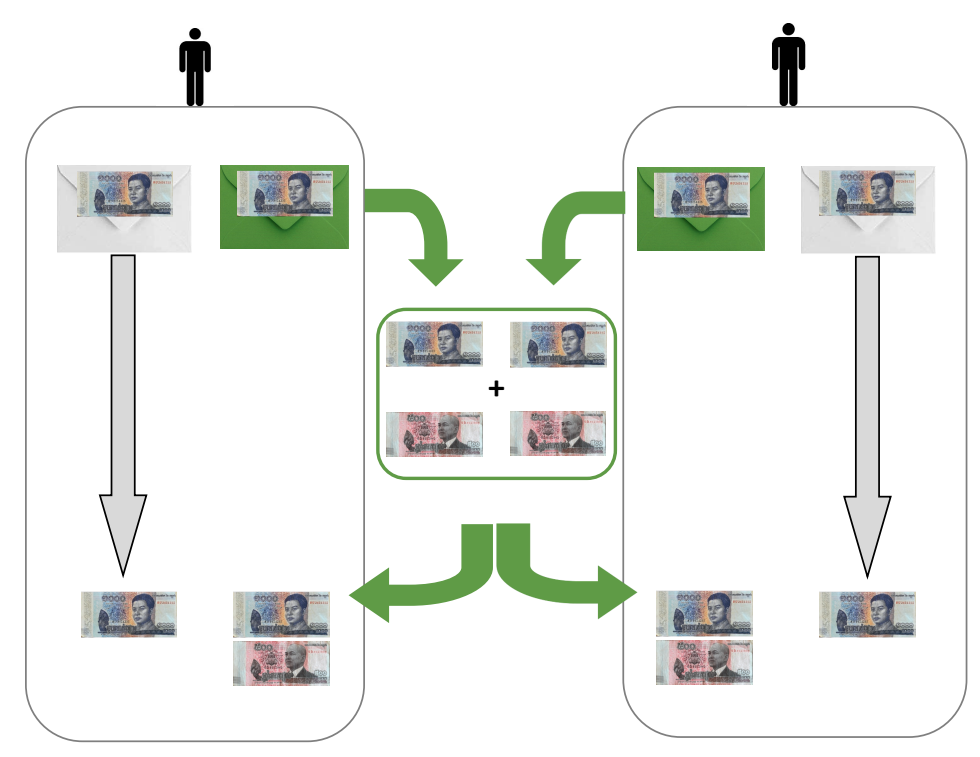

Figure A.2.1: Poster aid for the linear public good game

increases nor is it divided. Your final earning from the task is the sum of the amount you keep for yourself and the amount you get from the group fund.

Are there any more questions? If there are no questions anymore please sit down and put up the blinds. We will provide each of you with an endowment of 6000 Riels, containing 6 bills of 1000 Riels and a green and a white envelope.

\section{[Distribute the money and the envelopes]}

Please decide now how much you want to put into the group fund (green envelope) and how much you want to keep for yourself (white envelope). Once you are done, we will come and collect the envelopes.

[When everyone is done, please collect the envelopes and make sure that on both envelopes the ID number is written down]

\section{A.3 Instructions for conditional Public Good game}

Now we will read the instructions and give examples for the third task. This task is only slightly different from task 2 , which we have just finished. As before you are in groups of two: you will be matched with a new partner who is someone in your community. In the last task, you did not know how much your partner put into the group fund. In this task, 
we allow you to make a plan about how much to contribute given how much your partner puts into the group fund. For every 1000 Riels in the group fund (the green envelope), we will add 500 Riels extra. The group fund will be divided equally between you and your partner.

Do you have any questions? If there are no further questions we will distribute the money and the envelopes to you.

[The TASK] Now it's time to make 7 decisions. Please think carefully about those decisions.

[Distribute 6000 Riel and a green and a white envelope to the participants. Make sure the blinds are put up.]

Decision 1: Out of an endowment of 6000 Riels, your partner in the group contributes 0 Riel to the group fund [put the money on the green envelope and show to everyone]. Now, out of an endowment of 6000 Riels, how much would you like to contribute to the group fund? Please put the money you want to contribute to the group fund in the green envelope and the money for yourself in the white envelope. Now this decision is over. Please wait till we have collected the envelopes.

[Collect the envelopes, ensure that the id numbers are on them. Distribute new envelopes and another set of $6000 \mathrm{Riel}]$

Decision 2: Out of an endowment of 6000 Riels, your partner in the group contributes 1000 Riels to the group fund [put the money on the green envelope and show to everyone]. Now, out of an endowment of 6000 Riels, how much would you like to contribute to the group fund? Please put the money you want to contribute to the group fund in the green envelope and the money for yourself in the white envelope. Now this decision is over. Please wait till we have collected the envelopes.

[Collect the envelopes, ensure that the id numbers are on them. Distribute new envelopes and another set of $6000 \mathrm{Riel}]$

Decision 3: Out of an endowment of 6000 Riels, your partner in the group contributes 2000 Riels to the group fund [put the money on the green envelope and show to everyone]. Now, out of an endowment of 6000 Riels, how much would you like to contribute to the group fund? Please put the money you want to contribute to the group fund in the green envelope and the money for yourself in the white envelope. Now this decision is over. Please wait till we have collected the envelopes.

[Collect the envelopes, ensure that the id numbers are on them. Distribute new envelopes and another set of $6000 \mathrm{Riel}]$

Decision 4: Out of an endowment of 6000 Riels, your partner in the group contributes 3000 Riels to the group fund [put the money on the green envelope and show to everyone]. Now, out of an endowment of 6000 Riels, how much would you like to contribute to the group fund? Please put the money you want to contribute to the group fund in the green envelope and the money for yourself in the white envelope. Now this decision is over. Please wait till we have collected the envelopes.

[Collect the envelopes, ensure that the id numbers are on them. Distribute 
new envelopes and another set of $6000 \mathrm{Riel}]$

Decision 5: Out of an endowment of 6000 Riels, your partner in the group contributes 4000 Riels to the group fund [put the money on the green envelope and show to everyone]. Now, out of an endowment of 6000 Riels, how much would you like to contribute to the group fund? Please put the money you want to contribute to the group fund in the green envelope and the money for yourself in the white envelope. Now this decision is over. Please wait till we have collected the envelopes.

[Collect the envelopes, ensure that the id numbers are on them. Distribute new envelopes and another set of $6000 \mathrm{Riel}]$

Decision 6: Out of an endowment of 6000 Riels, your partner in the group contributes 5000 Riels to the group fund [put the money on the green envelope and show to everyone]. Now, out of an endowment of 6000 Riels, how much would you like to contribute to the group fund? Please put the money you want to contribute to the group fund in the green envelope and the money for yourself in the white envelope. Now this decision is over. Please wait till we have collected the envelopes.

[Collect the envelopes, ensure that the id numbers are on them. Distribute new envelopes and another set of 6000 Riel.]

Decision 7: Out of an endowment of 6000 Riels, your partner in the group contributes 6000 Riels to the group fund [put the money on the green envelope and show to everyone]. Now, out of an endowment of 6000 Riels, how much would you like to contribute to the group fund? Please put the money you want to contribute to the group fund in the green envelope and the money for yourself in the white envelope. Now this decision is over. Please wait till we have collected the envelopes.

[Collect the envelopes, ensure that the id numbers are on them.]

So far, we have finished 3 tasks. We will have a 15-minute break now.

\section{A.4 Instructions for the Threshold Public Good Game}

\section{A.4.1 Public Good Treatment}

Now we will read the instructions and give examples for the fourth task. Once we are sure that you understand the task, we will begin.

In this task, we will divide you into groups of three participants: you and two other persons who are members in your community. You will not come to know to which group you belong. Likewise, you will not come to know the identity of the other two members of your group. Similarly, the other two members will not come to know your identity either. In this task, each participant will receive an endowment of 6000 Riel consisting of 6 bills of 1000 Riel. With this endowment of 6000 Riel, you have to decide how much you want to keep for yourself and how much you want put into the group fund. The group fund is 


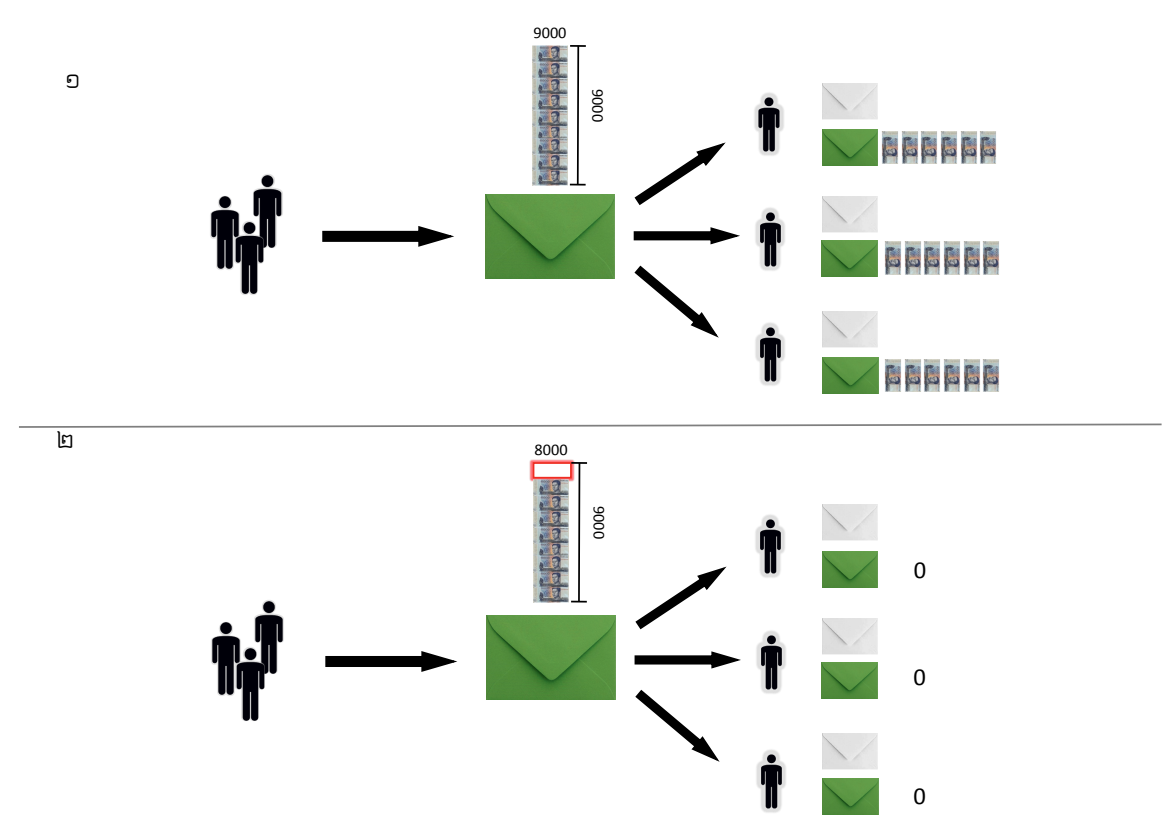

Figure A.4.1: Poster for the public good treatment.

the money contributed by you and by two other members in your group.

The money you want to keep for yourself you put in the white envelope. The amount of money you put in the white envelope remains the same, does not increase or decrease, and you will get it for sure.

The money you want to contribute to the group fund, you put in the green envelope. The amount of money you get from the group fund can change, depending on how much you and the other two group members put into the green envelopes. Each group member either get zero Riel or 6000 Riels from the group fund. If 9000 Riels or more are in the green envelopes, each group member will get 6000 Riel from the group fund. If less than 9000 Riels are in the green envelopes, each group member will get zero Riel from the group fund.

\section{[Ask the group]}

1) If the total money in the green envelopes is 8000 Riel which is less than 9000, how much will each member get out of the group fund? The answer is 0 Riel.

\section{[Ask the group]}

2) If the total money in the green envelopes is 9000 Riel which is exactly 9000, how much will each member get out of the group fund? The answer is 6000 Riel.

\section{[Ask the group]}

3) If the total money in the green envelopes is 10000 Riel which is more than 9000 , how much will each member get out of the group fund? The answer is 6000 Riel. 


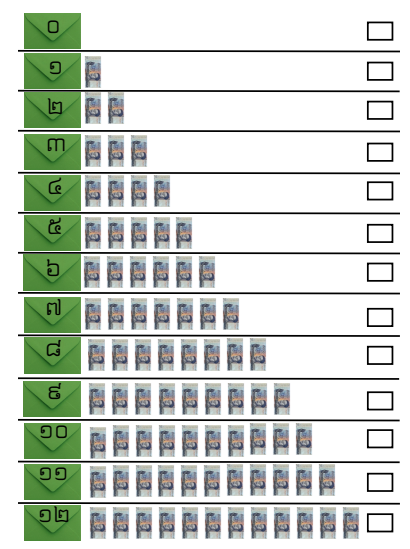

Figure A.4.2: Belief elicitation in the public good treatment.

Have you understood what I have just explained so far? If you have any doubts or questions at this point, please raise your hand and ask the questions.

Remember: The money you want to keep for yourself you put in the white envelope, and the money that you want to put into the group fund you put in the green envelope. Your total earning is the sum from the white envelope and the money you get from the group fund. The money you get from the group fund is 6000 Riels each if the total amount in the green envelopes is 9000 Riel or more. In contrast, the money you gets from the group fund is zero Riel each if the total amount in the green envelopes is less than 9000 Riel.

\section{[EXAMPLES]}

We will show you with an example how the task is done in action. In these examples you can see the decision of all the three participants. In the actual task, however, you will not know what the other two in your group decide.

[Randomly select 3 players and give them six bills of 1000 Riel and a white and a green envelope each. Assign who takes the role as participant I \& II \& III. Please make sure that each time YOU tell the persons on how much he should put into the green and white envelope. Do not allow the players to take the decision because this may influence the decision of other potential players.]

In the following we give you two examples:

\section{Example 1:}

Now we will see what happens if member I puts 3000 Riel in the green envelope, member II and member III put 0 Riel in the green envelope. member I, please put 3000 Riel on top of the green envelope and the remaining 3000 Riels on top of the white envelope. Member II and III, please put 0 Riel on top of the green envelope and the remaining 6000 Riels on top of the white envelope. 


\section{[Ask the group;}

Now, can you tell me how many Riel are in the green envelopes?

We have 3000 Riel in the green envelopes. The green envelopes contain less than 9000 Riel. Each member will thus get 0 Riel from the group fund [take away all bills on top of the green envelopes].

\section{[Ask the group;]}

How many Riel does member I get in total?

member I gets 3000 Riel in total, since he has 3000 Riel his white envelope and gets zero from the group fund.

\section{[Ask the group;}

How many Riel does member II get in total?

member II gets 6000 Riel in total, since he has 6000 Riel in his white envelope and gets zero from the group fund.

\section{[Ask the group;}

How many Riel does member III get in total?

member III gets 6000 Rielin total, since he has 6000 Riel in his white envelope and gets zero from the group fund. [Ask the participants to take the money of the envelopes again]

If you have any questions, please raise your hand and ask them now.

\section{Example 2:}

Now we will see what happens if member I puts 6000 Riel in the green envelope, member II puts 3000 Riel in the green envelope, and member III puts 0 Riel in the green envelope. Member I, please put 6000 Riel on top of the green envelope and the remaining 0 Riels on top of the white envelope. Member II, please put 3000 Riel on top of the green envelope and the remaining 3000 Riels on top of the white envelope. Member III, please put 0 Riel on top of the green envelope and the remaining 6000 Riels on top of the white envelope.

\section{[Ask the group;}

Now, can you tell me how many Riel are in the green envelopes?

We have 9000 Riel in the green envelopes. Each member will get 6000 Riel from the group fund. [add bills to each green envelope so the total is $6000 \mathrm{Riel}$ ]

[Ask the group;

How many Riel does member I get in total?

Member I gets 6000 Riel in total, since he has 0 Riel in his white envelope and gets 6000 Riel from the group fund.

\section{[Ask the group;}

How many Riel does member II get in total?

Member II gets 9000 Riel in total, since he has 3000 Riel in his white envelope and gets 6000 Riel from the group fund.

\section{[Ask the group;]}

How many Riel does member III get in total? 
Member III gets 12000 Riel in total, since he has 6000 Riel in his white envelope and gets 6000 Riel from the group fund.

If you have any questions, please raise your hand and ask them now.

Since there are no questions anymore, we are ready to make the decisions now.

[Distribute the envelopes (make sure that in the green envelope is a paper slip) and the 6 bills and make sure that the blinds are up]

The difficulty about making this decision is that you do not know how much your two group members will put into the green envelope. You can only guess how much you need to put in the green envelope to have jointly at least 9000 . We would like to know what you think how much your partners will put in the green envelope. Therefore, we included a paper slip in the green envelope [show the paper slip]. This paper shows you the thirteen options of how much your other two group members could jointly put into the green envelopes. The first option (the top one which has 0 Riel in the green envelope) means that the other two members jointly put 0 Riel in the green envelope. The last option (the bottom one which has 12000 Riel in the green envelope) means the other two members jointly put 12000 Riel in the green envelope. There is no way of knowing how much the other two group members will put in the green envelope. You have to guess. If you guess correctly, we will pay you another 1000 Riels.

How much do you think both of your group members will put jointly in the green envelope? Please tick the box. [Show how to tick the box]. Once you ticked the box, please put the paper strip back into the green envelope.

Now we are ready to make the decision. Please distribute the 6000 Riels between the green and the white envelope.

[Collect the envelopes and make sure that the ID number is on both envelopes. ]

\section{A.4.2 Public Bad Treatment}

Now we will read the instructions and give examples for the fourth task. Once we are sure that you understand the task, we will begin.

In this task, we will divide you into groups of three participants: you and two other persons who are members in your community. You will not come to know to which group you belong. Likewise, you will not come to know the identity of the other two members of your group. Similarly, the other two members will not come to know your identity either. In this task, each participant will receive an endowment of 6000 Riel consisting of 6 bills of 1000 Riel. With this endowment of 6000 Riel, you have to decide how much you want to keep for yourself and how much you want put into the group fund. The group fund is the money contributed by you and by two other members in your group.

The money you want to keep for yourself you put in the white envelope. The amount of money you put in the white envelope remains the same, does not increase or decrease, and you will get it for sure. 


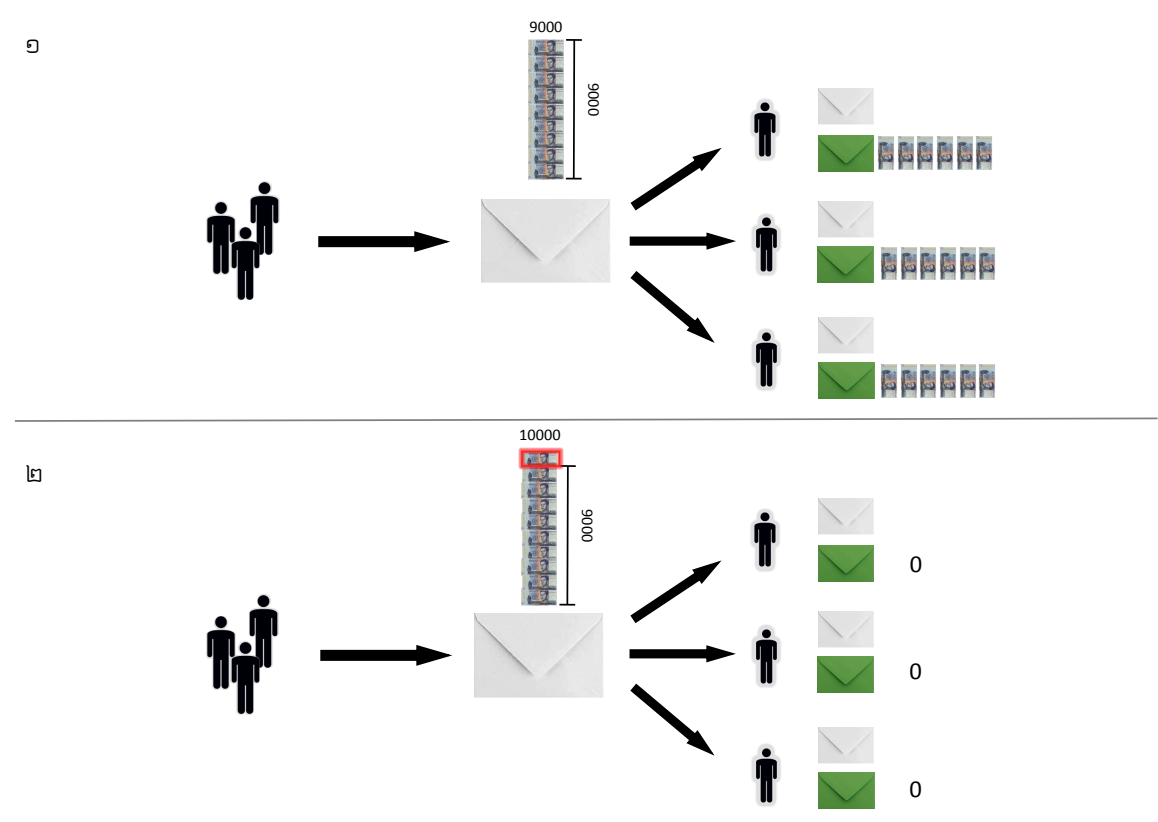

Figure A.4.3: Poster for the public bad treatment.

The money you want to contribute to the group fund, you put in the green envelope. The amount of money you get from the group fund can change, depending on how much you and the other two group members put into the white envelope. Each group member either gets zero Riels or 6000 Riels from the group fund. If 9000 Riels or less are in the white envelopes, you get 6000 Riel each from the group fund. If more than 9000 Riels are in the white envelopes, each of you gets zero from the group fund. [Ask the group]

1) If the total money in the white envelopes is 10000 Riel which is more than 9000 , how much will each member get out of the group fund? The answer is 0 Riel.

\section{[Ask the group]}

2) If the total money in the white envelopes is 9000 Riel which is exactly 9000 , how much will each member get out of the group fund? The answer is 6000 Riel.

\section{[Ask the group]}

3) If the total money in the white envelopes is 8000 Riel which is less than 9000, how much will each member get out of the group fund? The answer is 6000 Riel.

Have you understood what I have just explained so far? If you have any doubts or questions at this point, please raise your hand and ask the questions.

Remember: The money you want to keep for yourself you put in the white envelope, and the money that you want to put into the group fund you put in the green envelope. Your total earning is the sum from the white envelope and the money you get from the group fund. The money you get from the group fund is 6000 Riels if the total amount in the 


\begin{tabular}{|c|c|c|}
\hline 0 & & $\square$ \\
\hline o & & $\square$ \\
\hline 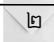 & FE & $\square$ \\
\hline m & 盛间 & $\square$ \\
\hline ๘ & 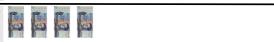 & $\square$ \\
\hline ๘ & 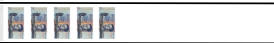 & $\square$ \\
\hline & 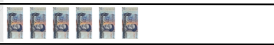 & $\square$ \\
\hline & 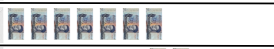 & $\square$ \\
\hline c & 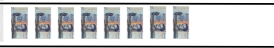 & $\square$ \\
\hline छ & 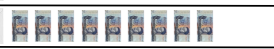 & $\square$ \\
\hline פ० & 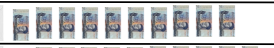 & $\square$ \\
\hline פอ & 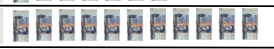 & $\square$ \\
\hline פ回 & 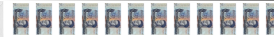 & \\
\hline
\end{tabular}

Figure A.4.4: Belief elicitation in the public bad treatment.

white envelopes is 9000 Riel or less. Each of you gets zero from the group fund if the total amount in the white envelope is more than 9000 Riel.

\section{[EXAMPLES]}

We will show you with examples how the task is done in action. In this example you can see the decision of all the three participants. In the actual task, however, you will not know what the other two in your group decide. [Randomly select 3 players and give them six bills of $1000 \mathrm{Riel}$ and a white and a green envelope each. Assign who takes the role as participant I \& II \& III. Please make sure that each time YOU tell the persons on how much he should put into the envelopes. Do not allow the players to take the decision because this may influence the decision of other potential players.]

In the following we give you two examples:

Example 1:

Now we will see what happens if member I puts 3000 Riel in the white envelope, member II and member III put 6000 Riel in the white envelope. Member I, please put 3000 Riel on top of the white envelope and the remaining 3000 Riels on top of the green envelope. Member II and III, please put 6000 Riel on top of the white envelope and the remaining 0 Riels on top of the green envelope.

[Ask the group;]

Now, can you tell me how many Riel are in the white envelopes?

We have 15000 Riel in the white envelopes. The white envelopes contain more than 9000 Riel. Each member will thus get 0 Riel from the group fund [take away all bills on top of the green envelopes]

[Ask the group;]

How many Riel does Participant I get in total? Member I gets 3000 Riel in total, since he has 3000 Riel his white envelope and gets zero from the group fund. 


\section{[Ask the group;}

How many Riel does member II get in total?

member II gets 6000 Riel in total, since he has 6000 Riel in his white envelope and gets zero form the group fund.

[Ask the group;]

How many Riel does member III get in total?

Member III gets 6000 Riel in total, since he has 6000 Riel in his white envelope and gets zero form the group fund.

[Ask the participants to take the money of the envelopes again]

Example 2: Now we will see what happens if member I puts 0 Riel in the white envelope, member II puts 3000 Riel in the white envelope, and member III puts 6000 Riel in the white envelope. Member I, please put 0 Riel on top of the white envelope and the remaining 6000 Riels on top of the white envelope. Member II, please put 3000 Riel on top of the white envelope and the remaining 3000 Riels on top of the green envelope. Member III, please put 6000 Riel on top of the white envelope and the remaining 0 Riels on top of the green envelope.

\section{[Ask the group;}

Now, can you tell me how many Riel are in the white envelopes?

We have 9000 Riel in the white envelopes. Each participant will get 6000 Riel from the group fund. [add bills to each green envelope so the total is $6000 \mathrm{Riel}$ ]

[Ask the group;

How many Riel does member I get in total?

Member I gets 6000 Riel in total, since he has 0 Riel in his white envelope and gets 6000 Riel from the group fund.

\section{[Ask the group;]}

How man Riel does member II get in total?

Member II gets 9000 Riel in total, since he has 3000 Riel in his white envelope and gets 6000 Riel from the group fund.

\section{[Ask the group;]}

How man Riel does member III get in total?

Member III gets 12000 Riel in total, since he has 6000 Riel in his white envelope and gets 6000 Riel from the group fund.

If you have any questions, please raise your hand and ask them now. [If necessary, repeat the examples in the same order]

Since there are no questions anymore, we are ready to make the decisions now.

[Distribute the envelopes (make sure that in the white envelope is a paper slip) and the 6 bills and make sure that the blinds are up]

The difficulty about making this decision is that you do not know how much your two group members will put into the white envelope. You can only guess how much you need to put in the white envelope to have jointly not more than 9000 . We would like to know what you think how much your partners will put in the white envelope. Therefore, we 
included a paper slip in the white envelope [show the paper slip]. This paper shows you the thirteen options of how much your other two group members could jointly put into the white envelopes. The first option (the top one which has 0 Riel in the white envelope) means that the other two members jointly put 0 Riel in the white envelope. The last option (the bottom one which has 12000 Riel in the white envelope) means the other two members jointly put 12000 Riel in the white envelope. There is no way of knowing how much the other two group members will put in the white envelope. You have to guess. If you guess correctly, we will pay you another 1000 Riels.

How much do you think both of your group members will put jointly in the white envelope? Please tick the box. [Show how to tick the box]. Once you ticked the box, please put the paper strip back into the white envelope.

Now we are ready to make the decision. Please distribute the 6000 Riels between the green and the white envelope.

[Collect the envelopes and make sure that the ID number is on both envelopes. ] 



\section{Appendix B}

\section{Survey}

1 Session ID

2 Identification number of the participant

3 What is your relation to the head of the family? [Pick one]

- I am the household head

- Spouse

- Child

- Parent

- Other relative

4 What is your marital status? [Pick one]

- Single

- Married

- Divorced

- Widow(er)

5 Gender [Pick one]

- Male

- Female

6 How old are you? (years) [integer]

7 How many years did you attend school?[ [integer]

8 What is your primary occupation? [Pick one] 
- Rice farmer

- Fisher

- Other

9 What is the primary occupation of your mother? [Pick one]

- Rice farmer

- Fisher

- Other

10 What is the primary occupation of your father? [Pick one]

- Rice farmer

- Fisher

- Other

11 How many people are in your family? (including you)[integer]

12 How many children are in your family? [integer]

13 Among all of the members, how many do earn income?[integer]

14 Does your family receive remittances?[Pick one]

- Yes

- No

15 Does anybody in your family earn wages? [Pick one]

- Yes

- No

16 Does anybody in your family earn salary? [Pick one]

- Yes

- No

17 Does your family own farmland? [Pick one]

- Yes

- No

18 [If Q17 yes], how many hectares of farmland does your family own? [decimal]

19 Did your family cultivate rice last year (2018)? [Pick one] 
- Yes

- No

20 [If Q19 yes], what is the main purpose of cultivating rice? [Pick one]

- Household consumption

- Sale

- Household consumption and Sale

21 [If Q19 yes], how many times per year did you cultivate rainy season rice? [integer]

22 [If Q19 yes], how many times per year did you cultivate dry season rice? [integer]

23 [If Q19 yes], how many hectares of paddy land does your family own? [decimal]

24 [If Q19 yes] Are you a member of a Farmer Water User Community (FWUC)? [Pick one]

- Yes

- No

25 [If Q24 no], why not? [pick multiple]

- I'm not interested in

- I don't have time/money for membership

- There is no FWUC here

- Other

26 [If Q19 yes], how many hectares of paddy land with access to irrigation does your family own? [decimal]

27 [If Q26 i0] For your most important paddy land with access to irrigation, did your family irrigate the paddy field last year? [Pick one]

- Yes

- No

28 [If Q27 yes], what was the water fee per hectares (KHR)? [decimal]

29 [If Q26 ;0] For your most important paddy land with access to irrigation, how far is it from the water source to your land? (in $\mathrm{m}$ ) [decimal]

30 [If Q26 i0] For your most important paddy land with access to irrigation, what is the closest water source?[Pick one]

- Perennial Stream 
- Intermittent stream

- Lake

- Reservoir

- Main canal

- Secondary canal

- Other

31 [If Q30 Other] For that water source, how well-maintained is it? [Pick one]

- Excellent

- Good

- Average/OK

- Poor

- Very poor

32 [If Q26;0] For that water source, did you have enough water for irrigating? [Pick one]

- Yes

- No

33 [If Q32 no], how scarce was it last year? [Pick one]

- Somehow scarce

- Moderately scarce

- Extremely scarce

- I cannot rate

34 [If Q32 no] Overall, how many times did you face such a scarcity in the last 5 years? [integer]

35 [If Q32 no] Overall, how would you rate the degree of water scarcity in your community? [Pick one]

- Somehow scarce

- Moderately scarce

- Extremely scarce

- I cannot rate 
36 [If Q32 no] What do you think are the reasons for this water scarcity? [Pick multiple]

- Drought

- Climate change

- People overuse

- Increasing demand for water

- Other reasons

37 [If Q32 no] If water is scarce, has there been any conflict related to water use or water sharing? [Pick one]

- Yes

- No

38 [If Q37 yes], who played a role in mediating those conflicts over water use/sharing? [Pick multiple]

- FWUC leader

- Village/Commune Chief

- Provincial government official

- Other

39 [If Q37 yes], how do you rate the effectiveness of that conflict resolution? [Pick one]

- Not effective

- Somewhat Effective

- Very effective

- Not sure

40 Did your family engage in fishing in the last year (2018)? [Pick one]

- Yes

- No

41 [If Q40 yes] What is the main purpose of fishing? [Pick one]

- Household consumption

- Sale 
- Household consumption and Sale

42 [If Q40 yes] How many motor boats does your family own? [integer]

43 [If Q40 yes] How many row fishing boats does your family own? [integer]

44 [If $Q 40$ yes] How many kilograms of fish does your family catch on a good trip? [decimal]

45 [If $Q 40$ yes] How many kilograms of fish does your family catch on a typical trip? [decimal]

46 [If Q40 yes] How many kilograms of fish does your family catch on a bad trip? [decimal]

47 [If Q40 yes] Are you a member of a community fishery (CF)? [Pick one]

- Yes

- No

48 [If Q47 no], why not? [pick multiple]

- I'm not interested in

- I don't have time/money for membership

- There is no CF here

- Other

49 [If Q40 yes] Has your family experienced a decline in fish catch in the past 5 years? [Pick one]

- Yes

- No

50 [If Q49 yes] what do you think are the reasons for a decline in the fish catch? [Pick multiple]

- Overfishing

- Illegal fishing

- Natural causes

- Other

51 [If Q50 Other] please specify [text]

52 [If $Q 40$ yes] In the past 5 years, has your family observed a collapse of certain type of fish? [Pick one] 
- Yes

- No

53 [If Q52 yes], which fish did collapse? [text]

54 [If $Q 49$ yes] If there was a decline in fish catch, have you observed any conflict in regard to fishing in your community? [Pick one]

- Yes

- No

55 [If Q54 yes], who played a role in mediating those conflicts? [Pick multiple]

- Community Fishery leader

- Village/Commune Chief

- Provincial government official

- Other

56 [If Q55 yes], How do you rate the effectiveness of conflict resolution in regard to fishing? [Pick one]

- Not effective

- Somewhat Effective

- Very effective

- Not sure

57 Did your family experience food shortage last year? [Pick one]

- Yes

- No

58 [If Q57 yes] In which months did you experience food shortage? [Pick multiple]

- January

- February

- March

- April

- May

- June

- July 
- August

- September

- October

- November

- December

59 [If Q57 yes] How does your family cope with food shortages? [Pick multiple]

- Selling rice

- Go fishing

- Selling labor

- Remittances

- Reduce Consumption

- Other

60 [If Q59 other], Please specify what you do to cope with food shortage. [text]

61 Have you taken loans? [Pick one]

- Yes

- No

62 [If Q61 yes] What is the primary purpose of taking loans? [Pick one]

- Agricultural activities

- Fishing activities

- Household consumption needs

- Paying existing debts

- Other

63 [If Q61 yes] Do you face difficulties paying back the loans? [Pick one]

- Yes

- No

64 Did your family experience any sudden drop in income (income shock) last year? [Pick one]

- Yes

- No 
65 [If Q 61 yes], what was the reason for that sudden drop in income? [Pick multiple]

- Crop loss

- Livestock loss

- Land loss

- Fishing equipment loss

- Agricultural equipment loss

- Other

66 Did your family experience any major natural disasters last year? [Pick one]

- Yes

- No

67 [If Q66 yes], what was it? [Pick multiple]

- Drought

- Flood

- Fish Dying

- Storm

- Other

68 Do you think most people in this community can be trusted? [Pick one]

- Yes

- No

69 Do you think most people in this community are willing to help if someone is in need? [Pick one]

- Yes

- No

70 Suppose that 10 of your neighbors are invited to help in community activities (e.g. repairing a canal or dam). How many would show up? [decimal]

71 We have reached the end of the survey. I thank you in the name of the team for your participation. 




\section{SENSE}

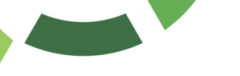

Netherlands Research School for the

Socio-Economic and Natural Sciences of the Environment

\section{I P L O M A \\ for specialised PhD training}

The Netherlands research school for the Socio-Economic and Natural Sciences of the Environment (SENSE) declares that

\section{Esther Schuch}

born on 30 September 1982 in Simmern, Germany

has successfully fulfilled all requirements of the educational PhD programme of SENSE.

Wageningen, 20 October 2020

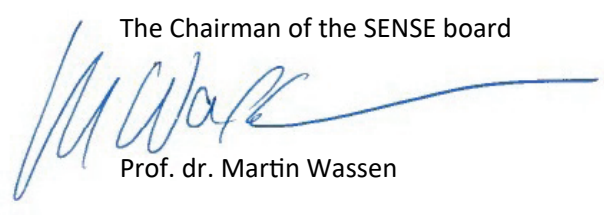

the SENSE Director of Education

The SENSE Research School has been accredited by the Royal Netherlands Academy of Arts and Sciences (KNAW)

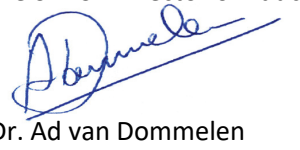

Dr. Ad van Dommelen

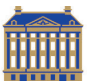

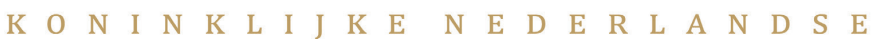

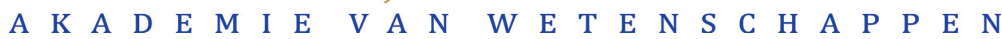




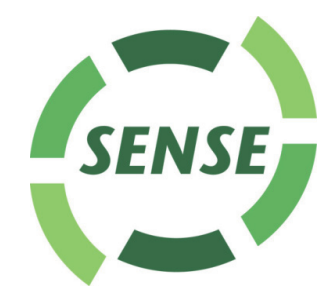

The SENSE Research School declares that Esther Schuch has successfully fulfilled all requirements of the educational PhD programme of SENSE with a work load of $48.0 \mathrm{EC}$, including the following activities:

\section{SENSE PhD Courses}

- Environmental research in context (2016)

- Research in context activity: 'Writing accessible science blog posts, coordinating Twitter outreach, and listing ten communicative recommendations for effective science communication' (2019)

o Bayesian Statistics (2016)

\section{Selection of Other PhD and Advanced MSc Courses}

- Economics and Management of Natural Resources, Wageningen University (2016)

- Behavioral \& Experimental Economics, Wageningen University (2016)

- Summer school Field Experiments, University of Copenhagen (2016)

- Bounded Rationality - Predictions under Uncertainty, Max Planck Institute (2017)

- From Single-Species to Ecosystem-Based (Fisheries) Management, University of Hamburg

- Climate Science and Climate Change Impacts, Météo France

- Advanced time series analysis, DTU Aqua

- Socio-Economics in Fisheries, Helsinki University

- Communication and networking, University of Oslo

\section{Management and Didactic Skills Training}

- Co-supervising MSc student with thesis entitled 'On the Determinants of Risk and ProSocial Preferences and their Role in Cooperation under Social Uncertainty' (2019)

- PhD Student Representative for scientific questions in the training network (2017-2018)

o Organiser of the monthly ENR PhD seminar series (2018)

\section{Selection of Oral Presentations}

- Cognitive Biases and Expert Judgements in Natural Resource Management. Economics Science Association (ESA) world conference, 28 June - 1 July 2018, Berlin, Germany

- Perfect is the enemy of good - When more accurate stock assessments are less valuable for management. International Institute of Fisheries Economics \& Trade (IIFET) world conference, 16- 20 July 2018, Seattle, United States of America

- The Good, the Bad, the Human - a threshold public good game with public good and public bad framing. MARmaED symposium, 25 - 26 June- 2019, Palma de Mallorca, Spain

SENSE coordinator PhD education

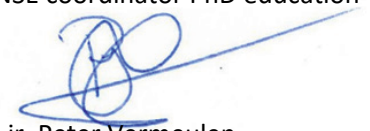

Dr. ir. Peter Vermeulen 
This research received funding from from the European Union's Horizon 2020 research and innovation programme under the Marie Sklodowska-Curie grant agreement No 675997.

Cover photo by Klaus Kemmer, design by Esther Schuch 

